Portland State University

PDXScholar

9-27-1996

\title{
The Influence of Student Gender on Teacher/Student Interactions in ESL Classrooms
}

Lisa Sybil Mann

Portland State University

Follow this and additional works at: https://pdxscholar.library.pdx.edu/open_access_etds

Part of the Bilingual, Multilingual, and Multicultural Education Commons Let us know how access to this document benefits you.

\section{Recommended Citation}

Mann, Lisa Sybil, "The Influence of Student Gender on Teacher/Student Interactions in ESL Classrooms" (1996). Dissertations and Theses. Paper 5085.

https://doi.org/10.15760/etd.6961

This Thesis is brought to you for free and open access. It has been accepted for inclusion in Dissertations and Theses by an authorized administrator of PDXScholar. Please contact us if we can make this document more accessible: pdxscholar@pdx.edu. 


\section{THESIS APPROVAL}

The abstract and thesis of Lisa Sybil Mann for the Master of Arts in

Teaching English to Speakers of Other Languages were presented

September 27, 1996, and accepted by the thesis committee and the department.

COMMITTEE APPROVALS:

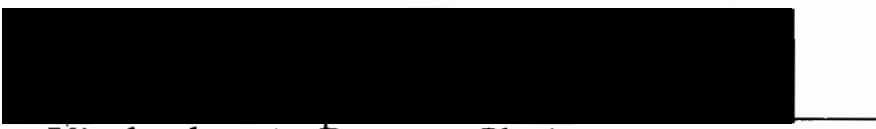

Kimberley A. Brown, Chair

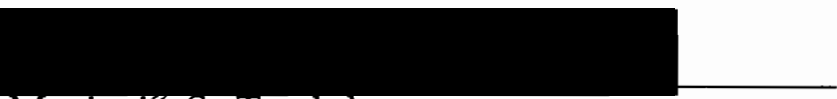

Marjorie S. Terdal

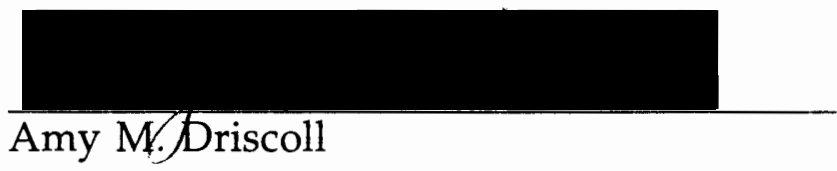

DEPARTMENT APPROVAL:

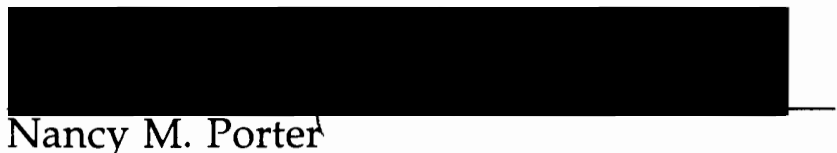

Representative of the Office of

Graduate Studies

Beatrice Oshika, Chair

Department of Applied Linguistics

ACCEPTED FOR PORTLAND STATE UNIVERSITY BY THE LIBRARY

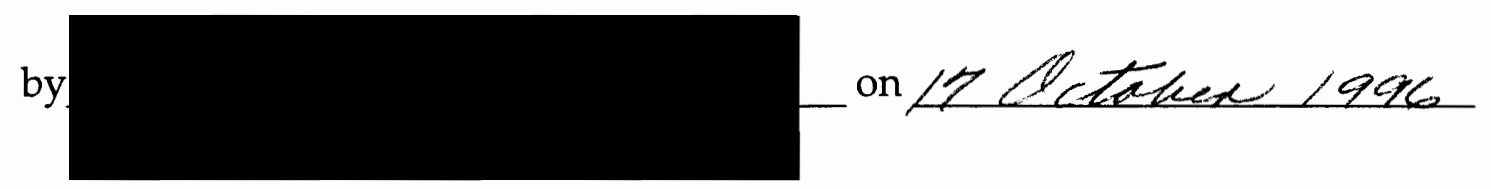




\begin{abstract}
An abstract of the thesis of Lisa Sybil Mann for the Master of Arts in Teaching English to Speakers of Other Languages presented September 27, 1996.
\end{abstract}

Title: The Influence of Student Gender on Teacher/Student Interactions in ESL Classrooms.

Because teacher/student interactions provide opportunities for correction and comprehensible input, a major component of successful language learning, equitable distribution of teacher/student interactions in the language classroom is an important element for the success of all second language students.

The purpose of the present study was to determine whether differences in teacher/student interactions based on student gender occurred in four college English as a Second Language instructors' classrooms. The role of instructor gender and student ethnicity in teacher/student interaction content and frequency were also examined. Informal interviews were designed to determine the instructors' awareness of their classroom behaviors as they relate to equality in teacher/student interactions.

The subjects in this study were two male and two female ESL instructors and their students from two private Portland area universities. 
Interaction frequency data were collected using a seating chart instrument which placed interactions into three categories. Interaction content was determined through the use of a modified Equivalent Talk Category Classroom Interaction Inventory (ETC) (developed by Bentley and Miller, 1971) which classified the interactions into eight separate categories. All data were analyzed using a factorial ANOVA for which the mean behaviors per fifty minute observation acted as the dependent variable and student gender, student ethnicity, instructor gender, and category type served as the independent variables. The analysis revealed that one male and one female instructor interacted significantly more frequently with their male students than they did with their female students and one female instructor interacted significantly more frequently with her female students. Student ethnicity was a major contributor to the disparity in interactions in both classrooms in which males interacted more than females. Middle Eastern and African male students were found to interact with their instructor significantly more frequently than Asian male students. No difference in interaction content was found in interactions between instructors and their male and female students. Instructor interviews revealed that all instructors believed they used a variety of methods to ensure interaction equality in their classrooms indicating that they were not aware of the differences in interaction frequencies which were discovered. 
THE INFLUENCE OF STUDENT GENDER ON TEACHER/STUDENT INTERACTIONS IN ESL CLASSROOMS

\author{
by \\ LISA SYBIL MANN
}

A thesis submitted in partial fulfillment of the requirements for the degree of

MASTER OF ARTS

in

TEACHING ENGLISH TO SPEAKERS OF OTHER LANGUAGES

Portland State University

1996 


\section{TABLE OF CONTENTS}

LIST OF TABLES $\ldots \ldots \ldots \ldots \ldots \ldots \ldots \ldots \ldots \ldots \ldots \ldots \ldots \ldots \ldots \ldots \ldots \ldots$

LIST OF FIGURES $\ldots \ldots \ldots \ldots \ldots \ldots \ldots \ldots \ldots \ldots \ldots \ldots$

CHAPTER

I. INTRODUCTION $\ldots \ldots \ldots \ldots \ldots \ldots \ldots \ldots \ldots \ldots \ldots$

II. REVIEW OF THE LITERATURE $\ldots \ldots \ldots \ldots \ldots \ldots \ldots \ldots$

Introduction $\ldots \ldots \ldots \ldots \ldots \ldots \ldots \ldots \ldots \ldots \ldots \ldots \ldots \ldots$

Gender Differences in Classroom Interactions . . . . . . 8

The Effects of Gender Based Differential Treatment in the

Language Classroom ........................ 19

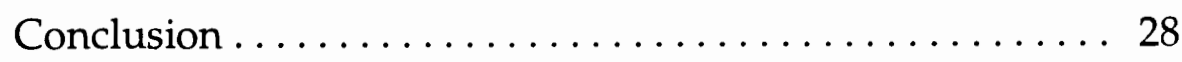

III. RESEARCH PROCEDURES $\ldots \ldots \ldots \ldots \ldots \ldots \ldots \ldots \ldots \ldots \ldots \ldots \ldots \ldots$

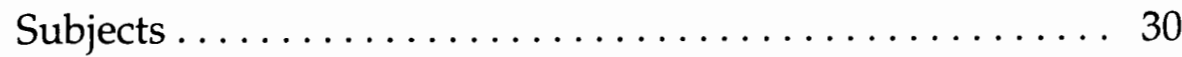

Procedures ............................ 34

Data Analysis ............................. 38

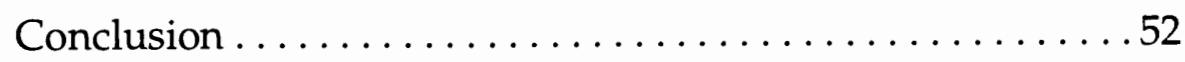

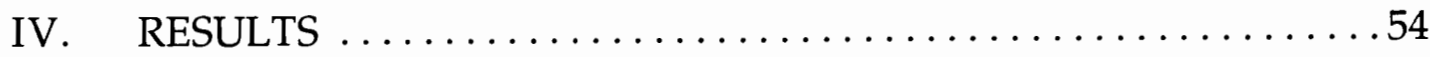

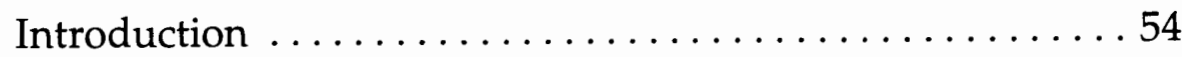

Findings $\ldots \ldots \ldots \ldots \ldots \ldots \ldots \ldots \ldots \ldots \ldots \ldots \ldots \ldots \ldots \ldots \ldots \ldots$

Conclusion .......................... 104 
V. SUMMARY, DISCUSSION AND CONCLUSION $\ldots \ldots \ldots \ldots 105^{\text {ii }}$

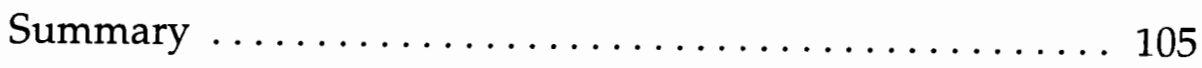

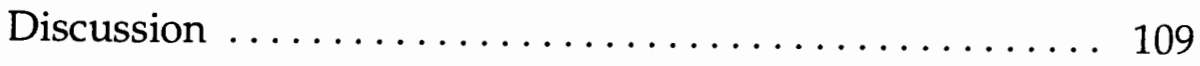

Conclusion $\ldots \ldots \ldots \ldots \ldots \ldots \ldots \ldots \ldots \ldots \ldots \ldots \ldots \ldots$

REFERENCES .......................... 122

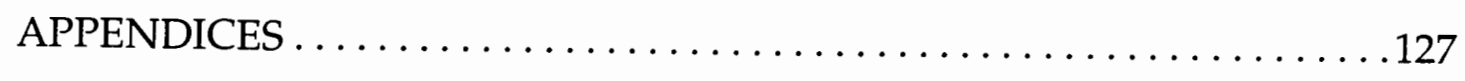

Appendix A: Consent Forms . . . . . . . . . . . . . . . . . 127

Appendix B: Sample Seating Chart .................... 130

Appendix C: ETC Definitions and Codes $\ldots \ldots \ldots \ldots \ldots \ldots 2$

Appendix D: Instructor Interviews $\ldots \ldots \ldots \ldots \ldots \ldots \ldots \ldots \ldots$

Appendix E: Seating Chart Raw Data . . . . . . . . . . . . 164

Appendix F: Seating Chart Data by Ethnicity ........... 173

Appendix G: ETC Raw Data ................... 178 


\section{LIST OF TABLES}

TABLE

PAGE

I

II

III

IV

V

VI-IX

X-XIII Seating Chart Data, Instructor B, Observations 1-4 167

XIV-XVII Seating Chart Data, Instructor C, Observations 1-4 169

XVIII-XXI Seating Chart Data, Instructor C, Observations 1-4 171

XXII-XXV Ethnicity Data, Instructor C, Observations 1-4 . . . 174

XXVI-XXIX Ethnicity Data, Instructor D, Observations 1-4 $\ldots . .176$

XXX-XXXIII ETC Instructor Behaviors, Instructor A,

Observations $1-4 \ldots \ldots \ldots \ldots \ldots \ldots . \ldots \ldots$

XXXIV-

XXXVII ETC Instructor Behaviors, Instructor B,

Observations $1-4 \ldots \ldots \ldots \ldots \ldots \ldots \ldots \ldots \ldots$

XXXVIII-

XLI ETC Instructor Behaviors, Instructor C,

Observations $1-4 \ldots \ldots \ldots \ldots \ldots \ldots \ldots . \ldots \ldots 2$

XLII-XLIV ETC Instructor Behaviors, Instructor D,

Observations $1-4 \ldots \ldots \ldots \ldots \ldots \ldots . \ldots \ldots$ 
XLVI-XIX ETC Student Behaviors, Instructor A, Observations $1-4 \ldots \ldots \ldots \ldots \ldots \ldots . \ldots \ldots 6$

L-LIII ETC Student Behaviors, Instructor B, Observations $1-4 \ldots \ldots \ldots \ldots \ldots \ldots \ldots \ldots \ldots . \ldots \ldots$

LIV-LVII ETC Student Behaviors, Instructor C, Observations $1-4 \ldots \ldots \ldots \ldots \ldots \ldots \ldots \ldots \ldots$

LVIII-LXI ETC Student Behaviors, Instructor D, Observations $1-4 \ldots \ldots \ldots \ldots \ldots \ldots . \ldots . \ldots . \ldots 189$ 


\section{LIST OF FIGURES}

FIGURE

PAGE

1. Transcription Sample and Notation Key ........... 37

2. Average Total Interactions between Instructors and Their Male and Female Students . . . . . . . . . . . . 62

3. Seating Chart Data, Instructors A and B ........... 64

4. Seating Chart Data, Instructors $C$ and $D \ldots \ldots \ldots 69$

5. Ethnicity Data, Instructor D $\ldots \ldots \ldots \ldots \ldots \ldots \ldots \ldots$

6. Ethnicity Data, Instructor $C \ldots \ldots \ldots \ldots \ldots \ldots \ldots \ldots$

7. ETC Instructor Behaviors, Instructor $\mathrm{A} \ldots \ldots \ldots \ldots 90$

8. ETC Student Behaviors, Instructor A . . . . . . . . 92

9. ETC Instructor Behaviors, Instructor B . . . . . . . 94

10. ETC Student Behaviors, Instructor B . . . . . . . . . . 95

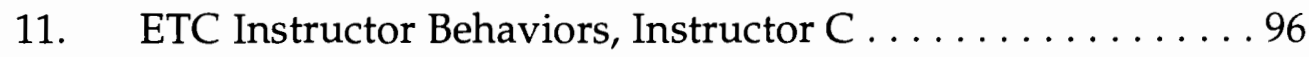

12. ETC Student Behaviors, Instructor $C \ldots \ldots \ldots \ldots \ldots$

13. ETC Instructor Behaviors, Instructor D . . . . . . . . 98

14. ETC Student Behaviors, Instructor D . . . . . . . . . . 100

15. Restricted and Expanded Thinking Questions Directed at Whole Class, All Instructors . . . . . . . . . . . . . . . . . 101

16. Sample Seating Chart..................... 131 


\section{CHAPTER I}

\section{INTRODUCTION}

Much research has been done on gender-based differential treatment in teacher/student interactions. The research has provided overwhelming evidence that in both the language classroom and the non-language classroom teachers interact differently with male students than they do with female students. A heightened level of awareness of gender issues has brought the problem of gender differences in the classroom into the public eye in the last few decades. Since Title IV, the gender equity component of the education amendments of 1972, the issue has been addressed by agencies governing education such as state departments of education. Teacher workshops and inservices have been designed to make teachers aware of the problem and to work towards its elimination. Unfortunately, the subtle nature of bias allows awareness of its existence to elude many teachers and it continues to be a problem.

In the past few decades educational institutions have made great strides toward gender equality in the classroom. What is most encouraging is that the cycle of inequity in the classroom has been exposed. The academic community and the public alike realize the harm that can stem 
from inequity in education. Unfortunately, as visible as the issue of gender inequity in education has become, it still exists in many classrooms and continues to escape the notice of many American educators.

Though in the past thirty years extensive research has proved that gender differences in teacher/student interactions exist in the regular nonlanguage classroom, few studies have focused on gender equality in the second language classroom. Gender differences in teacher/student interactions in the second language classroom are especially important for several reasons.

The primary reason gender differences in classroom interactions is especially important in the language classroom relates the students' exposure to comprehensible input. Many scholars of second language acquisition agree that comprehensible input is a necessary component of successful second language acquisition (see Krashen, 1982, Larsen-Freeman, 1991, Ellis, 1992, for example). Comprehensible input consists of syntactically and semantically simplified speech, sometimes referred to as "teacher talk". Long (1983) found that two-way interaction provided more opportunities for "confirmation checks (the native speaker confirming that he [or she] understood his [or her] conversational partner), comprehension checks (the native speaker making sure his [or her] conversational partner understood him [or her]), and clarification requests, (the non-native speaker asking for help)" (p. 34). These types of behaviors 
make up what have been termed "negotiation of meaning" strategies. These strategies increase the amount of comprehensible input a learner is exposed to and therefore increase their rate of second language acquistion. Therefore, students who are granted frequent opportunities to interact with their instructor are allowed increased access to comprehesible input while students who interact less frequently with their instructor receive less of this important ingredient for successful second language learning.

Second, if students are being treated differently in their classrooms based on their gender, this affects the students' perceptions of their own capabilities. The "self-fulfilling prophecy" hypothesis suggests that students who percieve their instructors' expections of them model their behavior to meet those expectations. Therefore, if some students conclude that they are not as capable of participating in classroom discussions as other students on the basis of differential teacher behaviors, their academic achievements will suffer.

Finally, second language instructors in America are often the only link their students have to American culture. The instructor is looked upon as a model of appropriate behavior (Long, 1988). If an instructor consistently treats males and females differently, this behavior might be impressed upon the students as acceptable conduct, and imitated outside of the classroom. 
The intention of this research is to determine whether the types of inequitable behaviors which have been found in mainstream classrooms also occur in ESL classrooms. The most notable and often cited form of differential treatment based on gender is the frequency with which teachers interact with their male and their female students. Though this information is important and shall be examined in this study, it is also important to determine whether there exists a difference in the content of teachers' interactions depending on the gender of the participating student.

This research strives to examine segments of classroom life in order to bring to light what really occurs in teacher/student interactions in college ESL classrooms. The difference between instructors' beliefs about their classroom behavior and their actual behavior, if such a difference exists, will be examined. If the teacher behaviors analysed reflect differential treatment in their verbal interactions with students based on student gender, it will be argued that gender bias in ESL classrooms exists. Bias is a strong word, and it is not this researcher's intention to condemn anybody's classroom practices. However, bringing behaviors into the level of awareness of instructors may help to shed light on the subtlety of gender bias in American classrooms. 
RESEARCH QUESTIONS

This research will answer the following questions about the instructors and classrooms studied:

1. Does student gender influence the frequency with which ESL instructors interact with individual students?

1a. If so, are instructors aware of this influence or is it occurring out of their level of awareness?

2. Does the content of teacher/student interactions in ESL classrooms vary according to student gender?

2a. Do ESL instructors ask more questions which require restricted thinking responses to members of one gender while asking questions that require expanded thinking responses to the other?

2b. Do ESL instructors react in a manner that maintains or terminates the current level of student participation more often to students of one gender while reacting in a manner that extends the level of participation to students of the other gender?

3. Does the gender of the ESL instructor influence the frequency of interactions or the content of interactions with male and female students? 4. Does the ethnicity of an individual or group of students influence the frequency with which ESL instructors interact with those students?

4a. If so, are the instructors aware of this influence or is it occurring out of their level of awareness? 


\section{CHAPTER II}

\section{REVIEW OF THE LITERATURE}

\section{INTRODUCTION}

Though the influence of student gender in the classroom has been closely examined in the last thirty years or so, the microscope has seldom been turned upon language classrooms. The following review of the literature will provide an overview of gender in classroom research. The much documented issue of gender discrimination in mainstream classrooms will be presented. Researchers have found myriad teacher behaviors which seem to favor male students while neglecting female students in mainstream classrooms. Though this study is concerned only with verbal interactions between teachers and their students, an awareness of other documented unequal behaviors reveals the subtlety of gender based differential treatment and provides insight into why it so often continues unnoticed.

Though many studies have documented discriminatory teacher behaviors in mainstream classrooms, few researchers have focused on the language classroom. The instructor and student processes in language classrooms differ greatly from those in mainstream classrooms. Rather 
than using language as a means to an end, such as analysing a poem, for example, the language used in interactions in language classrooms has two ends to meet. Though interactions in language classrooms have purpose and direction, the interaction is often an end in itself. For this reason, the instructor's orchestration of classroom interactions and student participation is crucial if students are to have equal access to an important component of their education. In addition to the complexity of the interactions themselves, ESL student bodies are often complex as well. The diversity of cultures and first languages that make up many ESL classrooms adds one more facet to the many roles language educators must play.

Finally, the effects of gender-based differential treatment in the ESL classroom will be discussed. Diminished access to comprehensible input, a major component of second language learning, is one of the major implications of differential treatment in teacher/student interactions. Another effect of inequitable interactions based on gender is the selffulfilling prophecy which relates teacher expectations to student performance. Of course, the effects of inequitable treatment of students reach far beyond the classroom walls. The review of the research concerning differential treatment in the classroom will end where gender bias begins, in American society. 


\section{GENDER DIFFERENCES IN CLASSROOM INTERACTIONS}

\section{Gender-Based Differential Treatment in Mainstream Education}

\section{How It Is Manifested, Why It Continues}

In 1972, the Education Amendments were passed in Congress and under these, Title IV. Title IV legally bound educational institutions receiving federal aid to provide equal education for all students regardless of their gender. According to the Mid-Atlantic Equity Consortium (1993a), Title IV requires that all schools treat their students without discrimination on the basis of sex in "courses and extracurricular activities (including student organizations and competitive athletics), benefits, financial aid, facilities, housing, rules and regulations and research. A student may not be limited in the enjoyment of any right, privilege, advantage or opportunity based on sex" (p. 2). While the implementation of Title IV has done much to diminish overt sex or gender discrimination in schools, "the reality is that while many schools adhere to the legal requirements of Title IX, they do not necessarily grant girls a full measure of equal educational opportunities" (Mid-Atlantic Equity Consortium, 1993b, p. 1). In other words, while Title IV has changed the educational policies of American schools, the practices of teachers in American classrooms have not undergone sufficient changes to create an educational atmosphere that is equally beneficial to all students. 
One of the most readily observed forms of differential treatment in the classroom is interaction frequency. In 81 teacher/student interactions covering preschool through high school, Kelly (1988) found that teachers consistently interacted with boys more than they did with girls. That is, teachers were found to praise, punish or call on boys more often than they did girls. Unfortunately, interaction frequency is just one small element in the long list of gender-based differential treatment researchers have observed in classrooms all over the nation and, indeed, the world. The ways women and girls are neglected by the American educational system include, among others, "curricula which largely exclude the experiences of females, professional advising that restricts their options, and male control of classroom talk" (Kramarae \& Treichler, p. 41). Cooper (1987) found that teachers both call on male students more often than female students and ask male students questions that require critical thinking or personal evaluation, while asking female students questions that require factual answers. In their much acclaimed and highly publicized work, "The Campus Climate, a Chilly One for Women," Hall and Sandler (1982) list many teacher behaviors that may be damaging to women and men students alike. Some of the behaviors they describe are, "ignoring women students while recognizing men students even when women clearly volunteer to participate in class; calling directly on men students but not on women students; calling men students by name more often than 
women students; coaching men but not women students in working toward a fuller answer; waiting longer for men than for women to answer a question before going on and crediting men's comments to their 'author' (...as Bill pointed out) but not giving authorship to women's comments" (p.8). The consequences of such instructor behavior in the university setting are obviously damaging to female students, but Hall and Sandler claim that such behavior is detrimental to male students as well. They claim that if limited views of women are projected by "persons of knowledge and status," men may find it difficult to "perceive women students as full peers, to work with them in collaborative learning situations, and to offer them informal support as colleagues in the undergraduate or graduate school setting" (p.3). In other words, if male students are either consciously or unconsciously influenced to regard the views of female students as less important than those of males, they will be less willing to exchange ideas with female students thereby denying themselves access to the full gamut of ideas and opinions that may be open to them.

Interestingly, inequitable behavior based on student gender has been found to exist in both male and female instructors' classrooms. In both Kelly's (1988) and Cooper's (1987) research the teacher behaviors outlined above occurred regardless of teacher gender. Good, Sikes, and Brophy (1973) found that in a study of sixteen junior high school teachers, a significant 
interaction between instructor gender and subject matter was discovered, but that only one significant interaction between instructor gender and student gender was found. This indicates that both male and female instructors use the same types of interactions with both their male and their female students, though they may interact with the members of one gender group more often than they do with the members of the other.

Though these behaviors have been found to exist in many classrooms, they continually elude both instructors and students alike. Sadker and Sadker (1994), in an extensive study of grade school classrooms, found that teachers make eye contact more often with males than with females, nod and gesture more often in response to male students' questions and comments than to female students', habitually choose a location near male students, wait longer for male student responses, ask females factual questions while asking males questions that demand critical thinking, and the list goes on and on. Though Sadker found evidence of differential treatment in many teacher behaviors, he claims that unless one is trained to detect such behaviors they are very difficult to perceive, even when one is looking for them. During a recent lecture Sadker shared an anecdote which illustrates the elusiveness of gender inequality in classrooms (1995). In an exposé on gender bias in American schools, the television show "Dateline" had to ask Sadker to critique their classroom observation video tapes because even though they were looking 
for bias and were very motivated to find it, it was not readily apparent to them. Once the incidents of differential treatment were itemized for the producers of the show, they immediately recognized the unfairness of the teacher's behavior. Critics of Sadker's work claim that he searches and searches until he finds what he is looking for; Sadker says that he does not need to search for gender bias in American education, he only has to "not refuse to see" (Sadker, 1995). It is not only difficult for observers to detect gender-based differential treatment in classrooms, but teachers themselves seldom recognize gender equity problems in their own classroom behaviors. A study by Spender found that though teachers spend less than $50 \%$ of their interaction time with girls, they think they spend more time with girls than with boys. One teacher from the study says:

...out of 10 taped lessons [in secondary school and college] the maximum time I spent interacting with girls was $42 \%$ and on average $38 \%$, and the minimum time with boys was $58 \%$. It is nothing short of a substantial shock to appreciate the discrepancy between what I thought I was doing and what I actually was doing. (Spender, 1982: Spender's italics)

Clearly, gender inequity is, by nature, a shadowy issue. One of the reasons it has persisted in classrooms to this day is that it is often not easily recognized by teachers, administrators, or even students.

\section{Differential Treatment in the Second Language Classroom}

Most studies about gender differences in the classroom are carried out in traditional non-language classrooms. However, one study that was 
conducted in a multicultural classroom revealed that the addition of a second variable, ethnicity, adds rungs to the ladder of perceived importance on which females already stand below males. De Bie (1987) found that in classrooms with both native speakers and non-native speakers of Dutch, female students get less attention than male students and non-native female students receive strikingly less attention than anyone else. In her study of teachers' interaction patterns with adult male and female ESL students, Yepez (1995) found that of the four instructors observed, only one exhibited behavior which might be considered biased against females. She mentions, however, that she saw a definite difference in the teaching styles of male instructors and female instructors. Male instructors were found to control the entire class more closely, managing their classes with what Yepez characterized as an attitude of dominance over all interactions.

The research on gender differences in teacher/student interactions in second language classrooms is very limited. Because language classrooms are heavily interaction dependent and tend to operate very differently from non-language classrooms, additional research in this area is very much needed.

\section{Classroom Management and Interaction}

As Yepez' study indicates, teaching style and classroom management techniques are important factors in determining whether differential 
treatment of one group of students is occurring in a particular classroom. Swann (1989) conducted a study of teacher-student interactions in four elementary classrooms. She was looking for gender-based differential behavior and she coded interaction frequency, interaction type and teacher non-verbal behavior. Because of the variety of classroom environments created by teachers, Swann found it very difficult to compare the findings between classes and her results were inconclusive. She emphasizes the importance of considering teachers' classroom management techniques before attempting to compare data collected from different classrooms.

Swann's call for attention to classroom management strategies is particularly applicable in the ESL classroom. It seems that the typical ESL instructor utilizes many more questions directed at the class in general (non-direct interactions) than questions directed at particular students (direct interactions). One reason for this might be the instructor's desire to create a comfortable atmosphere in the classroom and lower students' inhibitions. Krashen's (1982) "affective filter" theory stresses the importance of students' willingness to "take risks" when using a second language as an important component of language learning. Krashen's theory has influenced many language teachers to decrease the level of formality in their classrooms by using more non-direct interactions. Though this is a reasonable strategy for maintaining a non-threatening environment in the classroom, it also lends anonymity to students who 
are reluctant to voluntarily reply to a general question. While Swann may be correct in asserting that classroom management plays an important role in determining responsibility for differences in interaction frequency between students, it is still ultimately the teacher's decision to manage the classroom and classroom interactions. Classrooms which use primarily a non-direct question and answer format are dominated by students who, for one reason or another, feel comfortable speaking out. In many cases female students in such classrooms are denied teacher/student interactions due to their inhibitions about speaking out in class. The inhibitions girls and women have about volunteering to speak in class may stem from the perception that being quiet in class is an expected and rewarded behavior. A study of high school girls in England found that 11 out of 13 girls thought others regarded them as quiet whereas only 5 of 15 boys thought others would characterize them as quiet (Stanley, 1986). Surprisingly, every one of the above-mentioned girls claimed to be anything but quiet outside of school. Stanley contends that the self-imposed silence of girls is a result of a teacher attitude that able girls "lack confidence or lack ambition" (p. 40). In other words, girls perceive that their silence is an indication of their seriousness and studiousness which is a direct result of their teachers' expectations.

A classroom management strategy which encourages students to volunteer answers to general questions not only allows silence on the part 
of the less assertive students, it also creates an atmosphere that may not be the most conducive to second language learning. Wong-Fillmore (1989) in a study of Limited English Proficient (LEP) students in mainstream classrooms found that while "open" classes are great for some students, "those who find it difficult to socialize with others or who feel constrained by the language differences that bar easy communication with classmates and teachers do not learn as much English" (p. 25). Wong-Fillmore states that teachers of successful language learners are more likely "to use a variety of turn-allocation procedures", sometimes allowing students to shout out answers, sometimes requiring students to raise their hands when they wish to speak while calling on specific students for answers at other times.

Seliger (1983) also suggests limitations of non-direct classroom management techniques as it relates to comprehensible input, a major component of successful language learning. Seliger says that when nondirect input is directed at the class in general "some students will attend to this input and respond while others, having the option, will not respond and perhaps not even listen carefully to the input" (p. 252). In other words, students who habitually avoid voluntarily responding to non-direct questions get little or no benefit from their use. 
Cultures in the Classroom: Their Effect on Interactions

Just as female students are often excluded from interactions when it is their responsibility to choose participation, students from some cultures may also be at a disadvantage in classrooms which have adopted an "anyone answer" format. Kumaravadivelu (1990), compared a group of Japanese speakers learning English with a group of Spanish speakers learning English. The two groups were separately taught an identical lesson by the same teacher. The lessons were audio recorded and the distribution of teacher turns, student turns, turn allocation by the teacher, learner response to teacher solicits and individual and choral response to teacher general solicits was analyzed. Kumaravadivelu found that there was no distinct difference in distribution of the above features between the two groups. The researcher concludes that student culture plays a minimal role in determining the amount and type of interaction that occurs in the language classroom. Though this may be true in a monolingual classroom, the multi-cultural classroom dynamic is more prone to allow silent students to remain silent while more verbal students dominate interactions. In the multi-cultural classroom Furey (1986) says, "some students who come from cultures where they are quite passive in the classroom find it tremendously difficult to speak unless called on by the teacher" (p. 16). Maurice (1986) claims that Japanese students have a particularly difficult time adjusting to the American classroom format in 
which students are encouraged to answer individually and compete for the "right answer". The reason for this, according to Maurice, is that

Americans generally view individual freedom and independence as benchmark values of our society. Japanese, on the other hand, tend to value the group and being part of the group much more than individual freedom. (p. 40)

Consequently, when faced with a classroom situation that encourages students to act independently and to take the initiative to speak up in class, Japanese students often feel intimidated and left out of the discussion. This is exemplified in Sato's (1982) study of Asian students' interaction habits in ESL classrooms. Sato studied the distribution of interactions in an adult ESL class among Asian and non Asian students. She found that "Asian students took significantly fewer speaking turns than did nonAsian students" and "Asian students always responded to individually directed teacher solicitations but did not take initiative in class discussions" (p.19). Sato offered two possible explanations for the results. Sato hypothesized that Asian students may be inhibited by their view of the teacher as an authority and therefore do not feel comfortable volunteering information or initiating interactions. Sato believes another possible cause of the disparity between the number of Asian and non-Asian interactions in the classroom might be that teachers' perceptions of Asians as unwilling participants in classroom interactions induce them to call on Asian students less often. The latter hypothesis is parallel to the "silent schoolgirl" phenomenon that Stanley describes. If the classroom silence of 
Asian students is expected and reinforced by teacher behaviors those behaviors begin to shape the Asian students' assessment of their role in classroom interactions.

Contrary to Japanese classroom culture, Middle Eastern students seem to feel very comfortable initiating interactions and responding to general questions. According to Santos and Suleiman (1993), Middle Eastern students (Santos and Suleiman do not differentiate between the cultural rules within Middle Eastern cultures which differ for men and women) place a high value on making one's opinion heard. It, therefore, seems natural that Middle Eastern students would be more outspoken in a class which encourages individual response.

The combination of gender and cultural differences in ESL student groups makes the source of differential behavior in ESL classrooms difficult to trace. The fact remains, however, that any group of students who receive less access to interactions with their teacher for any reason are being denied an important part of their language learning experience.

\section{THE EFFECTS OF GENDER BASED DIFFERENTIAL TREATMENT IN THE LANGUAGE CLASSROOM}

\section{Comprehensible Input}

As stated earlier, comprehensible input is a crucial component of language learning. The comprehensible input theory was developed by 
Krashen (1982) and states that in order for language acquisition to occur, the language learner must be exposed to and be made to understand language that is a little more complex than that which he or she is accustomed to $(i+1)$. Language will only work as input if it is comprehensible to the learner (Long, 1981). Language can be made comprehensible through the use of context or extra-linguistic information such as repetition, gestures, simplified syntax, slower speech or visual aids or props. According to Wong-Fillmore, language serves as input "when it serves a genuine communicative function and when the learner does not have to know the language in which the message is encoded to figure out what is being said" (p33). In the language classroom, the teacher is the major source of comprehensible input. When input is personalized through "the nomination and specification of a particular addressee....the exchange...requires a higher level of attentiveness on the part of the receiver" (Seliger, p. 253). This turns the input into intake, that is, language that is fully processed and stored in the mind of the learner. Clearly, students who are participants in frequent teacher/student interactions have a better chance of receiving comprehensible input in the classroom than those who are not.

Another and equally important component of second language acquisition is comprehensible output (Swain, 1985). Comprehensible output is "output that extends the linguistic repertoire of the learner as he 
or she attempts to create precisely and appropriately the meaning desired" (p. 252). Though Swain concluded from a 1985 study that the opportunity for comprehensible output is "generally missing in typical classroom settings, language classrooms and immersion classrooms being no exceptions" (252), the importance of comprehensible output has become more apparent to today's language educator. While opportunities for comprehensible output in the language classroom need not come from the instructor, the instructor can certainly act as an instigator for many such opportunities.

Comprehensible input and comprehensible output are both necessary components of second language acquisition. In the language classroom opportunities for both are either provided or facilitated by the instructor. Instructors who deny access to comprehensible input and output to some students, through classroom management techniques or differential treatment, are effectively denying those students access to a successful, quality language learning experience.

\section{The Self-fulfilling Prophecy}

The notion of the self-fulfilling prophecy first gained public attention in 1968 with the publication of Rosenthal and Jacobson's Pygmalion in the Classroom. This study sought to forge a link between teacher expectations and student achievement. The study was carried out 
in first and second grade classrooms. Teachers were informed that certain students' test scores indicated that they would show increased academic achievement in the following year. The student subjects for the research were chosen at random. Achievement tests administered at the end of the school year indicated that the students who teachers believed would achieve academic growth did indeed score higher on a standardized test than those who were not identified as prospective high achievers. The conclusion was that positive teacher expectations result in increased academic achievement. The converse of this conclusion, that negative teacher expectations result in decreased academic achievement has, for ethical reasons, never been studied experimentally, however; nonexperimental designed studies suggest that negative expectations have more potent self-fulfilling effects (Smith, 1983).

Early self-fulfilling prophecy studies measured teacher expectancy effects through the use of standardized achievement tests. Good and Brophy (1974) sought to document the observable behavior differences in teacher interactions with students whom they deemed high or low achievers. The following is a model they developed to outline the selffulfilling prophecy process:

(1) the teacher develops an expectation predicting specific behavior and achievement for each student 
(2) because of these expectations, the teacher behaves differently toward each student

(3) this treatment informs each student about the behavior and achievement expected from him/her and affects the student's selfconcept, achievement motivation, and level of aspiration

(4) if teacher treatment is consistent over time and the student is behaviorally compliant, the student's achievement will come to correspond or remain correspondent with the teacher's belief. High teacher expectations will lead to or sustain student achievement at high levels, while low expectations will diminish or support low student achievement.

(Brophy \& Good, 1974)

Because Brophy and Good were examining classroom behavior rather than achievement test scores as they relate to teacher expectations, they were able to document how teacher expectations are transmitted. The features of classroom interaction which were found to communicate expectations to students teachers considered low achievers is alarmingly similar to the list of features found in classroom gender studies. According to Good and Brophy (1980), some of the behaviors through which teachers transmit low expectations are "paying less attention to lows in academic situations (smiling less often and maintaining less eye contact), calling on lows less often to answer classroom questions or to make public demonstrations, 
waiting less time for lows to answer questions, not staying with lows in failure situations (i.e., providing fewer clues, asking fewer follow up questions), providing lows with less accurate and less detailed feedback than highs and interrupting performance of lows more frequently than highs" (p.10). Though Cooper and Good speculate that these behaviors lead to lower student achievement, few, if any, studies have documented both teacher behavior and student achievement as measured by a standardized test using the same group of students. It seems highly plausible, however, that results such as those found in Rosenthal and Jacobson's study are products of behaviors such as those found in Brophy and Good's research.

The self-fulfilling prophecy is a cycle. Low teacher expectations lead to lower student self-esteem which, in turn leads to lower achievement which feeds teacher expectations. Cooper (1977) found that students who considered themselves the most competent were students who received little criticism in class. Conversely, students who were criticized often in class considered themselves less competent. Interestingly, Cooper also found that interaction initiation in the classroom seemed to be related to students' self-assessment of their competency. If this is accurate, the consequence in the language classroom would be that the student perceived to be less able would initiate fewer interactions thereby lessening 
opportunities for one of the crucial components of second language acquisition, comprehensible output.

Cooper's study indicates that low teacher expectations have an effect on students' assessment of their competency. High or low self-assessment of competency is directly related to academic performance. Dweck and Repucci (1973) had two presenters show two sets of puzzles to 40 fifth grade students. One presenter only showed puzzles that were unsolvable, the other presenter only showed solvable puzzles. The presenter of the unsolvable puzzles then altered the puzzles to be solvable. Some students were unable to solve the altered puzzles even though they were very similar to the solvable puzzles shown by the other presenter. All of the students who were not able to solve the altered puzzles attributed their failure to their ability rather than to the amount of effort they expended. Dweck and Repucci concluded that self-esteem directly corresponds to student success.

The parallel between documented teacher behavior toward female students and that toward students perceived to be low achievers is no coincidence. Extensive research has shown that females are treated as capable of achieving less than their male counterparts in many educational contexts. Though much of the research is conducted in primary education classrooms, as Hall and Sandler (1982) point out, the higher education system is not exempt from gender-based differential treatment in its 
classrooms. In fact, according to Sexton (1976), "more charges of sex discrimination have been brought against colleges and universities than against any other institution" (p.75). With more and more international students attending American universities every year, the effect of unfair university educational practices can have devastating results. There were 38,606 International students enrolled in American university Intensive English Language Programs (IELPs) in 1994-'95. Of those, nearly half (47.1\%) were female (Davis, 1995). If instructors in IELPs are conveying a message of inability to their female students through the behaviors outlined above, the consequence may be those students' lessened estimation of their ability to succeed in degree programs in American universities. This might result in fewer female international students wishing to remain in the United States to continue their course of study, thus barring themselves from the type of education that American universities have to offer and also denying American students that much less of the cultural diversity to which their presence contributes.

\section{Societal Issues}

Students look to their ESL instructor not only for factual information regarding the language they are learning, but for behavioral clues about the society in which they are newly immersed. Gender-based differential treatment in teacher/student interactions may be inferred by 
the students to mean that such behavior is normal, acceptable and expected in American society. Sunderland (1990) in her examination of classroom ESL materials found that most of the materials she looked at favored males in most areas. She believes that in such materials there is "subliminal influence of female characters as having restricted social, behavioral and linguistic roles [which] is disempowering for females" (p. 20). Miller (1993) says it best:

Through education we enter a cultural conversation, always somewhere in the middle. There we find and form our understanding of ourselves and our communities....Because knowledge and gender both are produced and reproduced against the background of available cultural representations, those who are excluded from or demeaned in those representations are at a distinct disadvantage. (p.53)

In addition to being detrimental to second language learning, general student achievement and student self-esteem, gender-based differential treatment perpetuates a society which emphasizes gender inequality. Both males and females are harmed by an atmosphere which encourages one and discourages the other. Such an atmosphere exaggerates the differences between men and women, setting up a paradigm which inhibits understanding and puts boundaries on potential.

Because classroom teachers act not only as educators but as socializers, their attitudes and beliefs about gender roles largely influence their students' attitudes and beliefs about gender roles. Cooper (1987) says that "teachers are a significant element in the development and 
continuation of sexism" (p. 5). If teachers' attitudes about gender roles are reflective of a male dominant-female subordinate society, they may be inadvertently perpetuating such a society through the socialization of their students.

\section{CONCLUSION}

The ESL classroom is a complex environment. Diverse student cultures and the educational and social expectations that each culture holds add even more facets to the already intricate design of classroom life. The research has shown that mainstream classrooms in which the dominant cultural expectations are similar if not identical continue to fall short of equality in both the quantity and quality of teacher/student interactions. In classrooms in which not only students' gender but their first culture play a role in their decisions about the appropriateness of classroom participation, instructors must determine an effective way to level out the classroom interactions to allow every student access to the same education. This study is based on the premise that ESL instructors strive toward this type of equality in their classrooms and, indeed, often believe that they achieve it. It is designed to show the elusiveness of equality, even in the face of resolute efforts to attain it. Because of the immense significance of teacher/student interactions in second language classrooms, it is important to know if student gender and ethnicity play a role in the quantity and 
quality of teacher/student interactions. This study is intended to

determine whether teachers in ESL classrooms, like teachers in mainstream classrooms, tend to interact with some students more or differently than they do with others. 
CHAPTER III

RESEARCH PROCEDURES

SUBJECTS

The subjects for this study consisted of two male and two female English as a Second Language instructors and their students.

\section{Instructors}

The four instructors who participated in this study were chosen out of convenience. Both of the colleges at which the instructor subjects teach are in the Portland Metropolitan area. The instructors were contacted by phone and/or e-mail and asked to participate in this study. The instructors were informed only that they were participating in a study about teacher/student interactions in the ESL classroom. The exact nature of the study was not revealed in order to limit the effect of the researcher's presence on instructor and student behavior.

One female and one male instructor teach at a small private college in the Portland Metropolitan area. The female instructor will hereafter be referred to as instructor A. She is a native speaker of American English. Data were collected in instructor A's high intermediate academic reading 
class and high intermediate/advanced speaking and listening class. These classes met four days a week for fifty minutes each meeting.

The male instructor (instructor B) is also a native speaker of American English and a recent MA TESOL graduate. Data were collected in instructor B's advanced academic reading class. This class met four days a week for fifty minutes each meeting. Data were collected in four meetings of instructor A's classes and four meetings of instructor B's classes for a total of two hundred minutes per instructor. The data collection in instructor A and instructor B's classes occurred during the seventh through ninth weeks of a sixteen week term.

The remaining two instructors teach at a large private college in the Portland Metropolitan area. Both instructors are native speakers of American English. Data were collected in the female instructor's (instructor C) high intermediate mixed skills class. Data collection occurred in instructor C's class during the twelfth and fourteenth weeks of a sixteen week term. Data were collected in the male instructor's (instructor D) advanced mixed skills class during the eighth week of a sixteen week term. Both instructor $C$ and instructor D's classes met four times a week for an hour and forty minutes each meeting. Data were collected in two meetings of instructor $\mathrm{C}$ and instructor D's Core classes for a total of two hundred minutes per instructor. 
Students

Prior to collecting data in each class, students were told by the researcher that their instructor had agreed to participate in this study and asked if they would also agree to participate. The students were given a brief explanation of what participating in this study would entail and were asked to sign a consent form. All students did so. For a complete copy of the student consent form please see Appendix A.

The students differed in number, gender and ethnicity from class to class and instructor to instructor (see table I). 
TABLE I

NUMBER, GENDER AND ETHNICITY OF

STUDENTS PER CLASS MEETING

\begin{tabular}{|c|c|c|c|c|c|c|c|c|}
\hline observ. & \multicolumn{2}{|c|}{1} & \multicolumn{2}{|c|}{2} & \multicolumn{2}{|c|}{3} & \multicolumn{2}{|c|}{4} \\
\hline $\begin{array}{l}\text { Inst A } \\
\text { (female) } \\
\text { students }\end{array}$ & \multicolumn{2}{|c|}{$\overline{\mathrm{N}=4}$} & \multicolumn{2}{|c|}{$\overline{\mathrm{N}=4}$} & & 10 & \multicolumn{2}{|c|}{$\overline{\mathrm{N}=9}$} \\
\hline ss gender & $2 \mathrm{~F}$ & $2 \mathrm{M}$ & $2 \mathrm{~F}$ & $2 \mathrm{M}$ & $6 \mathrm{~F}$ & $\overline{4 M}$ & $5 \mathrm{~F}$ & $\overline{4 \mathrm{M}}$ \\
\hline $\begin{array}{l}\text { ss } \\
\text { ethnicity }\end{array}$ & & & & $\overline{\text { ALL }}$ & IAN & $-\ldots$ & & \\
\hline $\begin{array}{l}\text { Inst B } \\
\text { (male) } \\
\text { students }\end{array}$ & \multicolumn{2}{|c|}{$\mathrm{N}=5$} & \multicolumn{2}{|c|}{$\mathrm{N}=6$} & & $=6$ & \multicolumn{2}{|c|}{$\mathrm{N}=5$} \\
\hline ss gender & $4 \mathrm{~F}$ & $1 \mathrm{M}$ & $4 \mathrm{~F}$ & $2 \mathrm{M}$ & $4 \mathrm{~F}$ & $2 \mathrm{M}$ & $4 \mathrm{~F}$ & $1 \mathrm{M}$ \\
\hline $\begin{array}{l}\text { ss } \\
\text { ethnicity }\end{array}$ & & & - & ALL & IAN & & & \\
\hline $\begin{array}{l}\text { Inst C } \\
\text { (female) } \\
\text { students }\end{array}$ & $\overline{\mathrm{N}}=$ & & $\mathrm{N}=$ & 13 & & & & \\
\hline ss gender & $4 \mathrm{~F}$ & $6 \mathrm{M}$ & $6 \mathrm{~F}$ & $7 \mathrm{M}$ & & & & \\
\hline $\begin{array}{l}\text { ss } \\
\text { ethnicity }\end{array}$ & $\overline{3 A S}$ & $5 \mathrm{ME}$ & $\overline{5 \mathrm{AS}}$ & $5 \mathrm{ME}$ & & & & \\
\hline & $1 \mathrm{EU}$ & $1 \mathrm{AS}$ & $1 \mathrm{RU}$ & $2 \mathrm{AS}$ & & & & \\
\hline $\begin{array}{l}\text { Inst D } \\
\text { (male) } \\
\text { students }\end{array}$ & & & & & & & & \\
\hline ss gender & $5 \mathrm{~F}$ & $7 \mathrm{M}$ & $6 \mathrm{~F}$ & $7 \mathrm{M}$ & & & & \\
\hline $\begin{array}{l}\text { ss } \\
\text { ethnicity }\end{array}$ & $4 \mathrm{AS}$ & $\overline{4 \mathrm{ME}}$ & $\overline{5 \mathrm{AS}}$ & $4 \mathrm{ME}$ & & & & \\
\hline & $1 \mathrm{EU}$ & $2 \mathrm{AS}$ & $1 \mathrm{RU}$ & $2 \mathrm{AS}$ & & & & \\
\hline & & $\overline{1 \mathrm{AF}}$ & & $\overline{\mathrm{AF}}$ & & & & \\
\hline
\end{tabular}

$\mathrm{AS}=\mathrm{Asian}, \mathrm{RU}=$ Russian, $\mathrm{ME}=$ Middle Eastern, $\mathrm{AF}=\mathrm{African}$ 


\section{PROCEDURES}

\section{Pilot Study}

An ESL instructor and his level three reading class at a public Portland area university were asked to participate in the pilot study. The class was observed and tape recorded for approximately forty minutes. During the class observation, all teacher/student interactions were recorded on a seating chart. The audio recorded data were difficult to transcribe because, having used only one tape recorder, many of the students' voices were difficult or impossible to hear. As a result of the pilot study, two tape recorders were used to collect data in other classrooms.

\section{Data Collection Procedures}

Before the classroom data collection began, the participating instructors were contacted and asked to inform students that data for this study was to be collected in their class on the pre-arranged day. This was intended to lessen the anxiety that may have occurred due to the

researcher's presence in the classroom. Before each class meeting began, tape recorders were placed in areas in which they might optimally perceive the voices of the students. The tape recorders were generally switched on as the instructor began to address the class as a whole. After all the students arrived a quick seating chart was sketched indicating where students were positioned in the classroom as well as the gender and ethnicity of each 
student. Student ethnicity was broken into four categories, Asian, Middle Eastern, Russian or African. Ethnicity information was concluded on the basis of appearance and first language accent when possible; additional information was obtained from instructors when necessary.

\section{Seating Chart}

A seating chart adapted from that which appears in Richards and Lockhart (1994) was used in each class to record interaction frequency. The chart consists of rectangles which represent the instructor's and students' desks. Tally marks were made inside the instructor's rectangle to indicate how many a) general questions were posed to the class b) questions were asked to male students and c) questions were asked to female students. Each student rectangle or "desk" was labeled with the student's gender and ethnicity. Inside the students' rectangles, tally marks were made to indicate how many a) general questions each student answered b) direct questions

each student answered and c) interactions each student initiated. A sample seating chart instrument can be found in Appendix B.

\section{Audio Recording and Transcription}

Each class observed was audio recorded using two audio tape recorders strategically placed around the classrooms. In addition to the audio recordings, notes were taken during the observation to clarify context 
when necessary. The recordings were transcribed following the conventions outlined by Jefferson (as cited in Hatch, 1992). Though they were counted on the seating chart instrument, too many voices at once made interactions which occured during pair and small group work impossible to transcribe. These periods were timed and the length of such periods recorded on the transcripts. An example of the transcription method is shown below in figure 1. The quality of the recordings was fairly high. Utterances which were not picked up on one tape were generally easily understood on the second tape. 


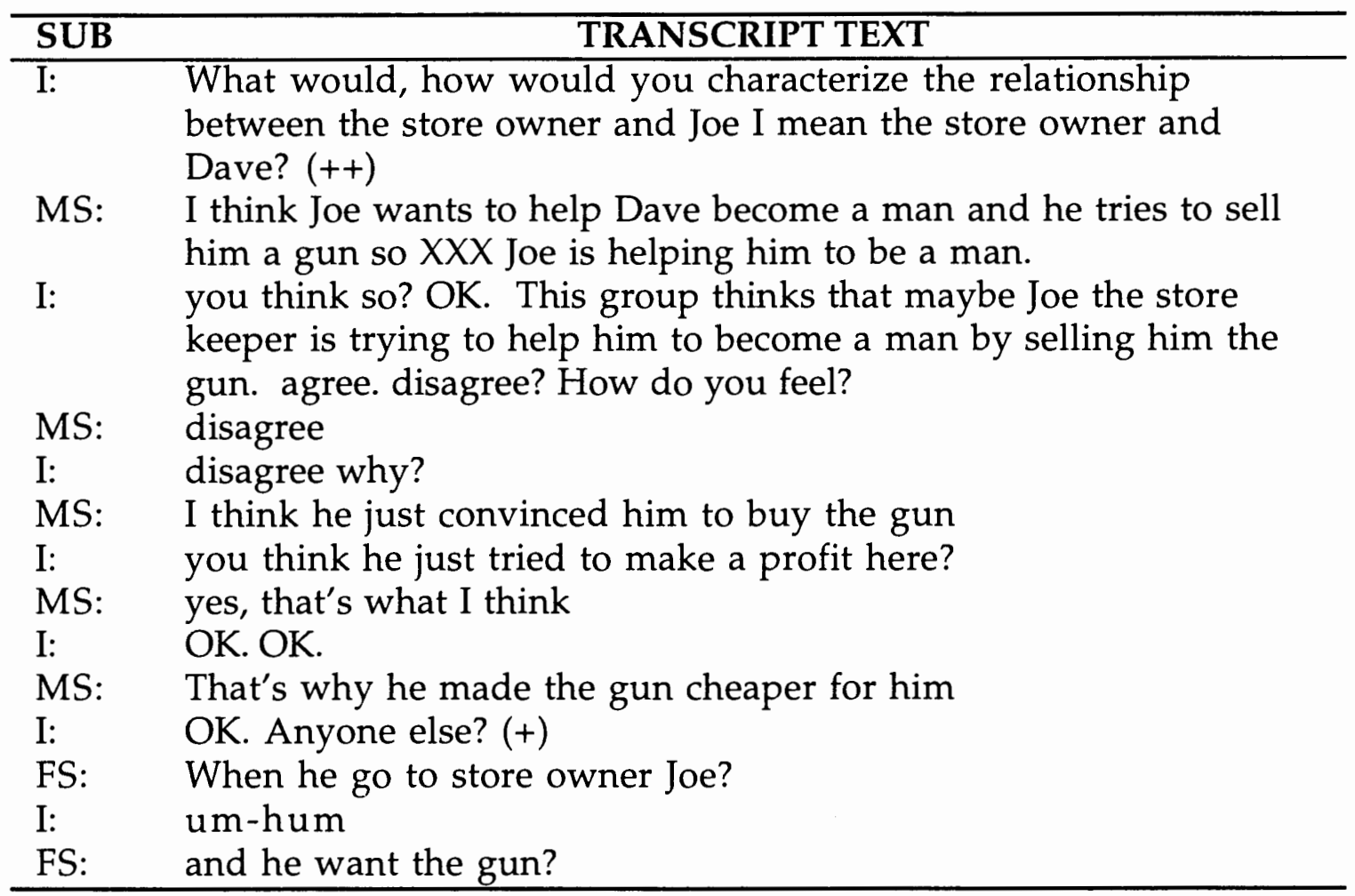

\begin{tabular}{|l|l|}
\hline \multicolumn{2}{|c|}{ TRANSCRIPTION NOTATIONS } \\
\hline I: & instructor \\
MS: & male student \\
FS: & female student \\
$(+)$ & pause of three to seven seconds \\
$(++)$ & pause of seven to fifteen seconds \\
$(+++)$ & pause of fifteen seconds or longer \\
XXX & utterance incomprehensible \\
$?$ & rising intonation \\
\hline
\end{tabular}

Figure 1. Transcription sample and notation key

\section{Informal Interview}

After the data at each participating college were collected, each instructor participated in an informal interview. The interview was designed to determine the level of awareness each teacher had of his or her 
teaching behaviors. The questions asked during the informal interview mainly concerned instructors' strategies for insuring equality in the teacher/student interactions which occur their classrooms. The interviews also broached the subject of gender equality in other cultures and many of the stereotypical behaviors observed and not observed among students of particular cultures. The format of the interview was semi-structured. Though the researcher had a list of interview questions to act as a guide (see appendix D), the informality of the interview often took on the form of a conversation and the questions were not so much presented as questions but rather offered as topics for discussion. The interviews were conducted in the offices of the instructors and generally lasted approximately fifteen minutes. For a complete transcription of the instructor interviews, please see appendix D.

\section{DATA ANALYSIS}

\section{Seating Chart Data}

The data collected with the seating chart during each observation were counted and placed in graphs which indicated the number of teacher/student interactions initiated by female students, the number of interactions initiated by male students and, in the case of Instructors $C$ and D's classes, the number of interactions initiated by students of each ethnic group. Instructors A and B's classes contained only Asian students so the 
ethnicity data were not counted in those cases. In addition to student initiated interactions, the number of male and female student responses to direct questions was tallied and, if this number differed from the number of direct questions asked this information was recorded. Again, in the case of Instructors $C$ and D's classes, information was also tallied pertaining to student ethnicity. Interactions which occurred during pair and small group work were indicated on the seating chart though they could not be transcribed and analysed using the ETC instrument. Lastly, the number of student responses to general questions was counted for both male and female students and, when appropriate, students of each ethnicity. The number of general questions asked by the instructor, if different from the total number of questions answered, was also recorded. All behavior categories and definitions were adapted from Richards and Lockhart (1994) and Acheson and Gall (1987).

\section{Instructor behaviors}

Instructor behaviors include asking direct questions to individual students and asking general questions to the class. Direct questions were coded as to whether they were directed at male or female students.

Direct questions. A question was coded as a direct question if a) the instructor called on a student by name:

I: "M------, would you like to start? (+) What class was it and what was interesting to you about that class?" 
b) if it was clear which student the teacher was singling out for a response because of the content of the question:

I: "Do they have anything like that at John Doe College?" or c) because of a non-verbal behavior such as pointing or eye contact:

I: "What about you? What did you have?"

When the same question was repeated more than once or was elaborated on for clarification, it was counted only the initial time it was asked. Therefore, sequences such as:

I: "H---, what is McCarthyism? (++) What did you say? What is McCarthyism?"

were counted as one direct question. However, sequences which contained one general question and were followed by a question asked to an individual student were coded as one general question and one direct question:

I: "What were the United States military goals? (++) [general question] M--------, what did you write?" [direct question]

General questions. A question was coded as a general question if the question was not intended for a specific individual's response. Again sequences in which a question was clarified or repeated such as,

I: "First of all, how would you describe containment? If someone asked you, what is containment, what would you say?" 
were counted as one general question. Confirmation check questions such as "ok?", "right?" or "everyone understand?" which were not followed by a fifteen second or longer pause were not counted as general questions because they were not considered requests for a response. If a student responded to a confirmation check, the utterance was counted as an interaction initiation, for example,

I: "Don't, don't read it just survey it, ok?"

MS: "What is survey?" [interaction initiation]

However, similar questions which were followed by a pause were counted as general questions because they seemed to invite response:

I: "OK, any questions? (++) If not then we'll continue."

\section{$\underline{\text { Student behaviors }}$}

Student behaviors include interaction initiations, responses to direct questions and responses to general questions. Again, the gender and ethnicity of the student displaying each behavior was coded on the seating chart.

Initiate interaction. All unsolicited utterances made by students were considered interaction initiations. This included interactions which began when the student asked a question:

FS: “open notes?"

or made a statement:

FS: "I find the reading very difficult and I hardly can understand it and every time you have quiz". 
Response to a direct question. A student was coded as responding to a direct question if he or she responded to a question that was directed at him or her.

I: "What's your highest score S-------?

MS: "highest score? 202."

Response to a general question. Responses to general questions were coded every time a student answered a question that the instructor asked to the class in general. If the student answered the general question with another question, the sequence was coded as one general question asked and one interaction initiated by that student, for example:

I: "For example if I said should we have class observation week next semester what would be your opinion, yes or no? [general question]

FS: "next semester?" [interaction initiation]

I: next semester $(+)$ is class observation week a good idea?" [reiteration of previous question, not counted]

If several students answered a general question at once each student who answered was credited with responding.

$\underline{\text { ETC }}$

The transcripted data were analyzed using a modified Equivalent Talk Categories Classroom Interaction Inventory (ETC) developed by Bentley and Miller (1971). The ETC is an inventory of 10 classroom behaviors which can be observed in both teachers and students. For the 
purposes of this study I have eliminated the ninth and tenth category structure/pause/silence and structure learning activities. The information included in the ninth category, structure/pause/silence is conveyed through the transcription method through the use of timed pauses or the transcription code for short pauses. The information included in the tenth category, structure learning activities, is not of particular relevance to this study and can be subsumed in the present information category. According to Bentley and Miller (1971) the sturucture learning activities category contains utterances which are used to give directions pertaining to exercises or activities. These types of utterances can be considered presented information without harming the integrity of the instrument. I have also modified the eight remaining categories of the instrument to indicate whether, in the case of the instructor, his or her behavior is directed at the class in general, a male student or a female student. The two response categories, respond restricted and respond expanded as well as the three reaction categories, react maintain level of participation, react extend level of participation and react terminate level of participation were deleted for the class category because the types of behaviors subsumed under these categories cannot generally be directed at a group. The student behavior categories were adapted to indicate whether the behavior originated from a male or a female student. Therefore, the total number of categories in the modified ETC is 35, 19 instructor behaviors and 16 student 
behaviors. Each speaking turn was analyzed using codes which correspond to the 35 categories (see appendix C). Intra-rater reliability of transcripts provided by Bentley and Miller was $89 \%$.

\section{ETC Categories}

Present information. Unsolicited information such as a lecture or information or explanation related to the lesson was categorized as presented information. This included demonstrations, descriptions, rhetorical questions and impromptu comments.

e.g. I: "Roosevelt felt it's very important to have an organization to promote peace in the world but also to have some power in keeping peace in the world so that if there were some international dispute that occurred there could be an objective organization..."

or

I: "I have a couple of announcements first of all here..."

or

MS: "I went by your house yesterday"

The present information category excludes questions and responses to questions as well as reactions to others' presented information. The distinguishing feature of the present information category is that it subsumes only unsolicited utterances.

\section{Question Categories}

An utterance was considered a question if the speaker seemed to expect or desire a response. This expectation was generally conveyed either 
through syntax or intonation, however, there were instances when neither of these indications were present yet a response was clearly desired. This usually occurred when an instructor was going through a list of questions fairly quickly and did not feel the need to read the questions out loud as the students had them in their books.

e.g. I: "Number two."

MS: "The people whom I met at a party last night are from California."

In this case the instructors utterance, "number two" could be rephrased as "what is the answer to number two?". The type of question that is being asked can be discerned from both the instructions the instructor gave earlier in the transcription and the student's response. In this case, "number two" is an expanded thinking question because it requires the student to apply his or her knowledge of grammar in order to respond correctly.

Question-restricted thinking. The restricted-thinking question category contains questions which require a factual answer. These types of questions often produce responses which result from simple recall of facts previously learned or easily produced. They may have an accepted or predetermined correct answer. These types of questions require lower levels of cognition. A question was considered a restricted-thinking question if it asked for information which the student had previously read, learned or compiled, 
I: "Mein Kamf is the title of what?"

I: "What is your topic J--------?"

I: "at the beginning of the chapter what's he looking for?"

Questions of a personal nature which students could answer readily were considered restricted-thinking questions:

I: “Do you know Japanese?"

I: "M------- who are you riding with?"

Student questions intended to clarify instructions were considered restricted-thinking questions:

FS: "We do it here on backside?"

MS: "When are we going to have the exam?"

MS: "What page?"

Questions about spelling were placed in the restricted-thinking question category, but requests for definitions were not:

FS: "What about jail?" [i.e. how do you spell jail?]

Question-expanded thinking. Expanded thinking questions include questions that call for responses which result from the generation and application of principles, concepts and generalizations. Open ended questions are often expanded thinking questions. They require responses that are generated by the application of rules or procedures. Questions which begin with why, how and what do you think are often expanded thinking questions. 
e.g. I: "Does anybody think that this story will have a happy ending?"

I: "Do you think that's useful to an ESL student?"

FS: "How come America is so afraid of Soviet Union, of communism, how come (+) they don't like the way ok, but why are they so afraid of communism?"

FS: "Is that school only for white people?" [discussing a short story]

Requests for definitions were considered expanded thinking questions because such questions require active thinking and careful consideration of the material:

MS: "urge is more stronger than encourage?"

MS: "Can I if I talk with someone and he says things I don't like it can I say I resent talking with him?"

FS: "What is urge?"

\section{Response Categories}

Responses are utterances which occur in answer to questions or in response to reactions. A response in the form of another question was considered either a reaction which maintains or expands the current level of participation depending on the content.

e.g. I: "When would you use the table of contents?" [questionexpanded thinking]

FS: "First, before I start reading." [respond-expanded thinking]

I: "before you read the book?(+)Why would you look at it?" [react extend level of participation] 
Respond restricted thinking. Restricted thinking responses are usually generated from restricted thinking questions. They include accepted or pre-determined correct answers, facts previously learned or easy to produce.

e.g. FS: "How much should we write?" [question-restricted thinking] I: "That's probably enough what you have there." [respondrestricted thinking]

I: "Oh yeah, what did you do?" [question-restricted thinking]

FS: "speech, speeches and writing and vocabulary." [respondrestricted thinking]

I: "Who suggested this idea of containment to the American government?" [question-restricted thinking]

FS: "George...George Keenan" [respond-restricted thinking]

MS: "what page?" [question-restricted thinking]

I: "three o eight" [respond-restricted thinking]

Respond-expanded thinking. Expanded-thinking responses are generally the result of expanded-thinking questions. They are answers to questions that begin with why, how and what do you think, are generated by application of rules or principles and are often the completion of openended questions.

e.g. MS: "I think there are conservative people who keep their children out of school, why?" [question-expanded thinking]

I: "Because they don't think, they think that certain kinds of things are being taught in schools that they don't want their children to know about." [respond-expanded thinking]

I: "What's struggle mean?" [question-expanded thinking]

FS: "It means fighting?" [respond-expanded thinking] 
I: "what, what in the story makes us feel that she's kinda a jealous person?" [question-expanded thinking]

MS: "When she asks about her husband's colleagues?" [respondexpanded thinking]

\section{$\underline{\text { Reaction Categories }}$}

Reactions generally occur after responses to questions, though they can also occur after presented information.

e.g. I: "What questions to the students do you find in your books?" [question-restricted thinking]

FS: "We don't have the questions." [respond-restricted thinking]

MS: "It don't have questions." [respond-restricted thinking]

I: $\quad$ "There are no end of chapter questions, but there are questions." [react-maintain level of participation]

MS: "Oh...it has beginning of chapter questions" [respondrestricted thinking]

In the above example, the instructor maintains the level of participation by reacting in such a way that subtly requests a reexamination of the original response. Though this is a request for a response, it is considered a reaction and not a question because it occurs in response to the answer of an earlier question.

React-maintain level of participation. A reaction which maintains the current level of participation is an invitation to continue talking or to amplify, clarify, or summarize ideas at the same or a lower level of cognition.

e.g. I: "...It was a little bit confusing because the professor gave you different pages to follow, is that right?" [question-restricted thinking]

FS: $\quad$ "He correct it. corrected it." [respond restricted thinking] 
I: $\quad$ He corrected everything, yeah, but he gave you different pages?" [react maintain level of participation]

I: "what are some of the goals of education?" [questionexpanded thinking]

MS: "what is objectives?" [react-maintain level of participation]

I: “objectives?" [react-maintain level of participation]

MS: "the same?" [question-expanded thinking]

I: "well, goal is more general than objective..." [respondexpanded thinking]

FS: $\quad$ last week I realize how much I need to study English because not every class I can understand so after a time I will become regular student and I must really study hard because I want to really understand every professor talking, so yeah." [present information]

I: $\quad$ "Yeah, it's good to help you know what you still need to work on?" [react maintain level of participation]

FS: $\quad$ "yeah, it's good." [react terminate level of participation]

React-extend level of participation. Reactions which extend the

level of participation request further consideration of ideas requiring

increased complexity of thinking. Such reactions build upon the speaker's response asking the speaker to elaborate or expand upon his or her original utterance.

e.g. I: "Does your book have an index?" [question-restricted thinking]

FS: "yes." [respond-restricted thinking]

I: "How can the index help you?" [react-extend level of participation]

MS: "I think there are conservative people who are keeping their children out of school, why?" [question-expanded thinking]

I: "because they don't think, they think that certain kinds of things are being taught in schools that they don't want their children to know about." [respond-expanded thinking] 
MS: "but isn't that the goal of a school, to teach them? I mean why you would keep your children from learning?" [react-extend level of participation]

React-terminate level of participation. Reactions which terminate the level of participation often occur in the form of a simple yes, no or ok. These reactions do not push for further information, they simply accept or dismiss the response to a question. These type of reactions may also occur in the form of topic switches or summaries of the discussion.

e.g. I: "OK, number eight?" [question-expanded thinking]

MS: "She applied for the job that was advertised in the paper." [respond-expanded thinking]

I: "very good. She advertised the job. And now, remember that we had done also reduced clauses, yes?..." [react-terminate level of participation]

FS: $\quad$ "I don't know how to spell demonstration." [questionrestricted thinking]

I: $\quad$ d-e-m-o-n-s-t-r-a-t-i-o-n" [respond-restricted thinking]

FS: "thank you." [react-terminate level of participation]

\section{Informal Interview Data}

Unlike the other two components of this study which yielded quantitative data, the analysis of the informal interview data is decidedly qualitative. The object of the interview was to determine which behaviors the participating instructors exhibited deliberately and which behaviors were occurring outside of their awareness. The interview was very informal, the researcher attempted to broach the subjects of gender and ethnic inequality in teacher/student interactions as delicately as possible to 
avoid creating an attitude of defensiveness during the interview. One of the ways which an informal environment was created was through the use of a very loosely structured interview format. The researcher attempted to guide the discussion toward the issues being explored rather than ask a predetermined series of questions. Though many questions intended to steer the topic of conversation toward the issues at hand, more often than not, the instructors wanted to talk about inequity in classroom interactions as they relate to personality type rather than student gender or ethnicity. The interview was also designed to address the instructors' classroom management strategies as they relate to interaction equality. Instructors were asked which techniques they felt were most effective at eliminating interaction inequality in the classroom. During the interview instructors attitudes about the value of teacher/student interactions in the classroom were also discussed. Complete transcripts of the instructor interviews can be found in appendix D.

\section{CONCLUSION}

The instruments used in this study were chosen to provide a fair and accurate picture of what occurs inside ESL classrooms. The seating chart instrument provided precise frequency data showing which, if any, students most often interact with their instructors. The ETC also provided frequency data showing what types of interactions most often occur 
between students and their instructors. Finally, the informal interview provided qualitative data which tell whether the intended behavior of these instructors is parallel with their observed behaviors. 


\section{CHAPTER IV}

\section{RESULTS \\ INTRODUCTION}

\section{Statistical Tests Used}

Both the data collected using the Seating Chart Instrument and the data yielded from the Equivalent Talk Categories Inventory were analyzed using a factorial Analysis of Variance (ANOVA). The ANOVA test was used to determine whether the mean responses in each category differed significantly according to instructor, instructor gender, behavior category or student gender. If a significant difference between variables or an interaction between variables was found using the ANOVA tests, planned comparison tests were used to determine where the differences occurred. A Tukey's test was also used to make comparisons within groups, such as categories or instructors.

The ethnicity data that the seating chart instrument yielded were analyzed using a one-way ANOVA. The difference in ethnic groups between the two ethnically diverse classes did not allow a multivariate analysis. One-way ANOVA tests were run on this data to determine 
whether instructor gender, ethnicity or student gender had an effect on the mean responses for the classes observed.

The assumptions underlying the use of the ANOVA were met. The groups studied were assumed to be representative of the population of college ESL students with normal distribution. Though the groups studied were not selected randomly, they were not selected on the basis of particular characteristics, therefore; this was not considered a risk to the reliability of the ANOVA results. The square root of the responses was used to stabilize the variance between responses. This allowed minimum variance between samples meeting this assumption for use of the ANOVA. The critical alpha value was set at $\mathrm{p}<.05$.

\section{Data Organization}

The data were organized by the instrument used to collect them. The following is a description of the data organization processes used for each data set by instrument.

Seating chart data. The seating chart data were first organized into categories for each instructor and each observation. The data were arranged into three categories, student initiated interactions, student response to general question, and student response to direct question. If the total number of general questions asked differed from the total number of general questions answered, this difference was noted. Similarly, if the 
number of direct questions asked differed from the number of direct questions answered this also was noted. These data were arranged to indicate the frequency of each behavior as originating from a female or a male student as well as the total number of male and female students present. The average number of behaviors per male student and per female student were then calculated for each observation. These averages were used as the dependent variable in the factorial ANOVA tests. In order to facilitate the statistical analysis, all response data had to originate from comparable time units. Because the observation periods of instructor $\mathrm{C}$ and instructor $\mathrm{D}$ were one hundred minutes long, while the observation periods of instructor A and B were fifty minutes long, the units were made comparable by dividing the results of the observations of instructor $C$ and $\mathrm{D}$ into four equal time segments of fifty minutes each. This gave each instructor four equal observation periods and allowed statistical comparisons between instructors. Tables showing the averaged frequencies for each observation can be found in appendix $\mathrm{E}$.

To more readily discuss the findings, the grand mean (i.e. the mean of the means) will be used to demonstrate the differences between responses. This figure is calculated by adding the means from of the four observations for each category and dividing by four. For example, the male students in Instructor A's class answered an average of .75 general questions during the third observation (see table II below) this average 
would then be added to the average number of responses for the other three observations and divided by four. The final figure is used in this study to discuss the average behaviors in each category per instructor or instructor student group.

\section{TABLE II}

\section{SAMPLE SEATING CHART DATA SET \\ INSTRUCTOR A \\ OBSERVATION PERIOD 3}

\begin{tabular}{|l|c|c|c|c|}
\hline & $\begin{array}{l}\text { student initiated } \\
\text { interactions }\end{array}$ & $\begin{array}{l}\text { student response to } \\
\text { general ques. }\end{array}$ & $\begin{array}{l}\text { student response to } \\
\text { direct question }\end{array}$ & total \\
\hline female (6) & $18(3)$ & $14(2.33)$ & $7(1.16)$ & $39(6.5)$ \\
\hline male (4) & 0 & $3(.75)$ & $1(.25)$ & $4(1)$ \\
\hline total (10) & $18(1.8)$ & $\begin{array}{c}17(1.7) \\
{[18 \text { asked] }}\end{array}$ & $8(.8)$ & $43(4.3)$ \\
\hline
\end{tabular}

(numbers in parenthesis represent the mean number of behaviors per student)

The ethnicity data from each observation were organized in a similar manner. Only instructors C and D had ethnically diverse student groups. The students in instructors A and B's classes were all Asian. The seating chart data collected in instructors C and D's classes were arranged by gender and ethnicity (see for example table III below). Again the mean responses from four fifty minute time segments were used to analyze the data. The mean of the means will be used to discuss the significant data in this study. Tables containing the ethnicity data collected in instructors $C$ and D's classes can be found in Appendix F. 
TABLE III

\section{SAMPLE ETHNICITY DATA SET \\ INSTRUCTOR C \\ OBSERVATION PERIOD 1}

\begin{tabular}{|l|c|c|c|c|}
\hline & $\begin{array}{c}1 \\
\text { stud. init. }\end{array}$ & $\begin{array}{c}2 \\
\text { general ques. }\end{array}$ & $\begin{array}{c}3 \\
\text { direct ques. }\end{array}$ & total \\
\hline Asian Females (3) & 4 & 2 & 2 & 8 \\
& $(1.33)$ & $(.66)$ & $(.66)$ & $(2.66)$ \\
\hline Russian Females (1) & 3 & 3 & 1 & 7 \\
& $(3)$ & $(3)$ & $(1)$ & $(7)$ \\
\hline Asian Males (1) & 2 & 1 & 2 & 5 \\
& $(2)$ & $(1)$ & $(2)$ & $(5)$ \\
\hline Middle Eastern Males & 26 & 21 & 12 & 59 \\
(5) & $(5.2)$ & $(4.2)$ & $(2.4)$ & $(11.8)$ \\
\hline total (10) & 35 & 27 & 17 & 79 \\
\hline
\end{tabular}

(numbers in parenthesis represent the mean number of behaviors per student)

ETC inventory data. The ETC inventory data were organized into two main categories, instructor behaviors and student behaviors. Each of these main categories contained the same eight categories, present information, question restricted, question expanded, respond restricted, respond expanded, react maintain, react extend and react terminate. The instructor behavior categories indicated whether each behavior was directed at a female student or a male student and were numbered one through eight. Three categories, present information, question restricted and question expanded, were also coded for direction at the class as a whole (see for example table IV below). Again the data were arranged into four fifty minute time units per instructor. The instructor behaviors directed at 
the class as a whole were not included in the statistical analysis because they fall beyond the focus of this study. However, the frequency of instructor behaviors directed at the entire class provide insight into instructor teaching style, a variable which was not directly addressed in this study but is believed to play an important role in the results of this research.

The student behavior categories indicated whether each behavior originated from a female or a male student and were numbered nine through sixteen (see for example table $\mathrm{V}$ below). All raw frequency data were averaged according to the number of students. Because these data were categorized from the transcripts of the audio recordings, student ethnicity information could not be determined. The complete set of ETC Inventory data can be found in Appendix G.

\section{TABLE IV}

SAMPLE ETC INSTRUCTOR BEHAVIORS DATA SET INSTRUCTOR A, OBSERVATION PERIOD 1

\begin{tabular}{|l|c|c|c|c|c|c|c|c|}
\hline & 1 & 2 & 3 & 4 & 5 & 6 & 7 & 8 \\
\hline $\begin{array}{l}\text { class } \\
(4)\end{array}$ & 22 & 29 & 17 & & & & & \\
\hline male (2) & 0 & 4 & 2 & $\begin{array}{c}1 \\
(2)\end{array}$ & $\begin{array}{c}1 \\
(1)\end{array}$ & $\begin{array}{c}9 \\
(.5)\end{array}$ & $\begin{array}{c}7 \\
(3.5)\end{array}$ & $\begin{array}{c}25 \\
(12.5)\end{array}$ \\
\hline female (2) & 2 & $\begin{array}{c}1 \\
(1)\end{array}$ & $\begin{array}{c}(.5) \\
(2)\end{array}$ & $\begin{array}{c}3 \\
(.5)\end{array}$ & $\begin{array}{c}1 \\
(.5)\end{array}$ & $\begin{array}{c}12 \\
(6)\end{array}$ & $\begin{array}{c}12 \\
(6)\end{array}$ & $\begin{array}{c}23 \\
(11.5)\end{array}$ \\
\hline
\end{tabular}

(numbers in parenthesis represent the mean behaviors per instructor) 


\section{SAMPLE ETC STUDENT BEHAVIORS DATA SET INSTRUCTOR A, OBSERVATION PERIOD 1}

\begin{tabular}{|l|c|c|c|c|c|c|c|c|}
\hline & 9 & 10 & 11 & 12 & 13 & 14 & 15 & 16 \\
\hline male (2) & 2 & 1 & 1 & 29 & 17 & 1 & 0 & 1 \\
& $(1)$ & $(.5)$ & $(.5)$ & $(14.5)$ & $(8.5)$ & $(.5)$ & & $(.5)$ \\
\hline female (2) & 5 & 3 & 1 & 31 & 26 & 2 & 0 & 0 \\
& $(2.5)$ & $(1.5)$ & $(.5)$ & $(15.5)$ & $(13)$ & $(1)$ & & \\
\hline
\end{tabular}

(numbers in parenthesis represent the mean behaviors per student)

All data from all observations were entered into spreadsheets with the mean responses from each observation being the dependent variable. Like the seating chart data, the independent variables for the ETC data were instructor, instructor gender, student gender and category. As was done with the seating chart data, the ETC inventory data were conceptualized as four separate fifty minute time units. This involved dividing instructor $C$ and instructor D's two one hundred minute classes into four fifty minute units.

\section{FINDINGS}

The results of the data analysis will be discussed as they relate to the research questions outlined in Chapter 1 . The research questions are grouped according to the instruments used to determine their answers. 
Questions 1, and 4

Question 1. Does student gender influence the frequency with which ESL instructors interact with individual students?

To answer question one, a factorial ANOVA test was used with the averaged behaviors per male or female student per observation collected using the seating chart instrument acting as the dependent variable and the instructor, student gender and category acting as the independent variables.

In an analysis of all the participating instructors a significant interaction between instructor and student gender was found $(f(3,72)=$ $4.44, \mathrm{p}=.006)$. This means that the analysis of all four instructors showed that there was a significant difference in the frequency of interactions based on student gender. Planned comparison tests on the data revealed where these differences occurred. It was determined that instructor A interacted significantly more frequently with her female students than she did with her male students $(\mathrm{f}(1,72)=4.470, \mathrm{p}=.037)$. These tests also showed that instructor $C$ interacted significantly more frequently with her male students than she did with her female students $(f(1,72)=5.20, p=.025)$. The same was found to be true of instructor D, who interacted significantly more frequently with his male students than he did with his female students $(\mathrm{f}(1,72)=4.11, \mathrm{p}=.046)$. Only instructor B did not interact with students of one gender significantly more frequently than the other (see figure 2 below). 


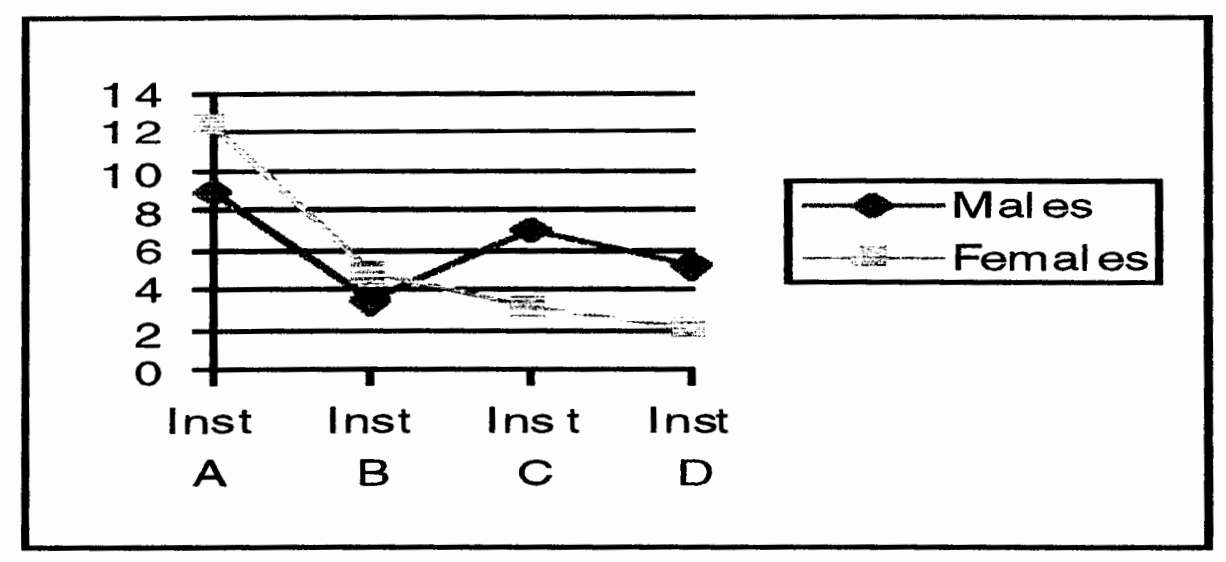

Figure 2. Average total interactions between instructors and their male and female students.

The ANOVA results showed that there was a significant difference between the overall interaction frequencies of instructors $(p=.024)$. A Tukey's test indicated that instructor A interacted more frequently with her students than either instructor $B(p=.043)$ or instructor $D(p=.044)$. Though she interacted with her students more frequently than did instructor $C$, this difference was not statistically significant $(p=.110)$

A notable difference between categories was found $(\mathrm{f}(2,72)=3.04, \mathrm{p}=$ .053) but this difference was not significant at the $p=<.05$ level. Further examination of the data revealed that of the three categories for all instructors, student initiated interaction, student response to general question and student response to direct question, the most interactions occurred in the student response to a general question category. The collective behavior frequencies for all instructors indicate that $48 \%$ of the interactions in their classrooms occur as student responses to general 
questions. $23 \%$ of all interactions begin in the form of direct questions asked by the instructor to a particular student and $29 \%$ are student initiated.

A notable interaction between category and instructor was found $(\mathrm{f}(6,72)=2.04, \mathrm{p}=.07)$ but this interaction was not significant at the $\mathrm{p}=<.05$ level. Though not statistically significant, this interaction is relevant because it indicates that the interactions between different instructors and their students vary by category. Closer examination of the data shows that instructor A showed the greatest difference in interaction frequency by category, interacting with students in the general question category over four times as frequently as in the student initiated interaction category and about three times as frequently as in the direct question category. The other instructors interacted with their students fairly equally across categories. There was not a significant statistical interaction between student gender and category, meaning that, overall, the type of interaction did not have an effect on the participation of male or female students.

Instructors $A$ and $B$ interacted more frequently with their female students than they did with their male students though the difference was significant only in the case of instructor A. Overall, female students in instructor A's classes participated in $57 \%$ of the teacher/student interactions while male students participated in $43 \%$ of the teacher/student interactions. Instructor B interacted with his female students only slightly more frequently than he did with his male students, with $52 \%$ of the 
teacher/student interactions in instructor B's classes occurring between he and his female students, while $48 \%$ of the interactions occurred between he and his male students.

In both instructor A and instructor B's classes, females initiated interactions nearly three times as often as males. Females answered more general questions than males in instructor A's classes though this difference was not great with males answering an average of 5.9 general questions per observation and females answering an average of 7.3 general questions per observation. Both instructors asked approximately the same number of direct questions to their male and female students (see figure 3 below).

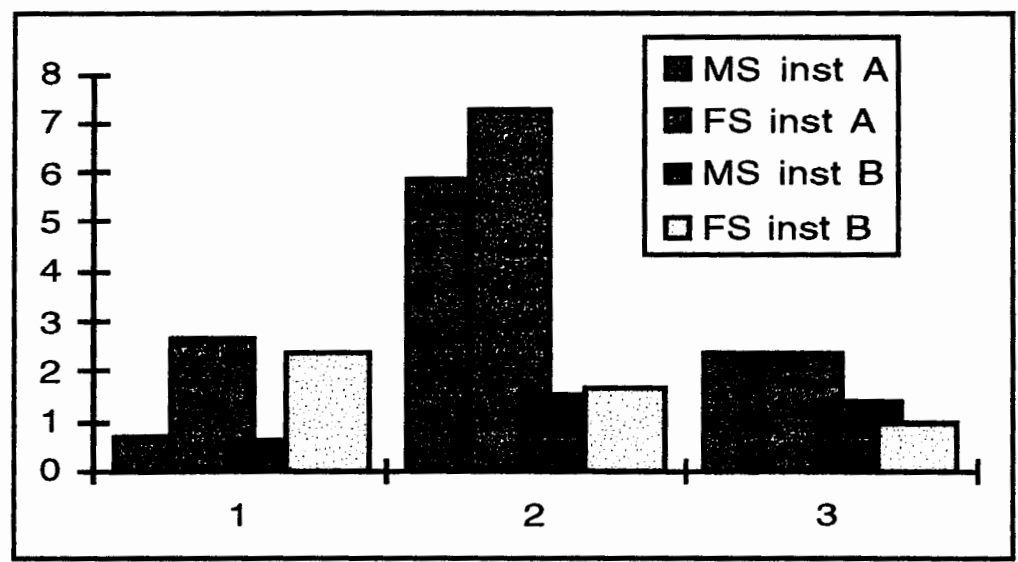

Figure 3: Seating chart data, instructors A and B.

$1=$ student initiated interaction $2=$ response to general question

$3=$ response to direct question

Instructor A interacted more frequently with her students than did any of the other instructors, an overall average of 10.9 interactions per student per observation, though this difference was only significant 
between instructor A and instructors B and D $(p=.043, p=.044$

respectively). Two observations of instructor A's classes took place in high intermediate academic reading classes which were designed to complement a mainstream history course that her students were preparing to take the following semester. Two observations took place in a high intermediate/advanced listening and speaking course. There was a very large difference in number of overall interactions between the two courses. The average number of overall interactions per observation in instructor A's academic reading courses was 17 per student. In her listening and speaking courses, the average number of overall interactions was 4.75 per student, over three and a half times fewer interactions than in the reading courses. There are two possible reasons for this disparity in average interaction frequencies. First, the reading course had a very small enrollment, only four students. This allowed more personal attention to the students and many more opportunities for teacher/student interactions. Second, the listening speaking course used several cooperative learning exercises in which the students interacted not with the instructor but with each other. This means that while the students are participating in fewer teacher/student interactions, they are nonetheless interacting in English.

Instructor B's classes were generally executed with a lecture type of format. All observations of instructor B's classes were of an advanced 
academic reading course. These classes were designed to interact with a mainstream history course which all of instructor B's students were enrolled in concurrently. Most of instructor B's classes consisted of lectures on the history text the students were required to read for their mainstream history course. The average number of overall interactions in instructor B's classes was 4.4 per student. As can be seen in figure 3, instructor B asked over four times fewer general questions to his classes than did instructor A. However, as already stated, instructor A interacted more with all her students than did any other instructor; therefore, the low number of general questions answered in instructor B's class is not as unusual as figure 3 seems to indicate. During each observation, instructor B began his classes with a history quiz. Because nobody spoke during these quizzes, no data were recorded. Usually these quizzes lasted ten minutes or less; however, on one occasion, students spent nearly thirty minutes taking the quiz. Consequently, the overall number of interactions recorded in instructor B's classes is lower than that recorded in the other three instructor's classes.

The data analyzed considered only the general questions answered by students, not the number of general questions asked. It is interesting to note that instructor $\mathrm{A}$ asked 25 more general questions than were answered and instructor B asked 38 more general questions than were answered. One reason for the disparity between general questions asked and general 
questions answered in instructor A and B's classes may be the difficulty of the material covered in these two classes. All of instructor B's classes and two of instructor A's classes were intended to work in conjunction with a mainstream university American history course. Many of the students seemed to find the reading very difficult and had trouble recalling facts from the text that they had read. Instructor B asked many factual questions to the class in general which none of the students could answer. Instructor A had a similar problem in her academic reading course. Another possible reason for students' lack of willingness to answer general questions might be related to their cultural backgrounds. All the students in instructors $\mathrm{A}$ and B's classes were Asian. Instructor A stated in her interview that she believes her Asian students would prefer to be called on directly rather than be required to volunteer an answer in class. She stated that she does not cater to this educational preference because the goal of the ESL classes at her college is to eventually mainstream the students into the regular academic curriculum. Therefore, the instructors at this college seek to imitate the type of classroom environment the students will encounter in their regular academic courses. This amounts to fewer direct questions asked by the instructor and frequent opportunities for voluntary student responses in ESL classes. Instructor A asked one female student one direct question that was not answered. All of the direct questions asked in instructor B's classes were answered. 
Instructors $C$ and $D$ interacted significantly more frequently with their male students than they did with their female students $(p=.0254$ and $\mathrm{p}=.046$ respectively). In instructor C's classes, male students participated in $69 \%$ of the overall teacher/student interactions while female students participated in $31 \%$ of the teacher/student interactions. The results of the seating chart data for instructor D are similar. In instructor D's classes, male students participated in $71 \%$ of the teacher/student interactions while female students participated in $29 \%$ of the teacher/student interactions.

As was found in instructor B's classes, the teacher/student interactions which took place in instructor C's classes were fairly evenly distributed across categories. Instructor D asked a great deal fewer direct questions to his students than did any other instructor, averaging less than one direct question per student. Unlike instructors A and B's classes in which the general question category contained the most interactions, in both instructors $C$ and D's classes the student initiated interaction category contained the most interactions overall. Though this is true of the overall interaction frequency in instructor $C$ and D's classes, male and female student interaction frequencies varied widely within categories.

Male students were found to interact with their instructors more often than female students across all categories. The most notable of these differences occurred in the student initiated interaction and student response to general question categories (categories 1 and 2 respectively). In 
instructor C's classes, male students initiated interactions over one and a half times more often than females did on average, 2.84 initiated interactions per male, 1.10 per female. In instructor D's classes, male students initiated an average of 2.57 interactions each, about two and a half times more often than the female students who initiated an average of .73 interactions each.

The males in instructor C's classes answered an average of 2.17 general questions per student while the females answered only .624 general questions per student; a difference of nearly three to one. In instructor D's classes, male students answered about twice as many general questions than female students did, 1 to 2.17 respectively. Like instructors $A$ and $B$, instructors $\mathrm{C}$ and $\mathrm{D}$ asked direct questions to their male and female students remarkably equally (figure 4).

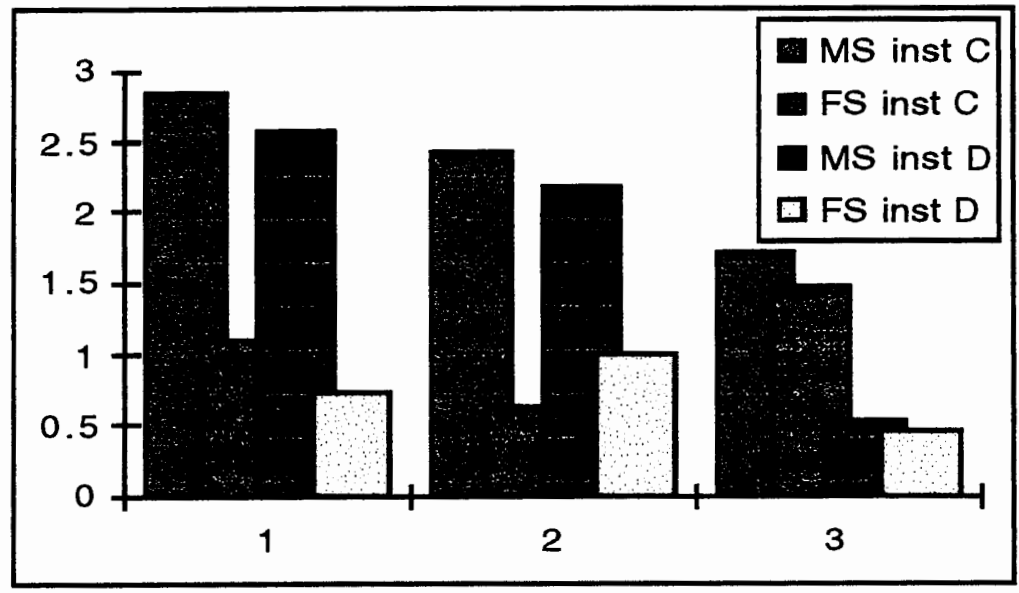

Figure 4. Seating chart data, instructors $C$ and D $1=$ student initiated interaction $2=$ response to general question $3=$ response to direct question 
Instructor $C$ interacted with her students slightly more often than did instructors B or D, but this difference was not significant. Instructor C averaged 4.975 interactions per student per fifty minute time segment. Instructor D averaged 3.925 interactions per student per fifty minute time segment. There were many fewer unanswered general questions in instructors $C$ and D's classes than there were in instructors $A$ and B's classes. Instructor $C$ asked only 9 general questions that went unanswered and instructor $\mathrm{D}$ asked 16 more general questions than students answered. Again, the high frequency of unanswered general questions in instructors A and B's classes is probably due to the relative difficulty of the material. It is likely that instructor D's high frequency of unanswered general questions stems from his tendency to ask students if they have any questions or problems fairly often. These types of questions were coded as general questions because they were followed by a pause long enough to indicate that the instructor was awaiting an answer. Instructor D asked one direct question to a female student that went unanswered, instructor $C$ did not ask any unanswered direct questions.

Interestingly, the only category that instructors have immediate control over, the direct question category, did not show a difference in average frequency between male and female students. However, as was revealed in the instructor interviews, each of the instructors claim that they try to keep the interactions fairly equal in the classroom by gently 
admonishing interaction dominating students, encouraging reticent students to speak out or both. Though the instructors do not favor either males or females when asking direct questions, they are clearly not managing student behavior in a manner which allows interaction equality.

It is interesting to note that instructors C and D's classes were comprised of ethnically diverse groups while instructors A and B's classes were solely Asian. As analysis of the ethnicity data examined for research question four shows, this ethnic diversity seems to play a large role in the frequency of interactions which occurred in instructors C and D's classes.

From this analysis of the seating chart data alone, the answer to research question one seems to be yes, student gender does influence the frequency of teacher/student interactions in the ESL classroom. Three of the four instructors observed in this study interacted with students of one gender more than students of the other. Instructors $C$ and D interacted significantly more frequently with their male students than they did with their female students while instructor A interacted significantly more frequently with her female students. Though the statistical analysis indicates that gender does seem to play a role in determining which students interact with their instructors the most, the student gender that dominates seems to change from class to class, instructor to instructor. The classroom is a very complex environment. There are many components of classroom life that were not considered here and likely play a role in the 
outcome of this research. One factor of ESL classroom life that clearly affects interaction frequency is student ethnicity which is examined by research question four.

Question 4. Does the ethnicity of an individual or group of students influence the frequency with which ESL instructors interact with those students?

The seating chart frequency data from instructors $C$ and D's classes were used to answer this question. Instructors A and B taught ethnically homogenous classes; therefore, the data collected in their classes could not be used to answer this question. The ethnicity data were analyzed using a one-way ANOVA design wherein the averaged behaviors per observation for male and female students of each ethnicity was the dependent variable and ethnicity was the independent variable. The ANOVA revealed a significant difference between ethnic groups $(F(3,50)=6.455, \mathrm{p}=.0008)$. A Tukey's test revealed that Middle Eastern students and African students interacted within all three categories significantly more often than did students of any other ethnicity. There were no significant differences found between Russian and Asian students nor between Middle Eastern and African students (see figures 4.8 and 4.9 below). There were also no significant differences in behaviors between instructors. 


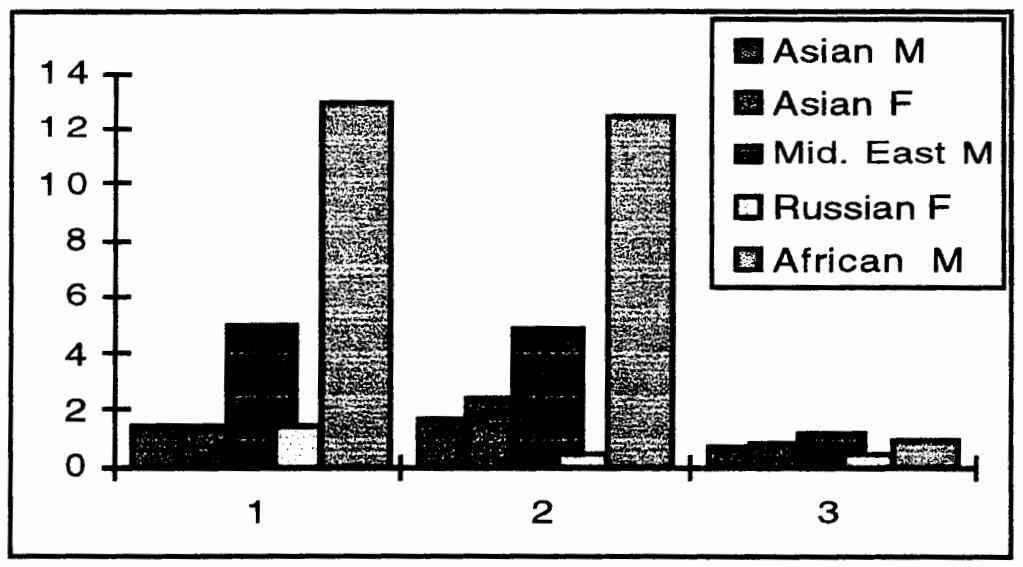

Figure 5. Ethnicity data, instructor D $1=$ student initiated interaction $2=$ response to general question $3=$ response to direct question

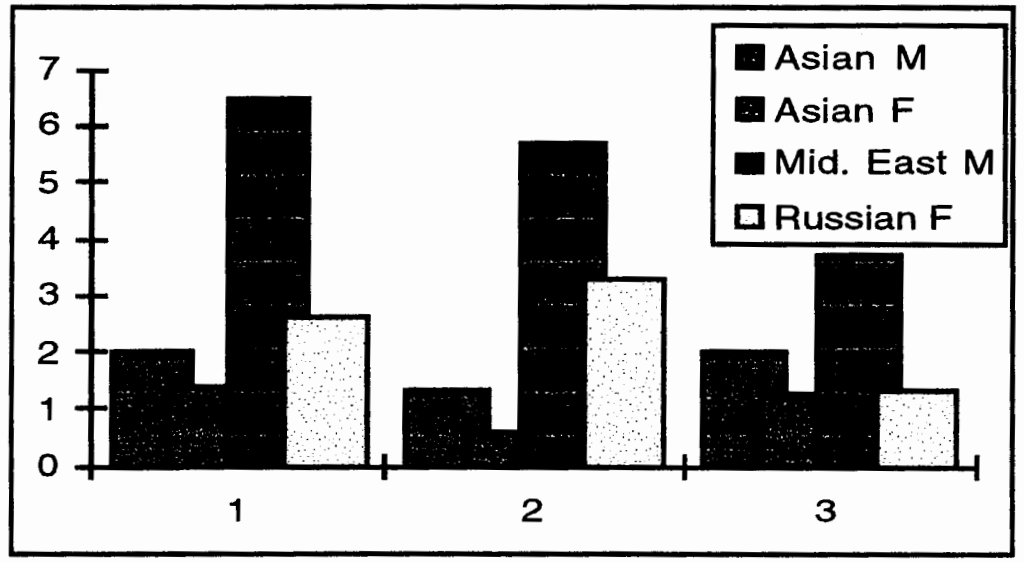

Figure 6. Ethnicity data, instructor C

$1=$ student initiated interaction $2=$ response to general question $3=$ response to direct question

The ethnic composition of instructors $C$ and D's classes may provide some insight into the ethnicity data findings. In instructor C's classes, there were three to five Asian females, one to two Asian males, five Middle Eastern males and one Russian female per observation. From this information we can see that though the Asian females numbered the same 
as the Middle Eastern males, this did not play a role in the frequency with which they interacted with their instructor. Similarly, though there was only one Russian woman and one or two Asian men, the Russian woman initiated more interactions and answered more general questions than did Asian men or women. This data seem to indicate that in instructor C's classes, student ethnicity does indeed play a role in the frequency with which students interact with their instructor. The Asian students interact less frequently with the instructor than any other group, though the difference in interaction frequency between the Asian students and the Russian student is not significant $(p=.99)$.

The breakdown by category shows that instructor $C$ not only interacted with Middle Eastern students more because they answered more general questions or initiated more interactions than other students, but also because she asked the Middle Eastern students, who were all male, more direct questions than she asked students of any other ethnicity. Though the whole class data showed that instructor $\mathrm{C}$ asked direct questions to males and female students fairly equally, it is now clear that the Asian male students in instructor C's classes were not asked an equal number of direct questions. This suggests that an element of the interaction inequality in instructor C's classes originates from the instructor. 
In instructor D's classes there were four to five Asian females, two Asian males, four Middle Eastern males, one African male and one Russian female per observation. The data show that the African male initiated more interactions and answered more general questions than any other group of students. Aside from the unusual verbosity of the African student in instructor D's classes, the ethnic breakdown of these classes reveals that, as was found in instructor C's classes, the Asian students interact much less frequently than the Middle Eastern students despite their relative equality of numbers. Unlike the Russian female in instructor C's class, the Russian female in instructor D's class rarely interacted with the instructor.

Because ethnicity data could only be collected in half of the classes observed, it is difficult to draw any firm conclusions from these data. The analysis of data collected in instructor C and instructor D's classes revealed that both of these instructors interacted with their male students significantly more frequently than they interacted with their female students. The ethnicity data show that the male students in instructor C's class who participated in the most interactions were Middle Eastern, in instructor D's classes they were Middle Eastern and African, all of these students were male. The Asian males in instructors C and D's classes interacted with their instructor with a frequency similar to that of the females in their classes, that is, significantly less than the other males. 
There seems to be a connection between student ethnicity and interaction frequency, perhaps an even stronger connection than the one between student gender and interaction frequency. If the significant student gender findings in instructors $C$ and D's classes were due to gender alone, one would expect that high interaction frequency would occur across all ethnicities for males. This is not the case.

\section{Question 1a and 4a}

Questions 1a and 4a focus on whether the differences in interaction frequency which occur in instructors' classrooms occur within the instructors' awareness. In other words, do these instructors believe that they interact equally with all their students or do they intentionally interact with different students differently for some reason. The following is a discussion of the instructor interviews as they relate to research question $1 \mathrm{a}$ and $4 \mathrm{a}$. These questions will be answered together because though it was the researcher's intention to address differences in interaction frequency based on student gender separately from differences based on student ethnicity, all instructors tended to lead the conversation toward a more general discussion of interaction equality among all students rather than between themselves and students with particular characteristics. Therefore, the instructors' beliefs about their classroom behavior applies to both situations. Because no significant difference in interaction frequency 
was found in instructor B's classes, his beliefs about his actions are not an issue and will not be addressed here. Instructors A, C and D's interviews will be discussed in turn.

Instructor A. The interview with instructor A revealed that she believes she does everything she can to make sure every student gets equal opportunities for interaction in the classroom. She believes she accomplishes this through using a variety of classroom management techniques and through the use of cooperative learning techniques. One of instructor A's main concerns is for the comfort of her students. She feels, as many instructors do, that making students feel "put on the spot" is counterproductive to successful language learning. The following is an excerpt from our conversation during which instructor A explains how she avoids putting students "on the spot":

Me: Every class has students who tend to monopolize the classroom discussion and some students who are kind of shy and hold back a lot. What kind of things do you try to do to sort of balance that out a bit?

IA: umm, the technique that I use, having the students talk to each other, like in pairs. If I ask questions in class, sometimes I'll let, cause I want every student to think about it I don't want some to just sit back and wait for another student to answer, so I'll just tell them to tell you know your partner your opinion about this tell them what you think about that or your idea and then I can go back to the whole group and kind of say you know what are some of the things you came up with and then you know everyone will have said something already and even if they don't say anything in the whole group that idea will come up and eventually usually will come up onto the board, so that's one way. 
Later in our conversation, the topic of "interaction dominators" came up. Instructor A remarked that several students had visited her during her office hours and expressed concerns about a particular student who they thought was speaking up too often in class. I asked her what she did to overcome that problem. She responded that in that particular case she didn't think the student was monopolizing the interactions but that she has seen it happen in other cases. She said, sometimes I just have to tell that student you know either privately or in the group, you know we want to have everybody have a chance to say something and you know I know you've got something to say and you contribute a lot but let's let somebody else contribute too.

Instructor A was clearly concerned about every student getting an equal chance for interaction in her classroom. It seems that her main method of assuring equality is to use cooperative learning techniques which allow students to feel more comfortable than when they must interact with the instructor in front of the whole class. Instructor A does, however, claim to use a variety of techniques to accomplish equality of interactions as the following excerpt suggests:

Me: Do you think that the classroom management, in other words what we were just talking about, whether you call on people or whether they raise their hands or whether they just shout out an answer plays a big role in how much English each student gets to practice?

IA: Yeah, and I think the students, uhh, if the students feel passive in the classroom, which they can feel if you don't involve them they get a lot less out of it. They have a poorer attitude towards it and they get a lot less out of it.

Me: So, you would say that, as a rule, you try to draw everyone in in whatever way you can using whatever strategy you have to? 
IA: Yeah, Yes.

Instructor C. Instructor C stated that she was not overly concerned with trying to encourage shyer students to participate more in classroom discussions. She believes in allowing students not to participate in whole class discussions if such participation makes them feel uncomfortable. Though she says she does not take special steps to encourage less verbal students to participate more, she says she does make an effort to curb the verbosity of students who tend to monopolize discussions. The following is an excerpt from our conversation about interaction equality:

Me: In every classroom there are students who are less verbal and students who are more verbal, what do you do to sort of equalize that, what kind of strategies do you use?

IC: Um, well let me think, it kind of depends on the class. In some cases, it used to worry me more than it does now, I used to be really upset because some students just wouldn't talk and I think I'm less worried about it now because I think that that's their personal comfort zone and if they don't feel comfortable speaking yet I won't, I don't umm try to contrive situation that will make them feel really uncomfortable so I kinda let it slide. As long as I feel like I'm making eye contact and they're sort of engaged in the class umm and so I try to umm keep making eye contact and if I get the feeling that they want to say something you know I'll call on them or ask them or whatever's going on. So I'm aware of them I'm trying to keep track of them but I don't want to put them on the spot because some people are just uncomfortable. But then you have the students who are, I mean that's what I try and do for the ones who don't want to talk but then there are the one's who want to talk all the time and sometimes I just want to to tell them you know, ok, thank you and now do we have something from somebody else and I don't call on those guys again cause they've already answered six out the last seven questions or something like that because there are people who want to dominate. It's just sort of a matter of trying to keep track of who is actually participating and you can usually tell if there are students who want to participate that are being bumped out by the 
ones who are dominant you know you can watch their faces and you can tell if they have something to say just by being aware of them.

Later in the interview, instructor $C$ reiterated that she doesn't push students to participate if she perceives that such an action would make them feel uncomfortable:

Me: So in speaking out in class, the amount of student talking that goes on, you try to make them feel comfortable by not forcing them to speak out or calling on students who you think are shy ..

IC: Yeah, I'll try to make them feel comfortable but on discussion things but like I said when I'm doing drill practice I'll go around and everyone answers umm but a lot of time if it's a kind of a discussion thing I don't find pushing beyond what they're comfortable, I mean a little bit beyond what they're comfortable with but not too much beyond what they're comfortable with. A little bit of pushing is ok but not too much. Some kids you just can't push at all and other ones they want to be pushed and they're sort of hoping you'll push them 'cause then they'll get a chance to talk and they won't offer to talk on their own because they feel like you don't really want to hear from them or something.

Instructor $C$ seems to be aware that some students are participating in classroom discussion somewhat less than others. Furthermore, she knows that student expectations about classroom behavior differ from culture to culture. She says that by being aware of her students and being aware of the cultural expectations they have about their role in the classroom she ensures that everyone who wants to speak and is ready to speak gets that opportunity. She says that the students are aware of their right to speak up in class, that verbal classroom participation is expected of them, and that they generally do not have a problem expressing their opinions in class. She is a strong believer in cooperative education and 
feels that if a student is not participating in small group work than that lack of interaction is more detrimental to their overall language education than not speaking up in whole class discussions:

Me: So really, I guess what I'm getting at is that part of your job and all of our jobs as teachers of English is to sort of give some sense of how our culture operates in the classroom and that we all have just as much right to speak up and that's in fact expected in our culture. That speaking up is a valued thing, and expressing your opinion is a respected action. So do you think that that is made clear or do you think that the students get that just by inference or...

IC: Yeah, I think so, yeah I think both, you know, it's sort of indirectly covered but I think it is also pretty explicitly covered too. You know, if somebody gives an opinion and you follow up with that by asking someone else what they thought of that person's opinion, you know compliment them on it and follow up on whatever they've said with somebody else's, it seems to me the harder thing than getting them to express their opinion is getting them to listen to somebody else. A lot of times they just want to dialogue with you. One student wants to talk and everybody else just tunes out and thinks that oh well he's talking and I'll get my chance and the next thing you know they're saying the same thing because they were never listening to the first person. And I think more difficult for me is to get them to listen and to have them get the idea that perhaps their peers have something to offer.

The male students in instructor C's classes were found to interact with her significantly more often than the female students. One explanation for this may be that instructor $C$ perceives the female students as undesirous of participating in teacher/student interactions. The seating chart ethnicity data collected revealed that the Middle Eastern males interacted the most with instructor $\mathrm{C}$ and that the Asian males interacted with instructor $C$ significantly less than the Middle Eastern males. Instructor $C$ may also consider the Asian males to be too shy to wish to 
participate often in classroom discussions. Because instructor $C$ claims that when some students speak up much more than other students she makes an effort to include other students, it is possible that she is not aware of the dominance of Middle Eastern males in the interactions in her classes.

Instructor $D$. Instructor $D$ believes that a combination of classroom management techniques and student awareness of appropriate classroom behavior alleviate most of the interaction inequality that occurs in his classroom. He believes that by making explicit his expectations about turn taking in the classroom the students understand that it is to their benefit to both participate frequently themselves and allow others to participate frequently:

Me: Do you have a few students who you consider, maybe one or two students who tend to monopolize the classroom interaction or do you try to keep that at an even keel?

ID: Yeah, there are some classes, of course, when that happens and it's hard to stop that kind of thing from happening but I think that's why it's good to do group work or even whole class work where you have everyone sit sort of in a semicircle or circle and have everyone respond and get a chance to say something. The person who wants to monopolize the conversation will be told at the beginning that the gameplay here, the plan is that everyone must speak before you have a second chance to speak, and I think the students respect that otherwise one person does you know monopolize the conversation. I think if you set the rules up you can handle that kind of thing.

Regarding the differing cultural expectations in terms of student roles in the classroom instructor D says that those can be somewhat overcome by explicitly explaining what his expectations as an American 
instructor are and what the general cultural expectations regarding student

behavior in American classrooms are:

Me: Right, do you find that some students, students from some cultures are more willing to take a risk than others?

ID: Yeah, of course the stereotypic thing is that the Asian students generally are not trained to respond very quickly, not that they don't know the answers but in general I think that that's true. Middle Eastern students European students who are trained in a different tradition tend to be more verbal in terms of expressing their opinions and so on.

Me: Yeah, I know from my experience, I work with mainly Vietnamese groups and I work with a Chinese group, they generally will wait for me to call on them before they want to offer an answer and it's not that they don't know the answer it's just that they expect me to ask them directly. So do you at first at least try to sort of cater to this educational expectation that they have regarding teacher-student roles at all?

ID: Yeah, uh-huh. uh-huh, we do talk about that and I explain that and I think they already know that really it's just a matter of making it concrete and putting it out in front of them but I think they already understand that. What happens is that because they come from cultures where they're hesitant to speak out for fear either that they'll make a mistake or even if they know the correct answer because they don't try to show off their knowledge that's another thing they don't want to do either they need to understand that that's ok to do that. Students from other cultures sometimes will answer the question even if it's not correct they just need the chance to feel they should offer something and you know we do a lot of talking about expectations. Because they're here studying in American colleges and universities and this is an expectation that they'll need to to cope with and it helps a little bit but of course what has been ingrained for years and years is difficult to undo and so even if they are comfortable in the class doing it when they get out into another quote authentic type of situation they may not be able to do it. So, but at least they cerebrate that, they know that cerebrally that this is what needs to happen.

Instructor $\mathrm{D}$ believes that his students understand that they are expected to speak up frequently in class. He knows that sometimes certain students tend to monopolize the discussion but he believes he generally 
takes steps to avoid such a situation. The Middle Eastern and African male students interacted with instructor D significantly more than the Asian male students or any of the female students. From our interview, it was clear that if instructor $D$ had been conscious of the vastness of this difference, he would have either informed the students that monopolization of the discussions was occurring or he would have altered his classroom management strategies to ensure a more equitable distribution of interactions.

The answer to questions $1 \mathrm{a}$ and $4 \mathrm{a}$ seem to be no, these instructors are not aware of the differences in interaction frequency that occur in their classes. Each of the instructors interviewed said that when they realized some students were speaking out in class much more than others they took steps to reduce the disparity of interactions between students. All instructors said they would mention the problem to the interaction dominating student or ask him or her to give other students a chance to participate. Instructor $C$ said she did not go out of her way to induce shy students to speak more, while instructors $A$ and D said they try to use a variety of methods to get all their students to speak out in class.

Unfortunately, the content of the instructor interviews rarely dealt directly with student gender as an influence on interaction frequency. Again, this is a result of the informality of the interview and the researcher's attempt to maintain a relaxed environment throughout the 
discussion. Though the interviews did not yield information about intructors' beliefs concerning their interactions with different students based on the gender of those students, they did reveal that each instructor believes he or she does whatever possible to ensure that each student gets an equal chance at interaction. They also revealed the instructors' genuine concern for the success of all of their students and their realization that frequent teacher/student interactions are a factor in that success.

\section{$\underline{\text { Research Questions 2, 2a and 2b }}$}

Research questions $2,2 \mathrm{a}$ and $2 \mathrm{~b}$ were all answered with the data yielded from the ETC inventory instrument. Though an analysis of the instructor behaviors alone is sufficient to answer these questions, the student behaviors will also be discussed. Discussion of both student and instructor behaviors allows consideration of the student behaviors which are often the catalysts behind instructors' actions.

Research question 2. Does the content of teacher/student interactions in ESL classrooms vary according to student gender?

To answer this question, the ETC inventory responses for each instructor and each instructors' students were analyzed using factorial ANOVA tests. The average frequency of instructor and student behaviors was used as the dependent variable and the student gender, category and instructor were the independent variables. It was assumed that a statistical 
interaction between student gender and category when the instructor behaviors are acting as the dependent variable would indicate differences in overall content of interaction based on gender. In other words, if male and female students are receiving significantly different numbers of instructor behaviors in different categories, a difference in interaction content would be indicated. No significant interaction between student gender and category was found using the factorial ANOVA test $(f(7,192)=.79061, p=.60)$. The same type of analysis done on the student behaviors did not show a significant interaction between student gender and category either $(f(7,192)=.1306, p=.27)$. Therefore, interaction category did not play a role in the frequency with which male and female students interact with their instructors. Though no evidence of a relationship between category and the frequency of instructors with their male and female students, the ANOVA test on the ETC results yielded many other notable findings.

The results of the ANOVA indicated a significant difference in interaction frequency between instructors $(f(3,192)=18.4, p=.00000)$. Again, instructor A interacted significantly more frequently with her students overall than did any of the other instructors. The ANOVA also revealed a significant interaction between instructor and student gender $(\mathrm{f}(3,192)=5.02, \mathrm{p}=.002)$. Planned comparison tests agreed with the seating chart data analysis in that instructor A interacted significantly more with 
her female students while instructors $C$ and $D$ interacted significantly more with their male students.

The ANOVA test found that there were significant differences between categories $(f(7,192)=25.63, p=.0000)$ with all instructors participating in the types of interactions subsumed in category 6 , react maintain level of participation, and category 8 , react extend level of participation, more than any other type of interaction.

The answer to research question 2 seems to be no, instructors do not vary the content of their interactions with students based on student gender. The ANOVA test did not show an interaction between category and student gender indicating that there was no difference in male and female interaction frequencies based on category. Though the answer to this question in essence answers research questions $2 a$ and $2 b$, interesting differences between instructors emerged and these differences are worthy of further discussion.

Research question 2a. Do ESL instructors ask more questions which require restricted thinking responses to members of one gender while asking questions that require expanded thinking responses to the other?

Research question $2 b$. Do ESL instructors react in a manner that maintains or terminates the current level of student participation more often to students of one gender while reacting in a manner that extends the level of participation to students of the other gender? 
Overall, no significant interaction between gender and category was found. That is to say, the type of interaction did not have a significant effect on the frequency of interactions between instructors and the male or female students. Though no significant difference between question types for male and female students was found, the question asking behaviors of individual instructors varied widely. Similarly, an examination of the frequencies of interactions which fall under the reaction categories illustrate the individual differences between instructors. The following is a discussion of the ETC inventory findings from each instructor as they relate to research questions $2 a$ and $2 b$.

Instructor behaviors instructor A. Instructor A asked slightly more restricted thinking questions to her male students than she did to her female students. On average, instructor A asked .94 restricted thinking questions per male student and .66 restricted thinking questions per female student. The distribution of expanded thinking questions asked by instructor $\mathrm{A}$ is fairly equal between male and female students, an average of .56 per male and .6 per female (see figure 7 below).

The response categories (categories 4 and 5) show an interesting difference between males and females. Instructor A responded to females with restricted thinking responses nearly three times as often as she did to males, and responded with expanded thinking responses to males slightly more than she did to females. The results of the response categories are 
best examined in relation to the ETC student behavior results (see figure 8 below).

Of the reaction categories, react maintain level of participation (category 6), react extend level of participation (category 7) and react terminate level of participation (category 8), the most common interaction types were those subsumed under categories 6 and 8 . Instructor A reacted in all three ways more often to female responses or presented information than she did to male responses or presented information. The most notable of these differences is in category 6 , react maintain level of participation, in which instructor A interacted with female students an average of 3.75 times per session. Instructor A reacted to males in a manner which maintained the level of participation an average of 2.5 times per session, $50 \%$ less often than females. Because the ANOVA test of the ETC results verified the seating chart results which indicate that the female students in instructor A's class interact more frequently with her than the male students, it is not surprising that instructor A reacts more frequently to female student behaviors. The student behaviors outlined in figure 8 help to clarify the reaction behaviors of instructor A. 


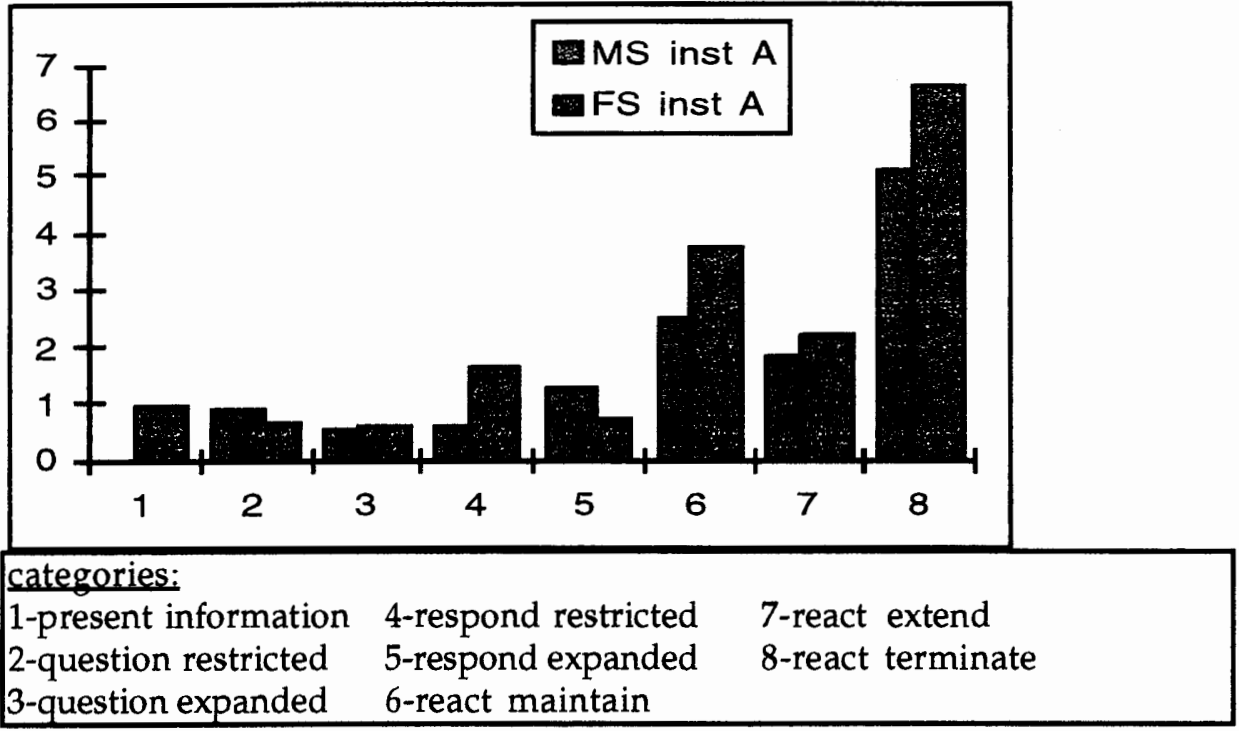

Figure 7. Averaged ETC instructor behaviors per student, instructor $\mathrm{A}$

Student behaviors instructor A. The overall ANOVA of the ETC inventory of student behaviors revealed a significant difference between instructors $(\mathrm{f}(3,192)=14.6, \mathrm{p}=.0000)$. A Tukey's test revealed that the students in instructor A's classes interacted more with their instructor than did the students in instructor $B(p=.022)$, instructor $C(p=.0004)$ or instructor $D^{\prime}$ s classes $(p=.004)$. The analysis also revealed that the female students in instructor A's classes interacted more with their instructor than did the male students $(\mathrm{f}(1,192)=.007, \mathrm{p}=.007)$, while the male students interacted more frequently with instructors $C(p=.013)$ and $D(p=.044)$. There was no significant difference between the interaction frequencies of male and female students in instructor B's classes. The analysis revealed a significant difference between categories $(f(7,192)=31.7, p=.0000)$. Most 
student interactions occurred in the restricted thinking and expanded thinking response categories, categories 12 and 13. Interaction types subsumed under these two categories occurred significantly more often than any other type.

The ETC student behaviors results reveal that the female students in instructor A's classes asked approximately twelve times as many restricted thinking questions than their male counterparts did on average. Female students also presented information to the instructor an average of nearly three times as often as did male students. These behaviors explain the difference in restricted thinking responses between male and females in the instructor behavior analysis.

Neither males nor females asked very many questions in instructor A's classes. Both male and female students asked less than one expanded thinking question each per observation session. However, the instructor behavior results indicate that instructor $\mathrm{A}$ responded with expanded thinking responses to her male student slightly more frequently than she did to her female students. The difference in the frequency of expanded thinking responses directed at males and females might be a result from differing types of responses to student reactions. Reactions are often in the form of questions, it is possible that male students' reactions were responded to with expanded thinking responses more often than female students' reactions were. 


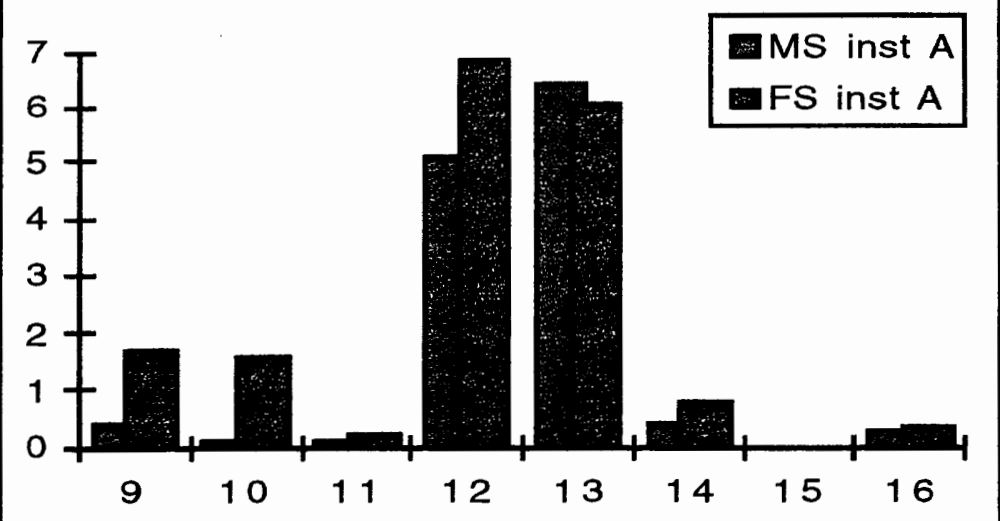

categories:

9-present information 12-respond restricted 15-react extend

10-question restricted 13-respond expanded 16-react terminate

11-question expanded 14-react maintain

Figure 8. Averaged ETC student behaviors per student, instructor $\mathrm{A}$

The student behavior analysis revealed that for all instructors category 12 , restricted-response and category 13 , expanded-response, were the most widely used types of interactions initiated by students in the classrooms. For instructor A, female students responded with restricted thinking responses to questions or reactions an average of $35 \%$ more often than did males. The number of expanded thinking responses did not greatly differ between males and females. Because female students in instructor A's classes responded more often to questions of all types, it is not surprising that instructor $A$ reacted in each of the three reaction categories more often to her female students than she did to her male students. 
Instructor behaviors instructor B. Instructor B asked more direct questions to his male students than he did to his female students. Though this seems to contradict the seating chart data outlined in previous sections, it does not. The criteria for a direct question categorization for the ETC inventory are much stricter than those used for the seating chart categorization. Questions which were categorized as direct questions on the seating chart instrument may be categorized either as questions or reactions depending on their context under the ETC inventory. Instructor B asked about the same number of restricted thinking questions to both his male and female students, an average of .75 per male and .68 per female. The difference between the instances of expanded thinking questions for male and female students is a little wider. Male students were asked approximately one and a half times more expanded thinking questions on average than were females (see figure 9 below). The response categories, categories 4 and 5, are best examined in relation to the student behaviors which are presented in figure 10.

The reaction categories for instructor B yielded interesting results. Instructor B reacted to his female students' responses or presented information in a manner which maintained the level of participation $50 \%$ more often than he reacted in such a manner to his male students. He terminated the level of participation of his female students nearly twice as often as he terminated the participation of his male students. However, 
reactions which extended the level of participation of males occurred twice as often as did those which extended the level of participation of females. Instructor reactions are best discussed in relation to student presented information and student responses, both of these behaviors are discussed in the student behaviors section below.

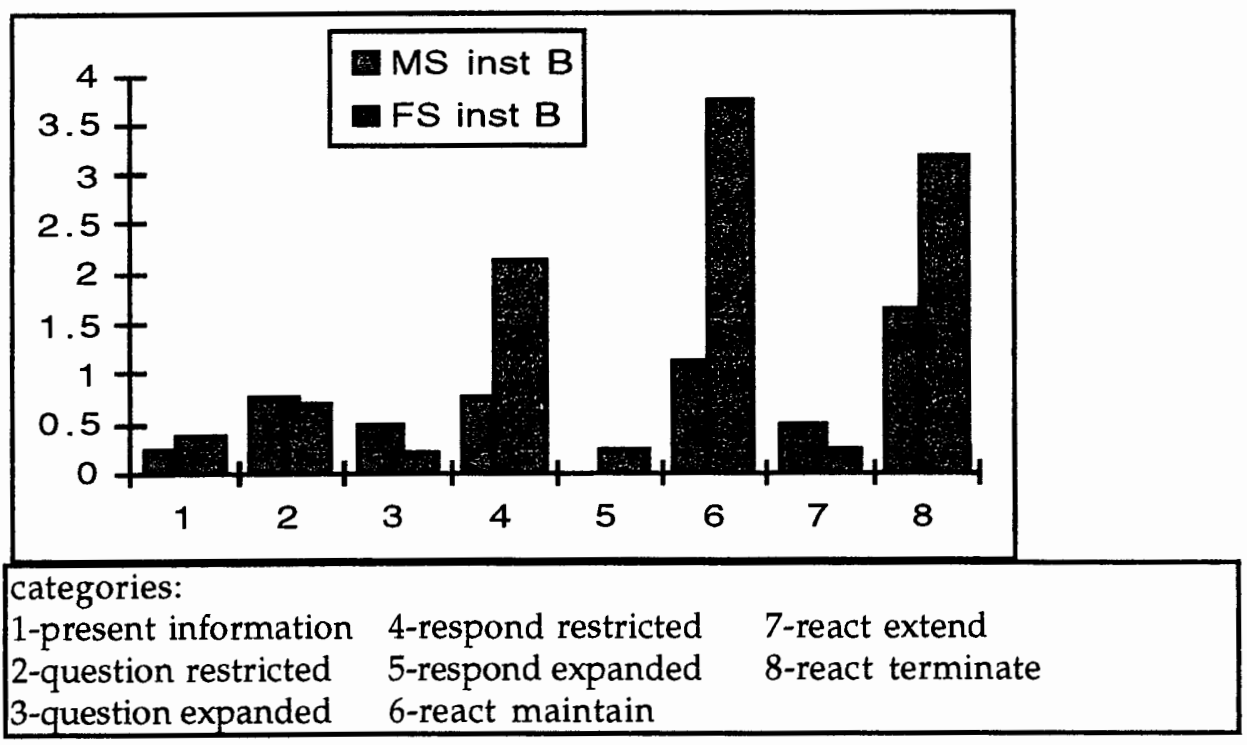

Figure 9. Averaged ETC instructor behaviors per student, instructor B

Student behaviors instructor B. The female students asked nearly all the questions in instructor B's classes and therefore received nearly all the responses. Only females asked expanded thinking questions asked in instructor B's classes and consequently only females received expanded thinking responses from the instructor. The male students were asked more expanded thinking questions per observation than were females, but this alone doesn't account for the relatively high number of expanded 
thinking responses per male student in instructor B's classes. As discussed earlier, instructor $B$ reacted in a manner which extended the level of participation of male students more frequently than he did so to female students. This might explain why the male students in instructor B's classes responded with expanded thinking responses more often than the females. The male students' responses in instructor B's classes were followed by reactions which extended their level of participation and required further expanded thinking responses more often than the female students' responses. Though these findings are notable, they were not found to be statistically significant.

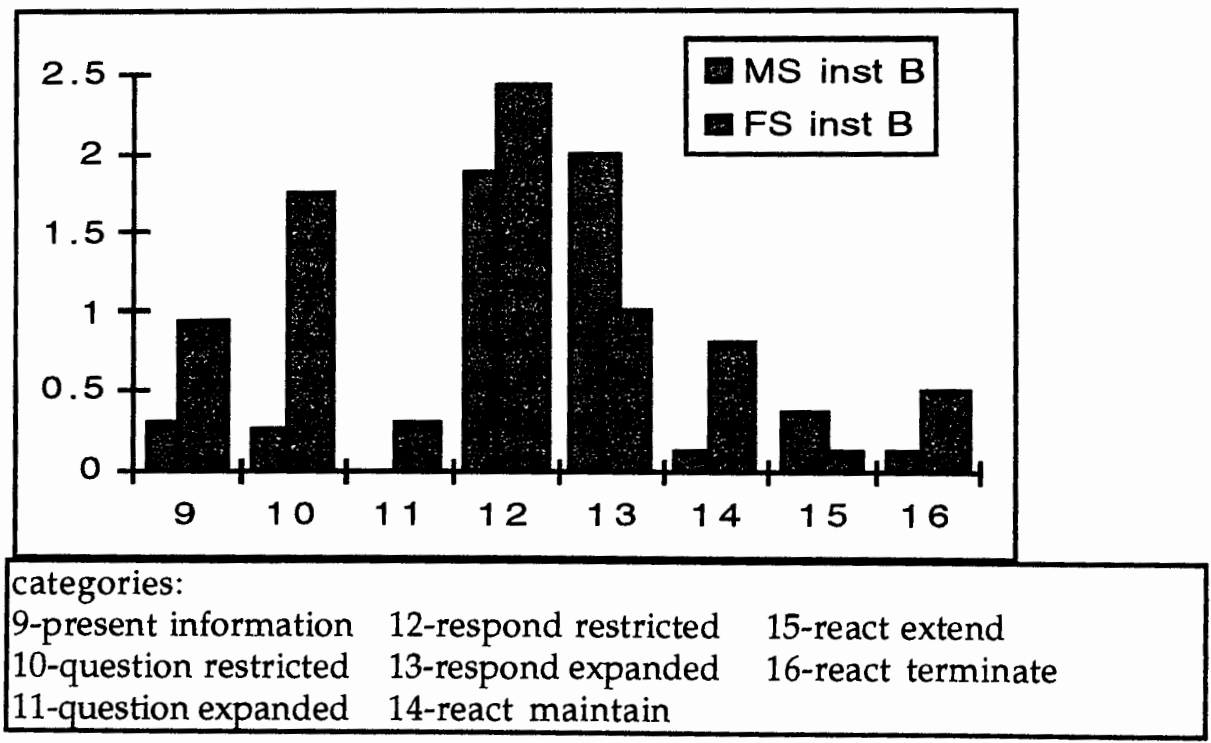

Figure 10. Averaged ETC student behaviors per student, instructor B.

Instructor behaviors instructor $C$. The average number of direct questions per student in instructor C's classes was fairly small, most of 
instructor C's questions were directed at the class in general rather than at individual students. When she did direct questions at individuals, instructor $C$ asked more restricted thinking questions to her male students, .43 per student, than she did to her female students who were asked .19 per student. Instructor $C$ asked about the same number of expanded thinking questions to both males and females (see figure 11).

The reaction categories indicate that instructor $C$ reacted to male students in each of the three reaction categories more frequently than she reacted to female students. As can be seen in the chart of the student behaviors in instructor C's classes (figure 12), male students both presented more information and responded more frequently to instructor questions than female students which accounts for the relatively high frequency of reactions to male students.

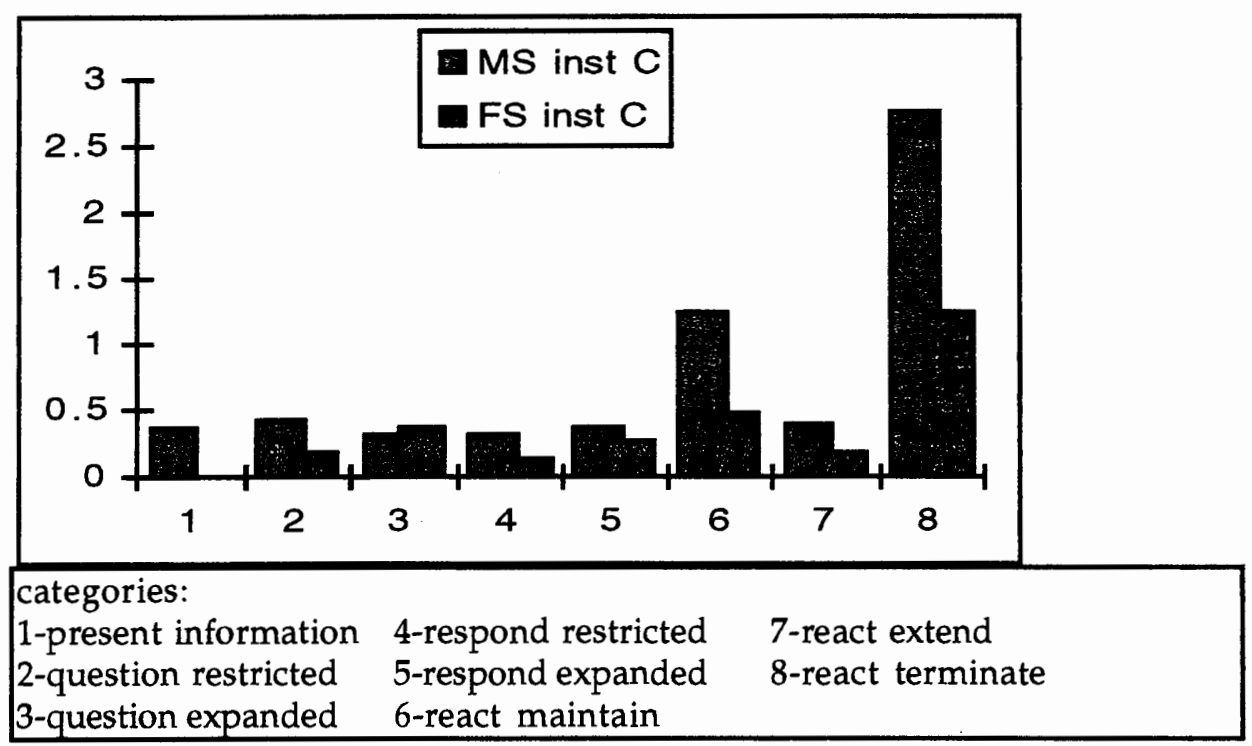

Figure 11. Averaged ETC instructor behaviors per student, instructor $\mathrm{C}$. 
Student behaviors instructor $C$. The student behaviors in instructor $C^{\prime}$ ' classes are interesting given that the male students were found to interact more frequently with their instructor than the female students. The male students asked over twice as many restricted thinking questions and presented information to the instructor over four times as often as females but the number of expanded thinking questions asked is remarkably similar. Just as was found in every class, the student response categories (categories 12 and 13) were by far the most often used type of interaction. In instructor C's classes, the male students responded to restricted thinking questions nearly five times as often as females did. Males also answered more expanded thinking questions, but only about $25 \%$ more than females.

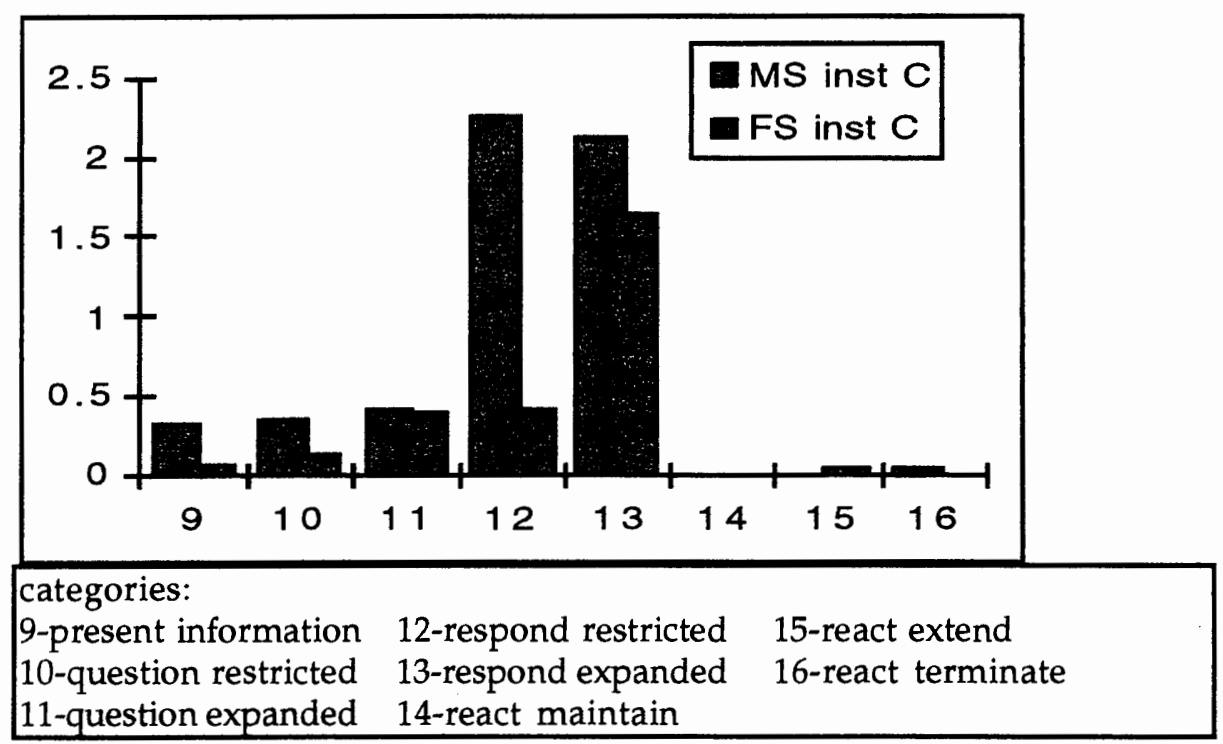

Figure 12. Averaged ETC student behaviors per student, instructor $\mathrm{C}$. 
Instructor behaviors instructor D. An analysis of the ETC inventory of instructor behaviors for instructor $\mathrm{D}$ indicates that he too asked very few direct questions of any kind to male or female students (see figure 13 below). The response categories (categories 3 and 4) show that instructor $D$ responded with restricted thinking responses to male student questions or reactions over ten times as often as he did to female student questions or reactions. Surprisingly, the number of expanded thinking responses directed at females outnumbers those directed at males by about $79 \%$. Again, these behaviors have their root in the student behaviors which are outlined in figure 14.

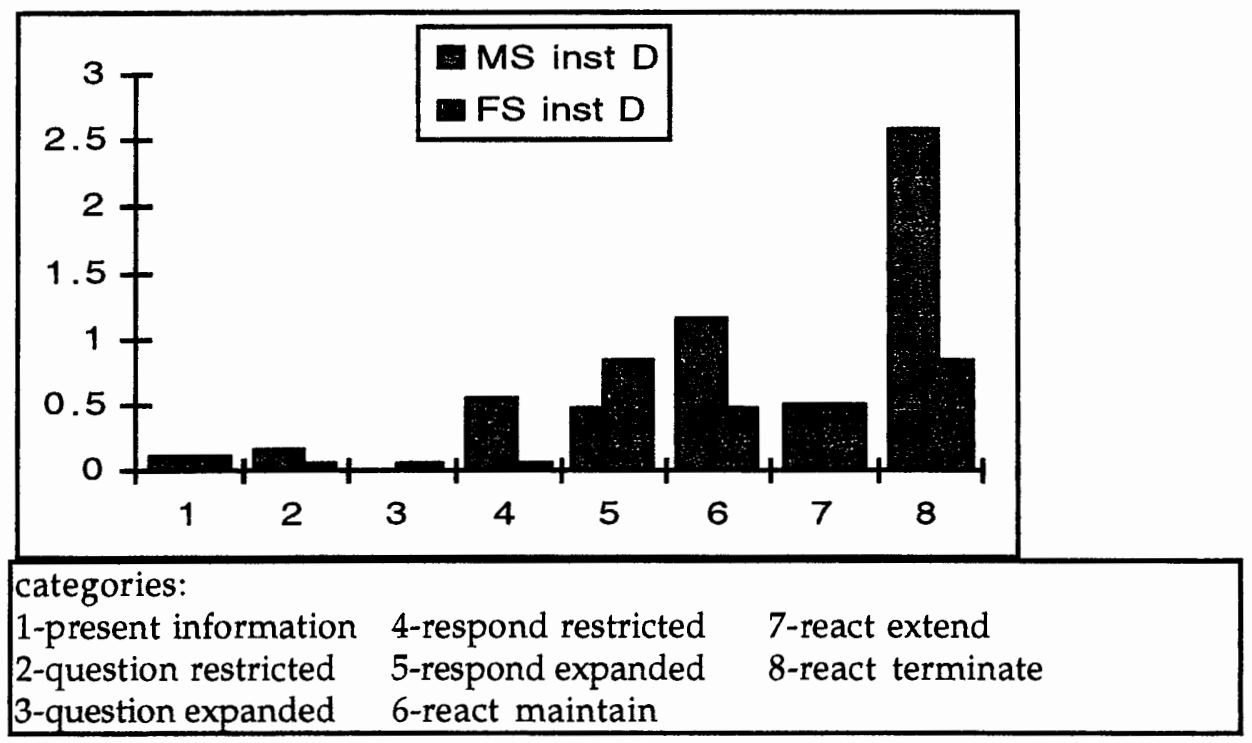

Figure 13. Averaged ETC instructor behaviors per student, instructor D.

Instructor $\mathrm{D}$ reacted to male and female student responses or presented information in a manner which extended the level of 
participation equally. He maintained and terminated the level of participation much more frequently than he did females. Again, the difference in male and female student behaviors is responsible for this difference (see figure 14 below).

Student behaviors instructor D. Male students asked about ten times more restricted thinking questions than female students did, but only slightly more expanded thinking questions than females (see figure 14). This accounts for the high frequency of restricted thinking responses directed at males in instructor D's classes. The relative high frequency of expanded thinking responses directed at females probably stems from a combination of answers to expanded thinking questions and responses to reactions by female students. Male students responded to restricted thinking questions at about the same frequency as female students but responded to expanded thinking questions over twice as often as female students. The disparity in the number of questions responded to between male and females is reflected in the disparity between instructor D's reactions. He was found to react more frequently to his male students than he did to his female students. 


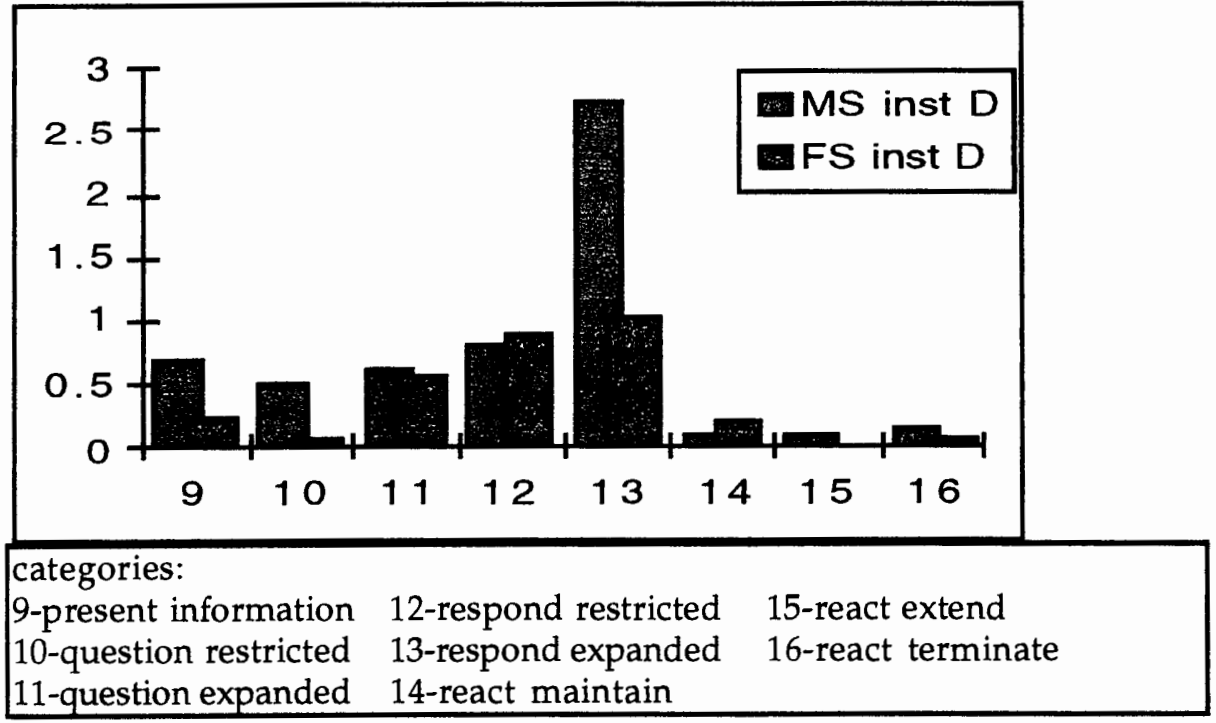

Figure 14. Averaged ETC student behaviors per student, instructor D.

\section{Questions Directed at the Class}

The above data show that there are few direct questions asked per student on average. This is because each of these instructors asked many more questions directed at the class in general than they do of individual students. Instructor A asked slightly more restricted thinking type questions to her class in general than she did expanded thinking type questions. Per observation, instructor A asked an average of 13 restricted thinking questions directed at the class in general and an average of 9.75 expanded thinking questions which were directed at the class (see figure 15 below). Instructor B asked fewer questions to the class than did any of the other instructors, asking only 6.5 restricted thinking questions to the class per observation and 2.5 expanded thinking questions to the class per fifty 
minute observation. Instructor $C$ asked an average of 5.25 restricted thinking questions to her class per fifty minute time segment, and 10.25 expanded thinking questions to her class per fifty minute time segment. Instructor D asked an average of 7.75 restricted thinking and 12.75 expanded thinking questions to his class per fifty minute time segment. Both instructors $\mathrm{C}$ and instructor $\mathrm{D}$ asked more expanded thinking questions to their classes than did instructors A or B. This may be a result of the content of instructors A and B's classes. Because their classes were designed to work with an American history class, factual questions which required simple recall of the history texts students had read occurred frequently.

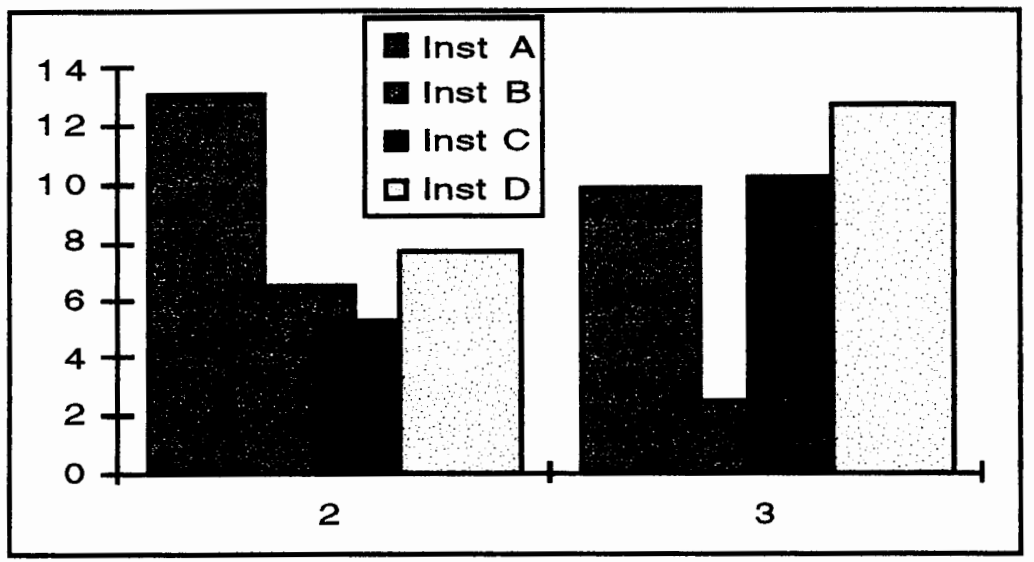

Figure 15. Average number of restricted thinking and expanded thinking questions directed at class in general, all instructors. $2=$ restricted thinking $\quad 3=$ expanded thinking

Research question 3. Does the gender of the ESL instructor influence the frequency of interactions or the content of interactions with male and female students? 
Research question 3 is really two separate questions. It asks whether instructor gender a) affects the frequency of interactions between instructors and their male and female students, and b) affects the content of interactions between instructors and their male and female students. The analysis and discussion of this question will be carried out in two separate sections, one regarding the relationship between instructor gender and interaction frequency and one regarding the relationship between instructor gender and interaction content.

Instructor gender and interaction frequency. A multivariate ANOVA test was used to determine whether a relationship between instructor gender and interaction frequency existed. The averaged interaction frequency for male and female students per observation obtained with the seating chart instrument served as the dependent variable and instructor gender and student gender as independent variables. This test was designed to determine any difference between interaction frequency due to instructor gender or any statistical interaction between male and female student interaction frequency and instructor gender.

The results of the ANOVA test of the seating chart data revealed that there was a significant difference between the overall frequency of interactions in the male versus the female instructors' classes 
$(\mathrm{f}(1,84)=4.417, \mathrm{p}=.0385)$. A Tukey's test showed that the female instructors interacted significantly more with their students overall, but that this was mainly due to instructor A, who interacted with her students significantly more than instructor B $(p=.043)$ or instructor D $(p=.044)$. The other female instructor, instructor $\mathrm{C}$, did interact more frequently with her students than the male instructors, but this difference was not statistically significant. There was no significant statistical interaction between instructor gender, student gender and interaction frequency $(f(1,84)=.3054$, $\mathrm{p}=.581)$

Instructor gender and interaction content. As was discussed earlier, no evidence of a difference in interactional content based on student gender was found. Nonetheless, a multi-factorial ANOVA test was implemented using the averaged instructor behaviors from the ETC inventory as the dependent variable while the instructor gender and category were the independent variables. No statistically significant interaction between instructor gender and category type was found $(f(7,224)$ $=1.566, \mathrm{p}=.146$ ). As was found with the seating chart data, the ANOVA test done on the ETC instructor behavior data showed that overall female instructors interacted with their students significantly more frequently than male instructors $(\mathrm{f}(1,224)=10.27, \mathrm{p}=.0015)$. Again, this was mainly due to instructor A who interacted with her students more than any other 
instructor and significantly more than the male instructors, instructor B and instructor D.

\section{CONCLUSION}

The data analyzed in this research yielded several interesting results. Though no difference in interaction content based on student gender was found to exist, the notion of gender based differential treatment seems to be supported by the interaction frequency data. However, a closer look at a second student variable revealed that student gender may play a lesser role in interaction frequency than student ethnicity. Males were found to interact with their instructors more frequently in two of the four classes observed. In both of those classes, Middle Eastern and African males dominated classroom interactions, participating significantly more than Asian females, Asian males or Russian females. If the disproportionate number of interactions with male students in instructor $C$ and instructor D's classes stemmed from gender alone, frequent interactions would be expected of all males. Because Asian males interacted significantly less frequently than males of any other ethnicity, something other than student gender is clearly affecting interaction frequency. 


\section{CHAPTER V}

\section{SUMMARY, DISCUSSION, AND CONCLUSION}

\section{SUMMARY}

\section{$\underline{\text { Research Questions }}$}

The intent of this research was to determine whether student gender played a role in the overall interaction frequency or interaction content in ESL classrooms. It further sought to determine whether student ethnicity was a factor in the frequency of teacher/student interactions. The influence of instructor gender on interaction frequency and interaction content was also examined. Finally, instructor interviews designed to reveal instructors' self perceptions about their teaching behaviors allowed comparisons between how instructors believe they behave and their actual classroom behavior.

\section{$\underline{\text { Results }}$}

The research yielded several interesting results. In the following section, each of the research questions and the findings related to them will be presented. Further discussion of these findings and possible 
explanations for them will be proposed in the discussion section that follows.

Research question 1. Does student gender influence the frequency with which ESL instructors interact with individual students?

The answer to research question one seems to be yes. The seating chart frequency data showed that in three of the four groups observed, student gender played a significant role in the frequency of teacher/student interactions. In two cases, the instructors interacted significantly more with their male students than they did with their female students. In one case, the instructor interacted more frequently with her female students than she did with her male students.

Research question 1a. If so, are instructors aware of this influence or is it occurring out of their level of awareness?

The information put forth during the informal interview leads one to conclude that the influence of student gender on interaction frequency which was found in the three instructors' classrooms was occurring outside of their awareness. All instructors stated that they take steps to discourage students who dominate discussions from doing so. Two of the three instructors claimed that they also encourage more reticent students to speak up more in class using a variety of methods. From the interviews, it can be assumed that if these instructors were aware of the unequal 
distribution of teacher/student interactions occurring in their classrooms, they would have taken steps to correct that imbalance.

Research question 2. Does the content of teacher/student interactions in ESL classrooms vary according to student gender?

The answer to this question is no. An analysis of the ETC inventory of instructor behaviors produced no evidence that instructors vary their behaviors with male and female students according to interaction type. That is to say, an analysis of all instructors and observation revealed that interaction category did not play a role in the frequency with which instructors interacted with their male and female students.

Research question 2a. Do ESL instructors ask more questions which require restricted thinking responses to members of one gender while asking questions that require expanded thinking responses to the other?

Because no overall difference in interaction frequency depending on student gender and category type was found in the analysis for question two, the answer to this question must be no. No significant difference between male and student behavior was related to the category of interaction.

Research question $2 \mathrm{~b}$. Do ESL instructors react in a manner that maintains or terminates the current level of student participation more often to students of one gender while reacting in a manner that extends the level of participation to students of the other gender? 
Again, the answer to this question is no. No significant statistical interaction between student gender and interaction category was found.

Research question 3. Does the gender of the ESL instructor influence the frequency of interactions or the content of interactions with male and female students?

The answer to research question three seems to be no. Though the female instructors interacted with their students more frequently overall, no statistically significant interaction between instructor gender and the frequency or content of interactions with male or female students was detected.

Research question 4. Does the ethnicity of an individual or group of students influence the frequency with which ESL instructors interact with those students?

This question is difficult to answer conclusively. Only two of the four instructors observed had ethnically diverse classes. In those two classes, the Middle Eastern and African males were found to interact with their instructor significantly more than any other student group. Because of the relatively small sample size, it is difficult to draw any conclusions from these results.

Research question $4 \mathrm{a}$. If so, are the instructors aware of this influence or is it occurring out of their level of awareness? 
Again, the informal interview revealed that instructors generally try to keep the interactions in the classroom fairly equal using a variety of techniques. Both of the instructors who had ethnically diverse classes seemed to be aware that Middle Eastern students were generally more outspoken than Asian students. Both said that they stabilized that difference in verbosity by making their classroom expectations very explicit. Both believed that this action was effective in reducing the interaction frequency gap between students of differing ethnicities.

\section{DISCUSSION}

\section{Frequency Data}

An analysis of the seating chart data revealed that three of the four instructors observed interacted with students of one gender more often than students of the other gender. Instructor A was found to interact with her female students more than with her male students, while with instructors $C$ and $D$ the reverse was true. There are several plausible explanations for these results which lay outside the gender bias argument. Student ethnicity, individual student differences, classroom management techniques, differing class sizes and course content certainly all contributed to the findings of this research.

Student ethnicity. The ethnicity data collected in instructors $C$ and D's classes shed a great deal of light on the interaction frequency findings. 
In both classes with ethnically diverse groups, both male and female Asian students interacted with their instructor at about the same rate, significantly less than Middle Eastern or African students. This indicates that ethnic diversity adds another component to the complexity of interaction behaviors in ESL classrooms. Asian students are clearly overshadowed by students who were educated in a tradition which values frequent voluntary participation.

Within homogenous student groups, like the Asian groups of instructors $A$ and $B$, the frequency of interactions between instructors and their female students outnumbers those between instructors and their male students, significantly so in the case of instructor A. There are a myriad of possible explanations for this finding, some of which are discussed in the following sections.

Individual student differences. The results of the frequency data in instructor A's classes may in part be a result of one or two relatively outspoken individuals. Unfortunately, the students were not identified and tracked from observation to observation so this could not be empirically determined. However, during the observations it became clear that one or two female students were responsible for many more teacher/student interactions than the other female students. Tracking of individual student behaviors would allow alternative analyses to 
determine whether student gender influenced the frequency of teacher student interactions despite widely varying individual differences.

The results of the ethnicity data from instructor D's classes showed that the African student in that class participated more in teacher/student interactions than any other student. Though this student is easily tracked because he is the only African student in these classes, a reliable analysis of individual differences would have to include total frequency counts of the teacher/student interactions for each student.

Classroom management. The way in which instructors initiated interactions with their students undoubtedly played a role in which students interacted the most frequently. All instructors asked more general questions than direct questions, a teaching style which seems to be quite common in the American higher education system. The use of frequent questions directed at the class in general allowed the students who participated frequently to do so unchecked while allowing the students who did not participate frequently to hang back and refrain from taking part in class discussions.

Instructors $\mathrm{A}, \mathrm{C}$ and $\mathrm{D}$ made frequent use of cooperative learning activities in which students were required to interact with each other in small groups rather than with the instructor. The interactions between students in the small group activities were not recorded. Though it fell beyond the scope of this research, whether students participate differently 
in small groups based on their gender would be an interesting study to undertake and deserves more research.

Class size. Instructor A was found to interact more frequently with her students overall than any other instructor. The small size of instructor A's academic reading class undoubtedly played a role in the frequency of overall interactions that occurred. The fewer students in a class, the more individual attention an instructor can give per student. It may also be that because instructor A's academic reading class had so few students the students felt more comfortable speaking out than they would in a larger group. This may be one of the reasons for the disparity between the overall number of teacher/student interactions in instructor A's classes and those in the other three instructors' classes.

Subject. Both instructor A and instructor B's classes were designed to complement a mainstream university American History course. The instructors' main task was to ensure that the students in their classes understood the history text and were prepared for the history class. The material seemed very difficult for many of the students. This may have played a role in the interaction frequencies observed in these classes. The students who understood the text better may have felt more comfortable in speaking out in class, while those students who were struggling with the material may have been reticent to speak. 


\section{Content Data}

The results of the Equivalent Talk Categories Inventory were analyzed to answer the questions concerning interaction content. No evidence that the content of interactions varied according to student gender was found. Instructors seem to interact with their male and female students in much the same way, though they may do so more frequently with one group than they do with another. An analysis of the relationship between student ethnicity and interaction content could not be performed because the ETC inventory was administered to transcribed audio recordings from which student ethnicity could not be determined.

\section{Instructor Interviews}

The instructor interviews were intended to unveil what Luft (as cited in Richards, 1990) terms "the open self", that is the information about a teacher's behavior that is known to the teacher, that he or she is able to see, understand and rationalize. Through comparing what instructors think they do in their classrooms with what they actually do, the subtlety of interaction inequity is exposed. It is clear that instructors want to participate equally with all of their students. Indeed, the instructors in this study believe that they do generally involve all of their students fairly equally. All instructors claimed in the informal interviews that when they perceive a large imbalance in the interactions occurring in their 
classrooms, they use a variety of techniques to overcome that imbalance. This indicates that whatever interaction imbalance that is occurring in these instructors' classrooms is occurring outside their level of awareness.

\section{CONCLUSION}

\section{Limitations of the Study}

Any study which relies on data collected through classroom observations is somewhat problematic. The classroom environment is too complex, there are too many variables to quantify and analyze in order to draw any firm conclusions. In the discussion section of this chapter, many of the classroom variables which were not considered in this study were mentioned in relation to the results yielded by this research. The following section outlines the methodological limitations of this study.

Individuals versus groups. It became apparent on about the third day of classroom observations that individual student differences were a substantial factor in the number of interactions which occurred between instructors and students. These student differences went beyond the categorizations of gender or ethnicity. Some individuals just participated in classroom interactions more than others. These students swayed the results because if the outspoken student happened to be male then the results might show that male students interacted more frequently with their instructor than female students. The design of this study did not 
account for individual student differences in teacher/student interactions. The students were not tracked from class to class so the results of the data could not be traced back to the individual students who participated in each interaction. It is this researcher's opinion that the lack of accountability for individual student behaviors tremendously hurt the reliability of the findings.

Differences between observed groups. Though it would be difficult to find four separate classes which did not have substantial differences between them, the differences between the groups observed for this study caused considerable problems. The main problem was that two of the instructors, instructor A and instructor B, had ethnically homogeneous groups. This substantially decreased the size of the data set used for the ethnicity analysis and weakened the results.

Another difference between groups which was problematic to the study was the difference in class length. Instructor C and instructor D's classes were one hundred minutes long while instructors A and B's classes were fifty minutes in length. In order to run a statistical analysis, the data had to be manipulated into equal time units. Though this was not thought to affect the outcome of the analysis, it was a less than ideal way of compiling data.

Lastly, data were collected in two different courses taught by instructor A, while observations of the other instructors' classes occurred 
in the same course every time. This made the data from instructor A's classes less reliable than the data from the other classes because it is possible that her behavior toward one group of students might be different than that toward another group. Also, the two courses observed differed in class size. One class was considerably smaller than the other, indeed, smaller than all the other classes observed. As discussed earlier, this probably lent to the fact that instructor A was found to interact with her students more frequently than any other instructor.

\section{Too many categories. The Equivalent Talk Categories Classroom} Interaction Inventory was not originally designed to distinguish between interactions with or originating from male and female students. The original ETC has ten categories which for the purposes of this study were modified to eight. The remaining eight categories were then modified even further to indicate whether, in the case of the instructor, the interaction occurred with a male or a female student or was directed at the class and, in the case of the student, whether the interaction originated from a male or a female student. This made a total of 19 categories for instructors and 16 categories for students. While some of these categories, the react categories for instructors and the respond categories for students, contained many interactions, some did not contain many at all. The relative scarcity of frequencies in each category made reliable comparisons difficult. 
No measure of ethnicity effect on interaction content. Because it was found that gender differences in teacher/student interactions in the ESL classroom are inextricably tied to differences in interaction rate between ethnic groups, it would have been very worthwhile to analyze the content data with regard to student ethnicity. This could not be accomplished because the ETC Inventory of Classroom Behaviors was applied to the data from audio transcription and student ethnicity could not be accurately determined.

\section{Suggestions for Future Research}

This type of study might yield more concrete results if some of the many variables which were encountered in this research were controlled more closely. Future research of this type would benefit by using classes of equal size and identical topic. This would allow for easier comparisons between classes and reduce the ambiguity of the results. Also, classes of similar ethnic composition would facilitate comparisons between interaction frequency among different ethnic groups.

Using video tape to record classroom observations would go a long way toward revealing many of the causes of results such as those found in this study. A video recording would allow tracking of individual students, provide access to the non-verbal behaviors of instructors and students as 
well as account for other outside influences on the frequency of interactions in the classroom.

The instructor interviews in this study did not directly cover gender differences in teacher/student interactions. Though the researcher attempted to introduce the topic during the interviews, inquiries about gender equity seemed to make the instructors uneasy and threatened to jeopardize the relaxed atmosphere the researcher tried to create. The instructor awareness data would undoubtedly be stronger had the topic of gender equity been directly addressed. Future researchers would benefit greatly from a more structured interview protocol which directly addresses gender equity. Because of the prospective discomfort which might result from a more structured interview addressing gender equity in the classroom, it is recommended that a second researcher act as interviewer. This would allow instructors to answer more freely than they might to someone who had actually observed their teaching. It would also allow the primary researcher to maintain an acceptable social relationship with the instructors.

Implications for TESOL

This study revealed that interactions in the language classroom do not occur equally among students. In both of the classes with ethnically diverse student groups, Asian students interacted with the instructor 
significantly less frequently than students of any other ethnicity. In classes which contained all Asian students, female students interacted with the instructor more frequently than male students, though this difference was only significant in one case. Because interaction is a crucial component of successful language learning, an imbalance in the distribution of teacher/student interactions may have serious implications. Students who do not interact frequently with the instructor are denied verbal practice opportunities which involve comprehensible input, an important element in successful language learning. Students who practice frequently with their instructors are exposed to more comprehensible input, more verbal corrections and more attended exposure to the English language.

Diminished access to comprehensible input is not the only problem which the findings of this study imply. The results of this study indicate that students whose first culture is one in which the classroom practices and educational expectations are similar to those in America interact more frequently with their instructor than those students whose cultural expectations about appropriate classroom behavior differ from the American view. The Asian and Russian students were found to interact with their instructors significantly less frequently than the Middle Eastern or African students. All of the Middle Eastern and African students were male. These facts may indicate to the Asian, Russian and female students in the classes observed that their participation in the course is not as 
important as that of their Middle Eastern and African male colleagues. It may also contradict the call for frequent participation that the instructors of the ethnically diverse classes claimed they often emphasize to their students. If these students are consistently interacting with their instructors less frequently than others, this may suggest to them that though frequent participation is expected at American universities, they are the exception to the rule. This could result in reduced success in mainstream university academic courses.

University ESL instructors must not only inform their students of the classroom behaviors that are expected of them in the American educational system but insist that they adhere to those behaviors in their English classes. This would allow students to not only realize cognitively that they are studying under a system with a much different set of expectations but to practice working within that system in a comfortable and controlled ESL environment.

Whether differences in interaction frequency occur in the classroom as a result of student gender, ethnicity, personality type or any other reason, the fact that they do occur is a problem. Though instructors seem to believe that they do what they can to insure equality among students, their actual classroom behavior contradicts this belief. Because all the instructors interviewed seem to want to interact equally among all their students, it is likely that awareness of their actual classroom behaviors 
would do much to rectify the problem. Perhaps observations such as the ones carried out for this study would help to bring the inequality that seems to exist in ESL classrooms into the awareness of individual instructors. Peer observations in teacher training programs during which interaction frequency is tallied on a seating chart would help to focus new language instructors' attention on the difficulty of keeping the interactions distributed equally among all students in language classrooms. 
Acheson, K. and Gall, M. (1987). Techniques in the clinical supervision of teachers. New York, NY: Longman.

Brophy, J. (1985). Interactions of male and female students with male and female teachers. In L. C. Wilkenson, \& C. B. Marrett (Eds.), Gender influences in classroom interaction (pp. 115-141). Orlando, FL: Academic Press Inc.

Brophy, J. and Good, T.L. (1991). Looking in classrooms. New York, NY: HarperCollins Publishers.

Cooper, H. (1977). Controlling personal rewards: Professional teachers differential use of feedback and the effects of feedback on the student's motivation to perform. Journal of Education Psychology, 69 (4), 419-427.

Cooper, P. J. (1987). In or out of the pumpkin shell? Sex role differentiation in classroom interaction. Paper presented at the Annual Meeting of the Speech Communication Association, Boston, MA. (ERIC Document Reproduction Number ED 291 125).

Davis, T. (ed). (1995). Open doors report on international education exchange. New York, NY: Institute of International Education.

De Bie, M. L.W. (1987). Classroom interaction: Survival of the fittest? In D. Brouwer, \& D. De Haan (Eds.) Women's language, socialization and self-Image. (pp. 76-89). Dordrecht, The Netherlands: Foris Publications.

Ellis, R. (1992). Second language acquisition and language pedagogy. Philadelphia, PA: Multilingual Matters Ltd.

Dweck, C. and Reppucci, D. (1973). Learned helplessness and reinforcement responsibility in children. Iournal of Personality and Social Psychology, 25 (1), 109-116.

Furey, P. (1986). A framework for cross-cultural analysis of teaching methods, In P. Byrd (Ed.) Teaching across cultures in the university ESL program. (pp. 15-28). Washington, DC: National Association for Foreign Student Affairs. 
Good T. L and Brophy, J. (1974). Teacher-student relationships:

Causes and consequences. New York, NY: Holt, Rinehart and Winston.

Good, T., Sikes, J., \& Brophy, J. (1973). Effects of teacher sex and student sex on classroom interaction. Lournal of Educational Psychology, $\underline{65,74-87 .}$

Good, T., \& Brophy, J. (1980). Educational psychology: A realistic approach. New York, NY: Holt.

Hatch, E. (1992). Discourse and language education. New York, NY: Cambridge Language Teaching Library.

Hall, B. and Sandler, R. (1982). The classroom climate: A chilly one for women? (ERIC Document Reproduction No. ED 215 628).

Kelly, A. (1988). Gender differences in teacher-pupil interactions: a meta-analytic review, Research In Education, 39, 1-23.

Kramerae, C. and Treichler, P. (1988). Power relationships in the classroom. In S. Gabriel, \& and I. Smithson (Eds.) Gender in the classroom: Power and pedagogy. (pp. 41-59). Chicago, IL: University of Illinois Press.

Krashen, S. D. (1982). Principles and practice in second language acquisition. Oxford, England: Pergamon Institute of English.

Krashen, S. D. (1985). The input hypothesis: Issues and implications. Essex, England: Longman Group Limited.

Kumaravadivelu, B. (1990). Ethnic variation in classroom interaction: Myth or reality. RELC Journal, 21, (2), 45-54.

Larsen-Freeman, D. and Long, M. H. (1991). An introduction to second language acquisition research. New York, NY: Longman Inc.

Long, M. H. (1981). Input, interaction and second language acquisition. In $\mathrm{H}$. Winitz (Ed.). Native language and foreign language acquisition. New York, NY: Annals of the New York Academy of Sciences.

Long, M. H. (1983). Inside the "black box": Methodological issues in classroom research on language learning. In M.H Long, \& H. Seliger (Eds.) Classroom oriented research in second language acquisition. (pp. 3-39). Rowley, MA: Newbury House. 
Long, M. H. (1988). Instructed interlanguage development. In L. Beebe (Ed.) Issues in second language acquisition. (pp. 113-140). New York, NY: Newbury House Publishers.

Maurice, K. (1986). Cultural styles of thinking and speaking in the classroom. In P. Byrd (Ed.) Teaching across cultures in the university ESL program. (pp. 39-50). Washington, DC: National Association for Foreign Student Affairs.

Miller, J. L. (1993). Constructions of curriculum and gender. In S. K. Biklen, \& D. Pollard (Eds.) Gender and education. (pp. 43-61). Chicago, IL: The National Society For The Study of Education.

Mid-Atlantic Equity Consortium (1993). An annotated summary of the regulation for title IX education amendments of 1972. (ERIC Document Reproduction Number ED 387 368).

Mid-Atlantic Equity Consortium (1993). Beyond title IX: Gender equity issues in schools. (ERIC Document Reproduction Number ED 387 367).

Ober, R., Bentley, E. and Miller, E. (1971). Systematic observation of teaching an interaction analysis-instructional strategy approach. Englewood Cliffs, NJ: Prentice-Hall.

Pica, T. (1990). Language learning through interaction: What role does gender play? Penn Working Papers in Educational Linguistics, 6, (1), 53-83. (ERIC Document Reproduction No. ED 335 932).

Richards, J. (1990). The language teaching matrix. New York, NY: Cambridge University Press.

Richards, J., Lockhart, C. (1994). Reflective teaching in second language classrooms. New York, NY: Cambridge University Press.

Rosenthal, R. and Jacobson, L. (1968). Pygmalion in the classroom: Teacher expectation and pupils' intellectual development. New York, NY: Holt, Rinehart and Winston.

Rosser, S. (1989). Creating an environment that is conducive to Learning for the Majority. Lournal of the Freshman Year Experience, 1, (1), $53-63$. 
Sadker, M. and Sadker, D. (1985). Sexism in the classroom. Vocational Education Journal, 60 (7).

Sadker, M. and Sadker, D. (1994). Failing at fairness; How America's schools cheat girls. New York, NY: C. Scribner's \& Sons.

Sadker, D. (1995, October). Failing at fairness. Lecture at Lewis \& Clark College, Portland, OR.

Santos, S. L. and Suleiman, M. F. (1993). Teaching english to arabicspeaking students: Cultural and linguistic considerations. In L. M. Malave, (Ed.) Annual Conference Journal. (ERIC Document Identification No. ED 360876 )

Sato, C. J. (1982). Ethnic styles in classroom discourse. Paper presented at the Annual conference of Teachers of English to Speakers of Other Languages. (ERIC Document Reproduction Number ED 223 081).

Seliger, H. (1983). Learner interaction in the classroom and its effect on language acquisition. In H. Seliger, \& M. Long (Eds.) Classroom observation and research. (pp. 246-267). Rowley, MA: Newbury House.

Sexton, P. (1976). Women in education. Bloomington, IN: The Phi Delta Kappa Educational Foundation.

Smith, D. J. (1983). An exploration of the self-fulfilling prophecy--A concept of hidden communication--As applied to traditional educational settings. Dissertation, New York University, NY.

Spender, D. (1982). Invisible women: The schooling scandal. London: Writers and Readers Publishing Co-operative Society with Chameleon Editorial Group.

Stanley, J. (1986). Sex and the quiet schoolgirl. In P. Woods, \& M. Hammersley (Eds.) Gender and ethnicity in schools. London: Routeledge.

Sunderland, J. (1990). The representation of gender in the language classroom. Paper presented at the World Congress of Applied Linguistics. (ERIC Document Reproduction Service No. ED 323 807). 
Swann, Joan. (1989). Talk control: An illustration from the classroom of problems of analyzing male dominance in conversation. In J. Coates, \& D. Cameron (Eds.) Women in Their Speech Communities. (pp.122-140). New York, NY: Longman Inc.

Wong-Fillmore, L. (1985). When does teacher talk work as input? In S. M. Gass, \& C. G. Madden (Eds.) Input in second language acquisition. (pp. 17-50). Rowley, MA: Newbury House.

Yepez, M.E. (1995). An analysis of four ESL teachers' interaction patterns with adult male and female ESL students. (Doctoral dissertation, Cornell University, 1995) Dissertation Abstracts International, 52 (3), 0832. 
APPENDIX A

CONSENT FORMS 


\section{Student Consent Form}

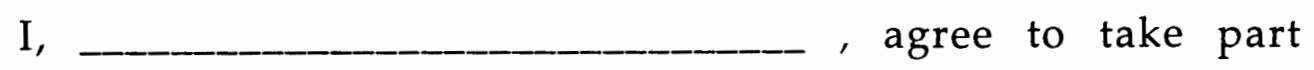
in this research project on teacher/student interactions.

I understand that the study involves the researcher's observation of my English class at least four times during Spring term.

Lisa Mann has told me that the purpose of the study is to learn more about how teachers and students talk to each other in the classroom.

I may not receive any direct benefit from taking part in this study. But the study may help to increase knowledge that may help others in the future.

Lisa Mann has offered to answer any questions I have about the study and what I am expected to do.

She has promised that the names of all people in the study ill be kept confidential.

I understand that I do not have to take part in this study and that this will not hurt my course grade or my relationship with $X$ College.

I have read and understand the above information and agree to take part in this study.

Date:

Signature

If you have concerns or questions about this study, please contact the Chair of the Human Subjects Research Review committee, Research and Sponsored Projects, 105 Neuberger Hall, Portland State University, (503) 725-3417. 


\section{Instructor Consent Form}

I, agree to take part in this research project on teacher/student interactions.

I understand that the study involves Lisa Mann observing and tape recording my class during four class meeting and interviewing me at the end of her observations.

Lisa Mann has told me that the purpose of this study is to learn more about how teachers and students interact in the ESL classroom.

I may not receive any direct benefit from taking part in this study. But the study may help to increase knowledge that may help others in the future.

Lisa Mann has offered to answer any questions I have about the study and what I am expected to do.

She has promised that all information I give will be kept confidential to the extent permitted by law, and that the names of all people will be kept confidential.

I understand that I do not have to take part in this study and that I may withdraw from the study without affecting my relationship with Portland State University.

I have read and understand the above information and agree to take part in this study.

Date

Signature

If you have concerns or questions about this study, please contact the Chair of the Human Subjects Research Review committee, Research and Sponsored Projects, 105 Neuberger Hall, Portland State University, (503) 725-3417. 


\section{APPENDIX B}

\section{SAMPLE SEATING CHART}



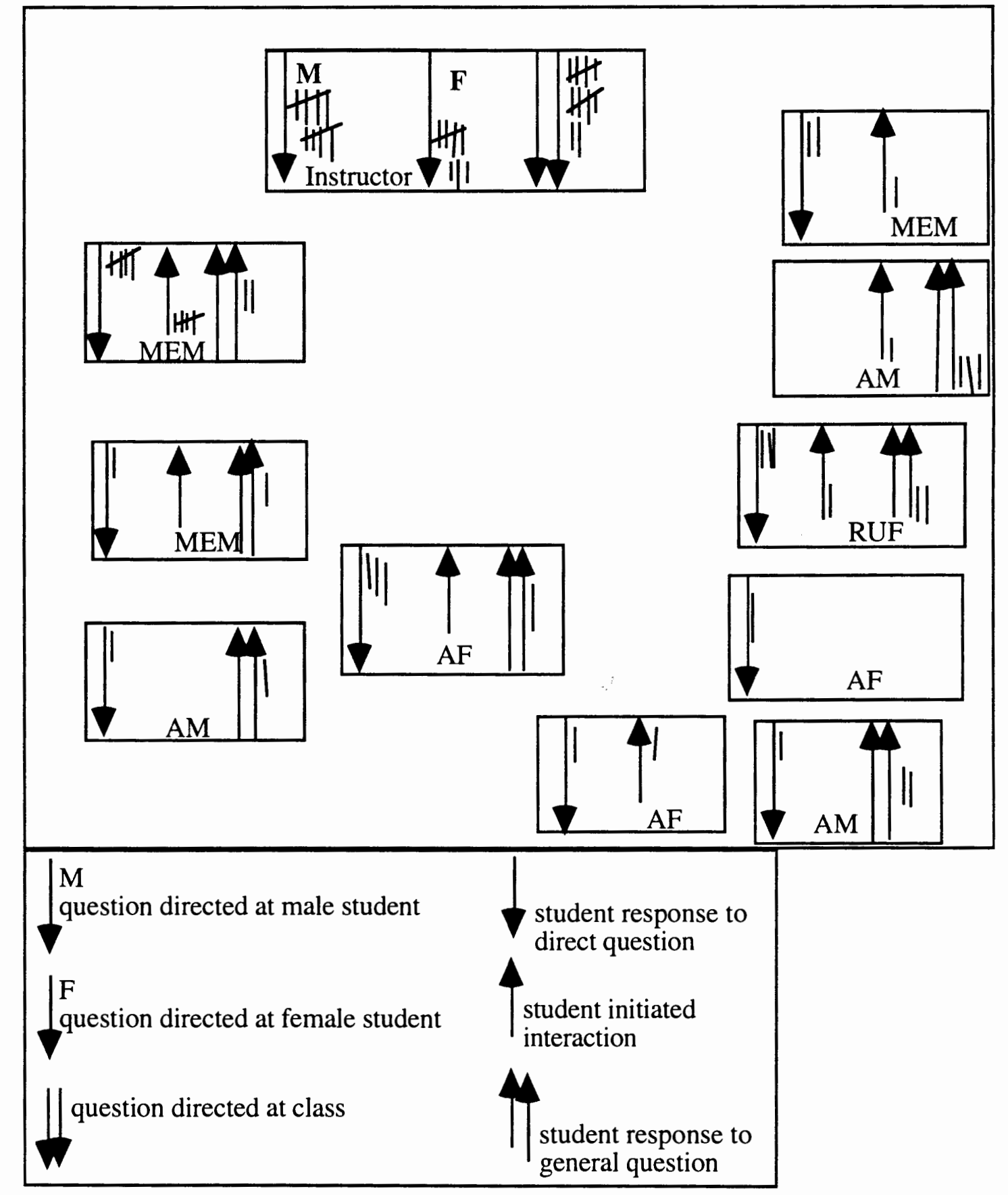

Figure 16. Sample seating chart.

$\mathrm{AM}=$ Asian male MEM=Middle Eastern male $\mathrm{AF}=$ Asian female RUF=Russian female 
APPENDIX C

EQUIVALENT TALK CATEGORIES DEFINITIONS, EXAMPLES, AND CODES 
EQUIVALENT TALK CATEGORIES: DEFINITIONS AND CODES

\begin{tabular}{|c|c|c|}
\hline $\begin{array}{l}\text { Inst. } \\
\text { code }\end{array}$ & category description/examples & $\begin{array}{l}\text { Stud. } \\
\text { code }\end{array}$ \\
\hline $1 \mathrm{C}$ & $\begin{array}{l}\text { present information directed at class: } \\
\text { unsolicited information-lecture; explanation related to } \\
\text { lesson; demonstration; description; impromptu } \\
\text { comments, rhetorical questions } \\
\text { example: } \\
\text { I: "Roosevelt felt it's very important to have an } \\
\text { organization promote peace in the world but also to } \\
\text { have some power in keeping peace in the world so that } \\
\text { if there were some international dispute that occurred } \\
\text { there could be an objective organization..." [1C] }\end{array}$ & \\
\hline \multirow[t]{2}{*}{$1 F$} & $\begin{array}{l}\text { present information directed at female } \\
\text { example: } \\
\text { I: "Selina, you'll have to sit closer to Ryan cause you'll } \\
\text { have to look at this together." [1F] }\end{array}$ & \\
\hline & $\begin{array}{l}\text { present information originates from female: } \\
\text { example: } \\
\text { FS: "umm, } M_{-} \text {I I forgot my... I forgot to take my } \\
\text { homework." [F1] }\end{array}$ & F1 \\
\hline \multirow[t]{2}{*}{ 1M } & $\begin{array}{l}\text { present information directed at male } \\
\text { example: } \\
\text { I: "It's only for people who were here in nineteen } \\
\text { ninety five if they worked or didn't work it doesn't } \\
\text { make any difference they still have to go but you just } \\
\text { came so you don't need to you and Machiko don't need } \\
\text { to." [1M] }\end{array}$ & \\
\hline & $\begin{array}{l}\text { present information originate at male } \\
\text { examples: } \\
\text { MS: "I went to your house yesterday" [M1] } \\
\text { MS: "I was not here last year." [M1] }\end{array}$ & M1 \\
\hline
\end{tabular}




\begin{tabular}{|c|c|c|}
\hline $2 C$ & $\begin{array}{l}\text { question-restricted thinking directed at class: } \\
\text { call for responses that result from restricted thinking- } \\
\text { factual knowledge or simple recall; an accepted or pre- } \\
\text { determined correct answer; facts previously learned or } \\
\text { easy to produce; lower levels of cognition. } \\
\text { examples: } \\
\text { I: "Mein Kamf is the title of what?" [2C] } \\
\text { I: "What, in number two, what exploded under his } \\
\text { feet?" [2C] } \\
\text { I: "at the beginning of the chapter what's he looking } \\
\text { for?" [2C] }\end{array}$ & \\
\hline $2 F$ & $\begin{array}{l}\text { question-restricted thinking directed at female } \\
\text { examples: } \\
\text { I: "What is your topic. Jennifer?" }[2 \mathrm{~F}] \\
\text { I: "oh, third from the bottom, is it propitiate?" [2F] } \\
\text { I: "Mekeiko, what did you write?" [2F] }\end{array}$ & \\
\hline & $\begin{array}{l}\text { question-restricted thinking asked by female } \\
\text { examples: } \\
\text { FS: "We do it here or on backside?" [F2] } \\
\text { FS: "I just write summary, right?" [F2] } \\
\text { FS: "what about jail?" (i.e. how do you spell jail) [F2] }\end{array}$ & $\overline{F 2}$ \\
\hline $2 M$ & $\begin{array}{l}\text { question-restricted thinking directed at male } \\
\text { examples: } \\
\text { I: "OK Ryan, very simple question, how are Hitler and } \\
\text { Mein Kamf related?" [2M] } \\
\text { I: "... and he decided two things. What did he decide? } \\
\text { Sayeed? you remember?" [2M] } \\
\text { I: "Do you know any Japanese?" }\end{array}$ & \\
\hline
\end{tabular}




\begin{tabular}{|c|c|c|}
\hline & $\begin{array}{l}\text { question-restricted thinking, asked by male } \\
\text { examples: } \\
\text { MS: "When are we going to have the exam?" [M2] } \\
\text { MS: "We're going to watch the movie?" [M2] } \\
\text { MS: "Excuse me, we're going to talk about Nancy and } \\
\text { Mike what they look like?" [M2] }\end{array}$ & M2 \\
\hline $3 \mathrm{C}$ & $\begin{array}{l}\text { question-expanded thinking directed at class: } \\
\text { call for responses that result from expanded thinking- } \\
\text { open ended responses; generation and application of } \\
\text { principles, concepts and generalizations; solutions } \\
\text { generated by application of rules or procedures; answers } \\
\text { to how, why, what do you think; higher levels of } \\
\text { cognition. } \\
\text { examples: } \\
\text { I: "Does anybody think that this story will have a happy } \\
\text { ending?" [3C] } \\
\text { I: "How does he think about that teacher? How does he } \\
\text { treat him?" [3C] } \\
\text { I: "Why would there be questions in the book?" [3C] }\end{array}$ & \\
\hline \multirow[t]{2}{*}{$3 F$} & $\begin{array}{l}\text { question-expanded thinking directed at female } \\
\text { examples: } \\
\text { I: "OK, Selina, do you agree?" [3F] } \\
\text { I: "How can the index help you? (+) Makoto?" [3F] } \\
\text { I: "What do you think about this book? Makoto? Do } \\
\text { you like it?" [3F] }\end{array}$ & \\
\hline & $\begin{array}{l}\text { question-expanded thinking asked by female } \\
\text { examples: } \\
\text { FS: "Is that school only for white people?" [F3] } \\
\text { FS: "How come America is so afraid of Soviet Union, } \\
\text { of communism, how come (+) they don't like the way } \\
\text { ok but why are they so afraid of communism?" [F3] } \\
\text { FS: "They can look and say he's Japanese he's } \\
\text { Chinese?" [F3] }\end{array}$ & F3 \\
\hline
\end{tabular}




\begin{tabular}{|c|c|c|}
\hline \multirow[t]{2}{*}{$3 \mathrm{M}$} & $\begin{array}{l}\text { question-expanded thinking directed at male } \\
\text { examples: } \\
\text { I: "Do you think that's useful to an ESL student?" [3M] } \\
\text { I: "...so do you think you might want to take Japanese?" } \\
\text { [3M] } \\
\text { I: "What's that mean he had changed? Changed from } \\
\text { what?" [3M] }\end{array}$ & \\
\hline & $\begin{array}{l}\text { question-expanded thinking asked by male } \\
\text { examples: } \\
\text { MS: "urge is more stronger than encourage?" [M3] } \\
\text { MS: "Can I if I talk with someone and he says things I } \\
\text { don't like it can I say I resent talking with him?" [M3] } \\
\text { MS: "the two ways it has the same meaning?" [M3] }\end{array}$ & M3 \\
\hline $4 \mathrm{~F}$ & $\begin{array}{l}\text { respond-restricted thinking directed at female: } \\
\text { results from restricted thinking-factual knowledge; an } \\
\text { accepted or pre-determined correct answer; facts } \\
\text { previously learned or easy to produce; lower levels of } \\
\text { cognition } \\
\text { examples: } \\
\text { FS: "How much should we write?" [F2] } \\
\text { I: "That's probably enough what you have there." [4F] } \\
\text { FS: "I just write summary, right?" [F2] } \\
\text { I: " right, yeah, just summary, ok?" [4F] }\end{array}$ & \\
\hline & $\begin{array}{l}\text { respond-restricted thinking from female } \\
\text { examples: } \\
\text { I: "oh, yeah, what did you do?" }[6 \mathrm{~F}] \\
\text { FS: "speech, speeches and writing and vocabulary" [F4] } \\
\text { I: "Who suggested this idea of containment to the } \\
\text { American government?" [2C] } \\
\text { FS: "George...George Keenan" [F4] }\end{array}$ & $\overline{\mathrm{F} 4}$ \\
\hline
\end{tabular}




\begin{tabular}{|c|c|c|}
\hline \multirow[t]{2}{*}{$4 \mathrm{M}$} & $\begin{array}{l}\text { respond-restricted thinking directed at male } \\
\text { examples: } \\
\text { MS: "We're going to watch the movie?" [M2] } \\
\text { I: "The movie, unfortunately did not come" [4M] } \\
\text { MS: "What page?" [M2] } \\
\text { I: "three o eight" [4M] }\end{array}$ & \\
\hline & $\begin{array}{l}\text { respond-restricted thinking from male } \\
\text { examples: } \\
\text { I: "He had a long piece of wood with a long point and } \\
\text { then what did he do?" }[2 \mathrm{C}] \\
\text { MS: "sliced it" [M4] } \\
\text { I: "What did he hear?" }[2 \mathrm{C}] \\
\text { MS: "the engine of a plane" [M4] }\end{array}$ & $\overline{\mathrm{M} 4}$ \\
\hline \multirow[t]{2}{*}{$5 F$} & $\begin{array}{l}\text { respond-expanded thinking directed at female: } \\
\text { result from expanded thinking-open ended questions; } \\
\text { generation and application of principles, concepts, and } \\
\text { generalizations; solutions generated by application of } \\
\text { rules or procedures; answers to how, why, what do you } \\
\text { think; higher levels of cognition } \\
\text { example: } \\
\text { FS: "They can look and say he's Japanese, he's } \\
\text { Chinese?" [3F] } \\
\text { I: "Yeah, I don't know how they can tell between } \\
\text { different Asians..." [5F] }\end{array}$ & \\
\hline & $\begin{array}{l}\text { respond-expanded thinking originate from female } \\
\text { example: } \\
\text { I: "before you read the book? (+) Why would you look } \\
\text { at it?" [7F] } \\
\text { FS: "you can see the pages." [F5] }\end{array}$ & F5 \\
\hline $5 \mathrm{M}$ & $\begin{array}{l}\text { respond-expanded thinking directed at male: } \\
\text { example: } \\
\text { MS: "I think there are conservative people who keep } \\
\text { their children out of school, why?" [M3] } \\
\text { I: "Because they don't think, they think that certain } \\
\text { kinds of things are being taught in schools that they } \\
\text { don't want their children to know about" [5M] }\end{array}$ & \\
\hline
\end{tabular}




\begin{tabular}{|c|c|c|}
\hline & $\begin{array}{l}\text { respond-expanded thinking originate from male } \\
\text { example: } \\
\text { I: "What should be some of the goals, objectives, what } \\
\text { are schools set up to do?" [3C] } \\
\text { MS: "knowledge" [M5] }\end{array}$ & M5 \\
\hline \multirow[t]{2}{*}{$6 \mathrm{~F}$} & $\begin{array}{l}\text { react-maintain level of part. directed at female: } \\
\text { A reaction which maintains the current level of } \\
\text { participation is an invitation to continue talking or to } \\
\text { amplify, clarify, or summarize ideas at the same or a } \\
\text { lower level of cognition. } \\
\text { examples: } \\
\text { I: "any problems with words you could not find the } \\
\text { definition to? (+) no?" [3C] } \\
\text { FS: "page one fourteen." [F4] } \\
\text { I: "one fourteen?" [6F] } \\
\text { FS: "one part Nancy was downcast" [F1] } \\
\text { I: "OK, Nancy was downcast at the top of the page and } \\
\text { then? which word is it?" [6F] }\end{array}$ & \\
\hline & $\begin{array}{l}\text { react-maintain level of participation originate from } \\
\text { female: } \\
\text { example: } \\
\text { I: "Can you explain why?" [7F] } \\
\text { FS: "why?" [F6] } \\
\text { I: "Yeah, why did Chinese come?" [7F] }\end{array}$ & F6 \\
\hline \multirow[t]{2}{*}{$6 \mathrm{M}$} & $\begin{array}{l}\text { react-maintain level of participation directed at male } \\
\text { example: } \\
\text { I: "What do they say about it?" }[2 \mathrm{C}] \\
\text { MS: "It's not so difficult to read." [M4] } \\
\text { I: "They say it's not so difficult to read?" }[6 \mathrm{M}]\end{array}$ & \\
\hline & $\begin{array}{l}\text { react-maintain level of participation originate from } \\
\text { male } \\
\text { example: } \\
\text { MS: "Any more papers?" [M2] } \\
\text { I: "I have a couple but not many." [4M] } \\
\text { MS: "to give in I said." [M6] } \\
\text { I: "I gave them back." [4M] } \\
\text { MS: "No, for us to give you." [M6] }\end{array}$ & $\overline{\text { M6 }}$ \\
\hline
\end{tabular}




\begin{tabular}{|c|c|c|}
\hline \multirow[t]{2}{*}{$7 F$} & $\begin{array}{l}\text { react-extend level of participation directed at female: } \\
\text { Reactions which extend the level of participation } \\
\text { request further consideration of ideas requiring } \\
\text { increased complexity of thinking. Such reactions build } \\
\text { upon the speaker's response asking the speaker to } \\
\text { elaborate or expand upon his or her original utterance. } \\
\text { example: } \\
\text { I: "When would you use the table of contents?" [3C] } \\
\text { FS: "First, before I start reading." [F5] } \\
\text { I: "before you read the book? Why would you look at } \\
\text { it?" [7F] }\end{array}$ & \\
\hline & $\begin{array}{l}\text { react-extend level of participation originate from female } \\
\text { example: } \\
\text { I: "...the United States also felt threatened, the more } \\
\text { countries in the world become communist the more } \\
\text { they were a threat to the United States." [1C] } \\
\text { FS: "yeah but basically helping them did not stop } \\
\text { communism..." [F7] }\end{array}$ & $\overline{\text { F7 }}$ \\
\hline \multirow[t]{2}{*}{$7 \mathrm{M}$} & $\begin{array}{l}\text { react-extend level of participation directed at male } \\
\text { example: } \\
\text { I: "A glossary is like a...?" }[3 \mathrm{C}] \\
\text { MS: "like a dictionary." }[\mathrm{M} 5] \\
\text { I: "its like a dictionary. How could that help you?" [7M] }\end{array}$ & \\
\hline & $\begin{array}{l}\text { react-extend level of participation originate from male } \\
\text { example: } \\
\text { I: "because they don't think, they think that certain } \\
\text { kinds of things are being taught in schools that they } \\
\text { don't want their children to know about." [5M] } \\
\text { MS: "but isn't that the goal of a school, to teach them? } \\
\text { I mean why you would keep your children from } \\
\text { learning?" [M7] }\end{array}$ & $\overline{\mathrm{M} 7}$ \\
\hline
\end{tabular}




\begin{tabular}{|c|l|c|}
\hline $\mathbf{8 F}$ & $\begin{array}{l}\text { react-terminate level of participation directed at female: } \\
\text { Reactions which terminate the level of participation } \\
\text { often occur in the form of a simple yes, no or ok. These } \\
\text { reactions do not push for further information, they } \\
\text { simply accept or dismiss the response to a question. } \\
\text { These type of reactions may also occur in the form of } \\
\text { topic switches or summaries of the discussion. }\end{array}$ & $\begin{array}{l}\text { example: } \\
\text { I: "no, not so much jealous but you're getting getting } \\
\text { close to it because it is sort of a negative thing. Not } \\
\text { jealous but..?" [7F] } \\
\text { FS: "ambitious" [F5] } \\
\text { I: "ambitious, that's right, ambitious..." [8F] }\end{array}$ \\
\hline $\begin{array}{l}\text { react-terminate level of participation originate with } \\
\text { female } \\
\text { example: }\end{array}$ & $\begin{array}{l}\text { FS: "What about jail?" [F2] } \\
\text { I: "j-a-i-1." [4F] } \\
\text { FS: "j-a-i-l" [F8] }\end{array}$ & $\begin{array}{l}\text { F8 } \\
\text { react-terminate level of participation directed at male } \\
\text { example: } \\
\text { I: "You know American society has some things they } \\
\text { value very highly. What's one? [3C] } \\
\text { MS: "freedom" [M5] } \\
\text { I: "freedom. American society values freedom very } \\
\text { highly." [8M] }\end{array}$ \\
\hline $\begin{array}{l}\text { react-terminate level of participation originate with } \\
\text { male } \\
\text { example: }\end{array}$ & $\begin{array}{l}\text { MS: "I was not here last year." [M1] } \\
\text { I: "You probably do not need to go." [4M] } \\
\text { MS: "yes, thank you." [M8] }\end{array}$ \\
\hline $\mathbf{8 M}$ & \\
\hline
\end{tabular}


APPENDIX D

INSTRUCTOR INTERVIEWS 
Interview questions:

1. How do you generally ask questions in class? Do you call on individuals, ask the whole class and call on those who raise their hands or ask the whole class and let those who know the answer shout it out or do you have some other method?

2. Do you find that some students tend to monopolize the classroom talk?

3. If so, how do you deal with this?

4. There are always at least a few students in every language class who are very timid about speaking the L2 in class, do you usually take any steps to try to get them to talk?

5. If so how?

6. How do you strike a balance between the very talkative students and those who are more reserved in classroom interactions?

7. Do you believe that student gender plays a role in which students are talkative and which are more reserved?

8. If so, what do you do to compensate for this?

9. With a multicultural class such as yours, different students must have widely different educational expectactions. Do you experience many problems because of cultural differences?

10. Do you ever alter your behavior to accommodate students' cultural practices? For example, if you knew the women of a certain culture did not generally work closely with the men of that culture, would you try to separate them when putting students into groups?

11. The accepted roles of men and women in many cultures differ greatly from those in American culture, has that posed any problems in your classroom?

12. Do you ever try to accommodate culturally differing gender roles when making classroom decisions about grouping or interactions? or do you try to treat all your students as you would treat American students, that is, equally? 
Me: You're classes are filled with a lot of Asian students, all Asian students. Do you find that Asian culture the differences in Asian culture and especially that gender roles makes any difference to you in the way you teach? Do you think you do anything differently because you're teaching to an all Asian group?

IA: I teach differently than I would teach to an American group, I'm sure, but teaching ESL to an American group is something you don't do. Umm...

Me: Have you taught to other groups?

IA: yeah, that's what I'm thinking, I've had diverse groups, I've groups with Latin Americans, Africans. I've had groups with many different cultures represented and I think I teach pretty much the same except I've become aware of cultural aspects that I can point out to students and say in some countries, I'll say it that way, I'll say in some countries people do this but in the United States, that isn't considered acceptable and you've gotta do this and if, you know, if it's different it's not that one is better than the other it's just that it's different. And I try to be sensitive not necessarily, I think with any group, with the groups, if I group students into small groups not to you know put one woman in with a group of men unless I think she's you know gonna feel comfortable.

Me: I noticed that also when you make the groups you also try to split up the languages to keep them from using too much of their first language.

IA: Oh, yeah definitely and what I, and they do, and I had later on in the semester they had a role play to plan and it was a cultural role play where they had to represent their culture and we had all the Japanese students together and we had the Korean and Taiwanese students together and the Korean and Taiwanese spoke English but the Japanese students did it Japanese. And it was an amazing process too because I put a female in charge and they just sort of spun their wheels time after time you know session after session and they had to perform this for another group it wasn't an in class assignment, it was for another group and so they had to have something ready they just spun their wheels and they you know made a couple false starts and then a student who, a male Japanese student who had been absent but was in that group he showed up the day before and took control and and they we did the whole role play and he basically wrote it all out and told everyone what to do and uhh that kind of amazed me because I'd chosen the student who had the most 
experience in the United States as the leader and he was just by his personality I think a better leader.

Me: I think I saw, I was there at the beginning of that when students asked American students about something, was that in your class when they said how do you feel about going to chapel or something like that.

IA: Yeah, that was different but it was connected maybe eventually because they had the contact, that was when they had the survey and they gave speeches. You should have come for the speeches which I didn't record so I don't have them. But the students ended up they used the information from the survey, they made up the questions I took the questions gave them to the students and distributed them gave the umm had them tallied gave the tally to my students and they had to take those and make a speech on conclusions that they could draw. Some of them were not contented with what they had and made more questions and gave them to their friends so they could fill in gaps that they had in their speeches but I think they learned a lot in that and I think there was a lot of frustration too because there are certain and I think every college has certain rules that umm the students aren't very happy with.

Me: right, yeah, students will always find something

IA: Right, they don't know how good they have it until they go someplace else.

Me: really, wait until they have to start working

IA: yeah umm that worked out that worked well.

Me: Every class has students who tend to monopolize the classroom discussion and some students who are kind of shy and hold back a lot. What kind of things do you try to do to sort of balance that out a bit?

IA: umm, the technique that I use, having the students talk to each other, like in pairs. If I ask questions in class, sometimes I'll let, cause I want every student to think about it I don't want some to just sit back and wait for another student to answer, so I'll just tell them to tell you know your partner your opinion about this tell them what you think about that or your idea and then I can go back to the whole group and kind of say you know what are some of the things you came up with and then you know everyone will have said something already and even if they don't say anything in the whole group that idea will come up and eventually usually will come up onto the board, so that's one way. And I've found that I this was the last semester but I've been working with the history class, I don't know if you're aware of that aspect

Me: yeah, I know 
IA: and serving as sort of a small group leader so what they have is fifty students in the class and he divides it into three groups for twenty minute or half hour discussion and I take one of those groups and we distribute the ESL students so there are two or three in each group not all globbed into one group one year they did that and that was just a disaster, and uhh but I know that my students are shy and that they're not going to speak up unless someone gives them time to answer and doesn't just put them on the spot so they have to be ready and they have to know what they're going to be talking about and I use that technique a lot then I just tell students well now here's our task now just work on that with a partner or in a group of three and you know tell each other your opinion or what you think, what you've learned about this and then I go back to the whole group and sometimes I don't even have to discuss the issue with the whole group because things have come up you know in the smaller groups well enough and that way in that small group or in the pair, they have to talk they can't just sit and be quiet because each person has a role there, where they can in a group of seventeen just sit and keep their mouths shut so that's umm and I've had a few cases of students who were always speaking up and there's one student in this group that the students really felt was speaking up to much and she came to me and said you know the students really think that I you know monopolize but they won't say anything and I let her, I didn't feel that she was monopolizing. You know I've had other students who just every time it's up and talk and talk and talk and talk and then all the other students are quiet and then sometimes I just have to tell that student you know either privately or in the group, you know we want to have everybody have a chance to say something and you know I know you've got something to say and you contribute a lot but let's let somebody else contribute too.

Me: What about calling on shyer students do you think that makes them more tense or...

IA: Oh, yeah, actually no what they've told me through the years is that that's what they're used to and so if you give them time you know tell them the question and then give them time to think about it. I wouldn't just say uhh so and so what do you think about da da da da because nobody's had any time to think about the question but $\mathrm{i}$ would put out the question and nobody was forthcoming or if I didn't want you know if I said wait until I call on somebody then I don't feel bad about calling on them individually at all but they're used to that and that's a problem that they're going to have when they get into regular classes because professors don't usually call on students by name usually they expect a volunteer. And so I tell 
them that too and of course they feel more comfortable volunteering in my class than when they get into the other class.

Me: Do you think that the classroom management, in other words what we were just talking about, whether you call on people or whether they raise their hands or whether they just shout out an answer plays a big role in how much English each student gets to practice?

IA: Yeah, and I think the students, uhh, if the students feel passive in the classroom, which they can feel if you don't involve them they get a lot less out of it. They have a poorer attitude towards it and they get a lot less out of it.

Me: So, you would say that, as a rule, you try to draw everyone in in whatever way you can using whatever strategy you have to?

IA: Yeah, Yes. I have a lot of experience in Romania and the History professor knew that and has asked me every year to make a presentation about Romania as a case study as the fall of the Russia and Eastern Europe and uhh.. I find myself using the same techniques in this class with fifty students, I start out and I ask them a question and then I say tell the person next to you and it takes a lot longer and then I say, I ask for a few answers but every single one of them had to answer to their partner and so I find that that style doesn't move along as quickly as a lecture would but I think the students get more interested in it because they find that have to take a position.

Me: And in ESL they should be trying to formulate their thoughts in English..

IA: Yeah! and they can it's a real struggle to express themselves so if you know you're expected whether in the context of understanding the class or if it's just talking to the person next to you you're expected to be able to formulate your thoughts and become more active.

Me: Do you see ever, and I'm not sure if this is sort of my own stereotype of Japanese society, but do you see a big difference in the way that Japanese and other Asian women and men speak in class and operate with each other for example in a small group do you find that the woman feels shyer if there are

IA: Not necessarily. You saw what happened in that class I had a couple of Japanese women in the back and they started ch ch ch ch ch and later on in the semester I had an eruption because of that kind of behavior. One of the other students really got angry because he could hear what was going on in class. And in that that, I haven't had that happen before and it was a difficult group, in general but I wouldn't say all the Japanese men, I gave you the one Japanese student who was a leader happened to be a male and the one Japanese female who I wanted to be a leader it turned out didn't feel comfortable leading, I mean it just wasn't working. 
Me: Do you think that was pretty idiosyncratic that it was just that this man ...

IA: Not necessarily but we had another Japanese man in there who wasn't a leader uhh several who weren't leaders and maybe the explanation I think it's pretty complex because the students who come here George Fox is not a well known prestigious place and traditionally a lot of the women who have come here have come through sister schools where the men have not because the sister schools well, that's not true some of the men have come through a sister school and some have been independent but the Japanese males who come here tend to be the Japanese males who can't make it or don't like it in the Japanese system. And so they're different they're not the traditional Japanese run of the mill male. And I'm coming to see that and so there is something about them that makes them special and you know their skills are weaker or their motivation is different or that they're very very interested in English and America and not so interested in Japan. We've had different types whereas the Japanese women in Japan they have limited prospects anyway. Even if they go through the Japanese system or if they go through the American system either way when they get back there's that ceiling there is a certain type of job they can get and they're not going to be able to keep if after they get married. and so they're they're just different and in that sense the Japanese women are more like Japanese average Japanese women but the Japanese men are atypical that's my evaluation of it. So I don't feel and I haven't what I've noticed and what I've been informed because I didn't notice it, I didn't know it was going on but some of the students came and told me you know kind of in the course of writing papers for other classes and I don't know whatever kind of context it would come up in, there's a hierarchy of students here and the students who have been here the longest are the senior you know are the elders and they have status. The newer students are peons and they don't have status and then there are the one's in between and there is a definite hierarchy and I had one student who had been here she graduated recently and she came to me and she said uhh such and such, a foreign student new this year, is miserable because she is she doesn't have a car and to go someplace she has to go with somebody and when everyone wants to go someplace she's the last one in line and if the car fills up with other people who have been here longer then she can't go and so it, and it wasn't a personality thing it wasn't anything other than the age rank or the seniority rank and so I see that they will rely on the elder student and you're not likely to have those students in your class but you might. The student that I chose as leader was one that had been here 
before, left gone to Portland State for a couple of terms and so I considered her a senior you know an elder within the group and so I picked her to lead the group the one who took over was a new student but they are I think, their personalities influenced their roles. But they tend to want you know they don't want to differ from they don't want to stand out from the others and the ones who will like this fellow is one who is willing to take a risk he's made a lot of American friends, he's gone on the college radio station, he's done lots of things for fun he's just he doesn't, I don't think he feels so dependent on the Japanese group. We've had other students like that who have been shunned because they chose not to speak Japanese in their spare time and they would make a point of speaking English and they would make a point of making American friends and hanging out with them and so they were kind of shunned by the Japanese group.

Me: They are sort of at a disadvantage being here in N---- rather than Portland.

IA: Yeah, it's really a close-knit community they really depend on each other a lot which has it advantages and disadvantages. So this fellow was willing to take risks while the other students in class and I think the other guys didn't feel so part of the group either but in a different way and so they weren't taking on leadership roles they were taking on following roles and were sort of like I've gotta do this task and I think the girls were probably really concerned about doing things right or doing things in an acceptable way so their not they're going to be hesitant about proposing something or suggesting a change or challenging something that someone else says.

Me: Was that one of your reasons for putting this girl in charge of the group was that to maybe try to bring her out a little bit?

IA: Well, I wasn't sure but I thought that she would take the leadership role, I hadn't I hadn't felt like she'd been so reticent you know she'd come to me a lot of times and talk to me about different things and she's living off campus and she's had more experience and I just thought she'd be able to handle it. And also that day I made the assignments I had a lot of absenteeism so I didn't have a lot to choose from but I thought you know she seemed my interaction when I was explaining to them what we were going to do and I was looking at the students and trying to figure out and I wasn't sure how to group them I wasn't sure and I had the students all together as a group talk through how we would organize ourselves because I wasn't sure if we were going to do one or two or three I mean I knew we were going to do at least two role plays but we coulda done three and I wasn't sure how divide them whether we should have mixed groups or culture groups and the students you know we went 
through a process of deciding that we were going to divide into Japanese and then the others and then in the course of that interaction I decided that she seemed to be pretty interested. In the other group, I'm trying to remember if I chose somebody to lead. Oh, I think I chose the one who is usually umm talkative.

Me: So that is pretty much the process for making decisions like that? Who is most interested, who might do a good job at it and not so much who everyone else will probably follow?

IA: Well...

Me: Because the one who is talkative you said some of the other students were a little thought she was dominating.

IA: Yeah, but she was doing the right thing and they were doing the thing that they weren't supposed to do and I think maybe they realize that. It's like in a union shop you're not supposed to stand out by producing the most that you can you're supposed the average amount that everyone else produces and if you take off and try to make an impression on the boss or something, you're going to get you're hand slapped by the union or by the supervisor that you've got and you know you're going make us all look bad so that was I think the dominant feeling and they were making her feel bad for doing what she should have been doing because they weren't feeling comfortable doing it.

Me: right speaking out... I've heard a lot that in Asian schools people are called on to answer and that students here might feel uncomfortable volunteering.

IA: And another thing, I'm thinking of other years, I've just made a point of rotating the leadership in small group activities. I just made a point of ok, who did it last time ok you're doing it this time and so that it rotated and each person took a leadership role. It was just who started with would be the one who I thought could handle it the most.

Me: Ok, I think we've talked about all my questions.

\section{INTERVIEW INSTRUCTOR B}

Me: How do you generally ask questions in class? Do you call on individuals or ask uhh.. general questions to the whole class and have people raise their hands or shout out their answers or what's your strategy?

IB: Well, I use a mixture of uhh... I'll ask questions and let people answer, kinda leave it open. Sometimes when then happens you get 
a tendency of one person tends to dominate and when I notice that happening, I'll try to call on specific people.

Me: uh-huh

IB: Sometimes, when you have a small class, if other people aren't prepared it's kind of obvious.

Me: yeah.

IB: And so you kind of let one person carry the discussion because other people aren't prepared to participate.

Me: Do you have a few students in your class who you feel consistently monopolize the, you know, question answering?

IB: Yeah, they have the potential too, yeah. I think there's Ariel who's very well prepared and able to answer any of the questions and willing to answer as many questions as she's allowed.

Me: uh-huh

IB: Uhhh... And I think the opposite, there are students who are very willing to let others, you know, participate and to let others express their idea and even let others do their work.

Me: Uh-huh, Do you think that's because of their culture or because they're shy or

IB: Well I think the Asian culture in general particularly the Japanese students are more reticent and, you know, comfortable letting others speak.

Me: um-hmm.

IB: At the same time we express to them the importance of participating and recognizing that's going to be an expectation of them when they take the regular classes. And it's important now for them to prompt themselves rather than just expecting to be asked.

Me: So, uhh... you don't, uhh... in your class if the Japanese students for example or the other Asian students are reluctant to speak a lot in class so you don't take that into consideration in terms of trying not to make them nervous or making them feel more comfortable by allowing them not to speak, is that at all a strategy you have?

IB: You mean letting them follow that pattern of. No, I think from the very beginning we explain to them the difference in the educational system here and what their expected, and often it 's perceived, if they don't answer, that's perceived as not knowing. And so we've worked with them on that, and I feel very comfortable, in fact I feel I would be doing them a disservice to let them sit quietly. Now what I do, out of consideration for their culture, is I don't mind silence. I don't mind asking them questions, letting them consider it, think about it. I won't go on to someone else. I'll just let them think about. And I'm comfortable with that silence, and I'm happy to let them reflect on whatever they want to say before they say it. 
Me: And that's what the cultural difference is. They may be very careful about what they say before they say it.

IB: Exactly, and I'm happy to accommodate that.

Me: Have you taught a homogenous group of students somewhere in the states or somewhere else?

IB: I taught at Portland State as a teaching assistant, as a lecturer. I taught at Mt. Hood Community College.

Me: Have you taught oversees, I mean a group of students that are all the same culture.

IB: oh, homogenous. Yeah, I taught in China. Not very long, I had a summer experience and so they were very young students.

Me: They were children?

IB: They were junior high students.

Me: Would you say that there were... When you were there did you try to conform to their cultural expectations of a teacher, or have them sort of conform to your expectations of how students should act?

IB: Well you know I don't think I knew what I was doing it was before I any teacher training. I think what I did was just try to put in as helpful as I could be. It actually wasn't a structured classroom situation it was more where we worked with individuals and small groups and then we gave lectures to entire groups, and so I think we fit into their style because that was what was happening. We were listening to lectures on Chinese culture, and learning the Chinese language informally and we were doing the same thing.

Me: You answered my questions without my even asking. You're students are all Asian here, right?

IB: Well no, at [this college] we've got Russian students, we've got some Latin American students. We've got a student from Pakistan.

Me: What nationality is A-----?

IB: She's Korean, but she married an American husband. She's a little more outgoing.

Me: Yeah, her personality type. Do you think the gender of your students plays any role in how much they speak out in class. (++) Do you find that even among Japanese students, who none of them really speak out too much, that there's a noticeable difference between women and men?

IB: I wouldn't say noticeable difference. I think if there's any difference, at least with the Japanese, in my experience I just sense the personality as being the difference. The fellows can be as quiet as the gals, and, you know, the opposite. And yet we've had some real extroverts both ways. We've had some fellas who were just really jumpy and even though they butchered the language they were very willing to communicate. And then we've had some real 
outgoing gals that just are very uhh.. willing to uhhh express their ideas or aren't shy in the least bit.

Me: yeah, uhhh. What about in small group work. Do you find that ummm I know in Japanese culture and a lot of Asian cultures, men and women have very different roles than we have here in the states. Do you find that in small group work that there is any conflict there between the men and the women?

IB: I haven't sensed a whole bunch of it, I sensed a little bit of it if, for example, the fellow was older. And I sensed that outside of the classroom too. Where the ones that are older or have been at the college longer are getting more respect. But if they both come at the same time and they're both about the same age, I don't sense much deference being given.

Me: Do you think that's because uhh.. in America they sort of toss a little bit of their cultural expectations out the window and in this new environment maybe adapted a little bit of a more open attitude?

IB: Yeah, I think that may be and I think also maybe back in Japan the young girls...people may be less, you know, traditional, you know, than they once were.

Me: Yeah, it's changing there. ummm.. So it's your policy in your classes at least to tell students from the very beginning what's expected of them in terms of verbosity, in terms of them speaking up in class and participation and that it's pretty much a typical classroom, American classroom, in that everyone's expected to participate. And if you don't, it's not always assumed that you know the answer and you're just too shy or whatever.

IB: Yeah, right. And I think even though I stress it uhhh...it takes a long time to sink in. You know, people are slow to change, we're slow to change and we can't just think that because you said that people are going to change their behavior over night.

Me: So it's hard to get students to initiate interactions with you, to bring up things say from their reading that they found say interesting? Would you say that?

IB: Yeah

Me: It would be difficult for them to come to you with a question?

IB: Well, I think it's more difficult for them to speak up in class.

Me: That's what I mean, in class.

IB: yeah, yeah, I think they feel comfortable coming and asking questions after class and a lot of times I'll pause and look around anybody have any questions and sometimes I'll even pull it out of them and Mewae you look confused and then they'll answer.

Me: Yeah, that's a common strategy I've seen that a lot lately in the classes I'm observing where the professor says something and stops and everyone's just sitting there and the instructor says $O K$, what 
did I just say? Can someone please summarize what you just heard just to make sure. OK, I think we've covered all my questions.

\section{INTERVIEW INSTRUCTOR C}

Me: In every classroom there are students who are less verbal and students who are more verbal, what do you do to sort of equalize that, what kind of strategies do you use?

IC: Um, well let me think, it kind of depends on the class. In some cases, it used to worry me more than it does now, I used to be really upset because some students just wouldn't talk and I think I'm less worried about it now because I think that that's their personal comfort zone and if they don't feel comfortable speaking yet I won't, I don't umm try to contrive situation that will make them feel really uncomfortable so I kinda let it slide. As long as I feel like I'm making eye contact and they're sort of engaged in the class umm and so I try to umm keep making eye contact and if I get the feeling that they want to say something you know I'll call on them or ask them or whatever's going on. So I'm aware of them I'm trying to keep track of them but I don't want to put them on the spot because some people are just uncomfortable. But then you have the students who are, I mean that's what I try and do for the ones who don't want to talk but then there are the one's who want to talk all the time and sometimes I just want to to tell them you know, ok, thank you and now do we have something from somebody else and I don't call on those guys again cause they've already answered six out the last seven questions or something like that because there are people who want to dominate. It's just sort of a matter of trying to keep track of who is actually participating and you can usually tell if there are students who want to participate that are being bumped out by the ones who are dominant you know you can watch their faces and you can tell if they have something to say just by being aware of them.

Me: So, in terms of classroom strategies and asking questions, do you ask more general questions or do you tend to call on people less as individuals or a variety? In general.

IC: In general yeah, you know I'm trying to think, right now I'm teaching a certain class and it's different from what I was teaching in the Spring and I mean it's different for different things. I think it's sort of both. A lot of times I'm doing pattern practice kind of drills and grammar things, you know, I just go around the circle or go through... 
Me: Call everyone once.

IC: Yeah, everyone gets a chance and it's kind of repetitious and boring and it's just kind of patterning a little bit and discussion questions, I'll usually, the first few will be open, and I'll ask something and someone raises their hand and I'll call on them and then I won't call on those people again until I've called on several other people and they'll keep raising their hand and I'll say well how 'bout I call on somebody else first and then I'll eventually get somebody else to answer. Because I get tired of hearing from the same people.

Me: right. Your classes here at [this college] are really mixed. Culturally diverse.

IC: We hope, not always but we hope

Me: Well you've got a lot of students from a lot of different countries. Do you think that culture plays a big role in who is speaking and who is not?

IC: Oh sure.

Me: Their $\mathrm{L}$ one and their first culture influences their classroom behavior quite a bit?

IC: Oh absolutely because the Asian students won't answer and the Arabs will. I mean it's not that diverse it's pretty much Asians and Arabs that's about it and once in awhile a Russian or two but... Yeah, there is definite cultural problems there you just have to be aware of them.

Me: In group work and stuff like that do you find it difficult to pair them together or more beneficial?

IC: Oh, ummm... what I do when I'm pairing up groups now is the first the first one or two times that I have them make groups I let them choose who they want to be in a group with. I just say make groups and they just stand up and make groups. Maybe the first time or the second time I would do that. Or I just say ok, the first four students in one group and the second four students in another group and like that and then if this is an on-going group thing I'll let them sort of anonymously, and this is for on-going group things not just for a little exercise, quickly get in groups and do this but an on-going thing, they uhh I have them give me a piece of paper that tells me the names of three students that they think they could learn something from in a group and then one student that they don't think they could learn something from in a group.

Me: and this is done anonymously?

IC: Well, they have their name on it but nobody else sees it. So actually I shouldn't have said that. They give it to me but nobody else sees it. So then I just put all those out on a table and I try to make groups then so that they at least, for sure they don't get with the one person who they can't stand, or that they think has nothing to offer them 
because they don't have any respect for that person and they're not going to value that person's contributions or encourage that person to participate. They can only pick one person but I always, it seems like, I've never had everybody in one class pick the same person so it's always worked out. So and then I always try to get them at least one person that they think they can learn from and that way they have somebody who they admire or really respect and I've always been able to work it out so they don't get the person they really dislike and they do get at least one person. And so it takes awhile but I usually like to do it that way and then those are the groups that would meet on a regular basis for discussion like when we're discussing a novel or we're discussing something else.

Me: So that's a pretty good strategy.

IC: Yeah, and I try and mix and match the nationalities and stuff but I've found they never do pick all their country you know I think I can learn something from these two guys and they're not going to pick all three from the same country because they know what people in their country are like and more often than not they pick other people. So that hasn't really been a problem. It really works well, I like it.

Me: What about pairing up women and men, I know in a lot of middle eastern cultures there's a big cultural difference and I know you don't have any middle eastern women

IC: rarely we rarely get middle eastern women and if I do I usually can pair them up with a Japanese woman and it's not bad

Me: I just am imagining sort of a very shy timid Asian woman being paired with an

IC: with an Arab guy? yeah. that happens, and it happened oh it's tough sometimes with gender differences especially at the lower levels when we almost always have mostly men and they're mostly Middle Eastern and occasionally we'll get one or two Japanese and even more rarely one of them will be a woman, it seems recently anyway so this term we have thirteen Arab men in level one hundred and two Japanese guys. And so we don't have any women at all. Last time I taught level one hundred it was all men and one, not all Arab men but all men, one was a Korean one and a couple of Japanese guys, and one Russian woman and she was the only woman in the whole class out of fifteen or something and so it's really tough, it's tough. It depends on the woman though.

Me: Do you try to make it clear from the very beginning what your expectations are for all the students in terms of speaking up in class or umm

IC: yeah, yeah

Me: that here, whatever goes on in their culture, here .. 
IC: things are different. Yeah, yeah, I talk about that in the beginning and I talk about it in the middle and probably at the end too that this is how it works. And it's hard, probably at the lower levels harder than at the higher levels I think. Because if they've had less experience with English language study and less exposure to the cultural expectations it's real hard, the group we have right now in one hundred for example, it's really hard to convince them that their peers have anything to offer them. They're very, these guys haven't studied English before. And they have a very clear expectation that the teacher should be teaching them and that their peers don't know anything and they have nothing to learn from them. So I put them in groups and I'm having a really hard time getting them to work in groups and getting them to uhh to listen to what somebody else says, you know unless it's just, even having them compare answers when they finish an exercise you know two or three guys will finish before anybody else and I'll say check your answers together and they don't want to check with them they want to go and have me check them well you can check with the guy next to you. With the upper level students my expectations are much higher for discussing and sharing and stuff than the lower level it should be higher but I don't know maybe it's just this particular group but they're really resistant to group work and sharing at all. It's just tough it's a really tough group this time.

Me: So you think that that expectation then is pretty clear. At the upper levels they probably know to some extent when they walk in the classroom what is expected of them.

IC: Not always when they walk in the classroom but if you start doing it right from the beginning and have it fairly structured, have the group work structured well enough so that they know what they're that everybody has something that they should be doing in the group and a lot of times in the group work if it's discussion questions or something for the novel they've read or something I have them with a double entry journal and they've done the questions at home and then they're expected to write information that differs from that which they have written, you know, what their peers have given them and they're expected to have notes on the other half of the entry of what well Ahmed said this or so and so disagreed with my answer and comments on their answers on what the other people have said and so it's pretty clear to them that they have to be sharing their answers and be getting something from what the other people have said.

Me: And with their interactions with you they all have some notion or are clued in that you would like everyone to participate with 
you, to speak up whenever they feel like it, whenever they have something to say?

IC: Oh, yeah, yeah.

Me: think that that is something that a lot of times is not clear to people who in their own country are not expected to just speak up.

IC: Oh it's really tough, it's really tough. And their expectations, it's hard to know whether they're not speaking up because they're not into the system yet or if they're not speaking up because they don't feel comfortable speaking up or if they have something to say but they don't want to say it or is it that they don't have anything to say, you know, it's real hard especially when they've just arrived. And some of them arrive much more worldly and sophisticated and into the American system and others have whatever education they've gotten before is in a very traditional and conservative system and they don't come with that. It just depends on where they went to school or what city they grew up in or whatever.

Me: So really, I guess what I'm getting at is that part of your job and all of our jobs as teachers of English is to sort of give some sense of how our culture operates in the classroom and that we all have just as much right to speak up and that's in fact expected in our culture. That speaking up is a valued thing, and expressing your opinion is a respected umm action. So do you think that that is made clear or do you think that the students get that just by inference or...

IC: Yeah, I think so, yeah I think both, you know, it's sort of indirectly covered but I think it is also pretty explicitly covered too. You know, if somebody gives an opinion and you follow up with that by asking someone else what they thought of that person's opinion, you know compliment them on it and follow up on whatever they've said with somebody else's, it seems to me the harder thing than getting them to express their opinion is getting them to listen to somebody else. A lot of times they just want to dialogue with you. One student wants to talk and everybody else just tunes out and thinks that oh well he's talking and I'll get my chance and the next thing you know they're saying the same thing because they were never listening to the first person. And I think more difficult for me is to get them to listen and to have them get the idea that perhaps their peers have something to offer.

Me: And you do that by rewarding

IC: yeah

Me: that's really tough

IC: Yeah, it is, it is, because a lot of them do feel that it's the teachers job to teach them and that's where they're going to get the information and that they're not going to get anything from anyone else in the class because it's the teacher's job. 
Me: So you don't do anything to accommodate that kind of cultural insecurity or if they want to interact with you more than anyone else?

IC: Yeah, I just sort of don't let 'em I don't know. You know you just sort of have to push it sometimes and especially when they're really, like the one's we've got now they're so unwilling to learn from each other you have to structure it more rigidly with you know information gap exercises or something where each of them knows something and they have to share to get a whole picture and that kind of stuff and sometimes they do that but I don't know but when they're being really rigid it's difficult to convince them that there is some value to that that it's not just some sort of game that you're playing. That they are actually getting something out of it is really hard, that's with the real low level students. The upper level students aren't as bad and the upper level students are more umm accustomed to people from other cultures and what's going on, maybe it's just this group I've got right now that's just so low these Arabs and they're so rigid and so closed-minded. Here I am generalizing about students, low-level students do this and it might be just this group I've got that's just driving me crazy.

Me: So in speaking out in class, the amount of student talking that goes on, you try to make them feel comfortable by not forcing them to speak out or calling on students who you think are shy ..

IC: Yeah, I'll try to make them feel comfortable but on discussion things but like I said when I'm doing drill practice I'll go around and everyone answers umm but a lot of time if it's a kind of a discussion thing I don't find pushing beyond what they're comfortable, I mean a little bit beyond what they're comfortable with but not too much beyond what they're comfortable with. A little bit of pushing is ok but not too much. Some kids you just can't push at all and other ones they want to be pushed and they're sort of hoping you'll push them 'cause then they'll get a chance to talk and they won't offer to talk on their own because they feel like you don't really want to hear from them or something.

Me: That's tough because then a lot of times on paper you'll have these A students and..

IC: Oh, yeah, and they can't say a word or they won't say a word, and it is really tough and then you have these kids who talk all the time but they can't pass a test because their spelling and their grammar is so bad but they're very expressive.

Me: It's hard to balance that.

IC: It is very hard. It's really difficult sometimes.

Me: OK, good. 
INTERVIEW INSTRUCTOR D

Me: I'd like to talk about how you generally get students to talk in class. Do you usually ask general questions and allow students to raise their hands or call on people or use a variety, what's your strategy?

ID: Well I use a variety of methods to do that but I think that one of the important things that you need to remember when you do anything like that is that you need to actually before the class actually begins early on in the semester, the thing is you have to get some sort of bonding, I hate to use that word but, some sort of bonding kinds of exercises so that the students know each other well enough that they're willing to cooperate and trust each other so that when you do call on them or whatever they are not afraid to answer and make a mistake in front of the other students and that's sort of preparatory to any other sort of eliciting of response so I after that happens I do various kinds of things I mean I will call on students individually um I like to have students actually they'll do things in groups first before they respond. so they'll split up into small groups first so they can sort of discuss the topic and have an understanding of it and ask them some questions so that they can keep the discussion going because I think that in small groups they tend to respond more are less reticent to respond. And then from the small groups then open it up to the entire class and then ask students to respond I mean I ask them the questions but after they've been prepped a little first rather than cold because I think some of them asking them putting students on the spot by asking them without preparation can be sort of intimidating.

Me: Right, do you find that some students, students from some cultures are more willing to take a risk than others?

ID: Yeah, of course the stereotypic thing is that the Asian students generally are not trained to respond very quickly, not that the don't know the answers but in general I think that that's true. Middle Eastern students European students who are trained in a different tradition tend to be more verbal in terms of expressing their opinions and so on.

Me: Yeah, I know from my experience, I work with mainly Vietnamese groups and I work with a Chinese group, they generally will wait for me to call on them before they want to offer answer and it's not that they don't know the answer it's just that they expect me to ask them directly. So do you at first at least try to sort of cater to this educational expectation that they have regarding teacher-student roles at all? 
ID: Yeah, uh-huh. uh-huh, we do talk about that and I explain that and I think they already know that really it's just a matter of making it concrete and putting it out in front of them but I think they already understand that. What happens is that because they come from cultures where they're hesitant to speak out for fear either that they'll make a mistake or even if they know the correct answer because they don't try to show off their knowledge that's another thing they don't want to do either they need to understand that that's ok to do that. Students from other cultures sometimes will answer the question even if it's not correct they just need the chance to feel they should offer something and you know we do a lot of talking about expectations. Because they're here studying in American colleges and universities and this is an expectation that they'll need to to cope with and it helps a little bit but of course what has been ingrained for years and years is difficult to undo and so even if they are comfortable in the class doing it when they get out into another quote authentic type of situation they may not be able to do it. So, but at least they cerebrate that, they know that cerebrally that this is what needs to happen.

Me: Along that same vein, do you find that the gender roles of students from other cultures ever pose a problem, for example, that the female students in particular are a little reluctant to speak out in a group with males or something like that? I know that you have a wide variety of cultures in your class .

ID: You know it really depends on the class and it depends on the individuals. Now we have lots of women who come and because they come that is something very telling. They tend to be less stereotypic in some ways, not that they all are, some of them are more reticent to speak in some ways but we get a lot of women who are willing to take a chance. They are here they are taking a chance already in a way. They are away from their culture and this is different to begin with so they tend to be a little less reticent to speak. So there is some problem sometimes but quite often I think if you start them off in small group or if they know each other well enough, which is, as I said, very important to do at the beginning so that they're all comfortable and sort of friends that the gender thing doesn't really interfere too much in the discussion that the women will in fact in groups with men offer their opinions because they know that the men are not going to make fun of them. Now another thing that sometimes operates in the classroom in not just gender but age roles and I find that in certain cultures, for example the Koreans who come now have a very definite sense of status and age and role and quite often it's not a gender thing but young men will not speak before older men get a chance to speak and that kind 
of thing. The Japanese used to be like that but they are not quite as rigid as they used to be anymore in fact that also operates not only gender but age expectations as well.

Me: Again, they must know that in this culture that that doesn't really play as big a role and with gender roles also.

ID: Right and in fact our whole curriculum is geared towards apprising them of the expectations of university life, etcetera, and the roles that they need to play. They play many roles and as students they need to assume a slightly different role than those that they play at home. And as I said again it's very difficult for them because though they can understand that cerebrally, cognitively, affectively they have a very difficult time and to get over years and years of that kind of training you just cannot do it one semester.

Me: So it puts on you in addition to teaching about English grammar and what not, it puts on you the role of enforcing the expectation of equality that comes with our culture. So you're teaching major aspects of our culture sort of by implication in your classroom.

ID: That's right, that's right, the teacher's role I think is very very difficult, I forget now, I have an article about the seven roles a teacher plays or whatever and the teacher needs to be has to be so many different people in the classroom and has to be really very sensitive to and part of it really a teacher needs to be sort of a therapist in some way and in fact I think there's an analogy there but I think the teacher needs to be very sensitive to the students needs and know exactly when to play which card. And I think that's part of the art of teaching and it comes after years of teaching we gain a sort of sensitivity as to when a question is appropriate or inappropriate, when it is appropriate to ask a person to respond or not to respond and with the group dynamics you sort of feel out etcetera so I think this sort of sensitivity builds up I think and some people have it to begin with, are more sensitive than others but I think that people who don't necessarily have it when they begin teaching I think after years of thinking do gain that sense. You know you kind of walk a very fine line every day and that's what's so exciting about it and that's what's also kind of dangerous about it because if you're not really too sensitive or you have an off day yourself you may not be attending properly to what needs to be done. Language is only part of it.

Me: Do you have a few students who you consider, maybe one or two students who tend to monopolize the classroom interaction or do you try to keep that at an even keel?

ID: Yeah, there are some classes, of course, when that happens and it's hard to stop that kind of thing from happening but I think that's why it's good to do group work or even whole class work where you 
have everyone sit sort of in a semicircle or circle and have everyone respond and get a chance to say something. The person who wants to monopolize the conversation will be told at the beginning that the gameplay here, the plan is that everyone must speak before you have a second chance to speak, and I think the students respect that otherwise one person does you know monopolize the conversation. I think if you set the rules up you can handle that kind of thing.

Me: Have you taught a homogenous group of students before in terms of L1? A group of students that all spoke the same first language?

ID: Yes, I have, uh-huh.

Me: Did you find that students using their L1 in the classroom was a big problem?

ID: It can be ummm that's always a problem but I think it depends on the setting. I have had classes like that where the students are a homogenous group but in the United States and I think there is less of a problem there than I've done it in Japan too and when there is a homogenous group in Japan, that's more difficult it's more difficult to get them to not use their own language. I think it's sort of a mental set that when you get away from your own country than using English is not as threatening or something. It can be a problem, obviously, but I think some of it needs to go on too because I think, sometimes cognitively to understand something they need to use the language that they know. And umm especially if they're not really proficient in English yet they need to use their own language to sort of discuss things and get the concepts and then sort of translate them or not really translate but use English to try to express those ideas. So it's not necessarily bad but if too much of it goes on then it can be.

Me: What I'm driving at, I think that in a group that is all from the same culture, the teacher role changes a bit in that you do have to in some ways take into account the first culture and the roles and the rules that are going on there in that group whereas in a bigger group of students from many cultures, it would be unfair to say cater to one person's culture.

ID: yeah.

Me: Did you feel that when you taught a homogenous group in the United States, that in a class with only one culture you were more aware of sort of the underlying rules that were playing a role in the classroom interactions?

ID: yeah, that's right, that's right.

Me: Because of course we can't know everything about every culture ID: That's true, but you're right I think you do develop a sensitivity to that particular group's way of doing things, the norms that are operating whereas in a heterogeneous group the norms sort of wash 
163

out because they all have different norms and they just have to play to the middle whatever that happens to be, a sort of synthesis of the norms that are in play.

Me: I think that's all of the questions 
APPENDIX E

SEATING CHART RAW DATA 
TABLE VI

SEATING CHART DATA

INSTRUCTOR A

OBSERVATION 1

\begin{tabular}{|l|c|c|c|c|}
\hline & $\begin{array}{c}1 \\
\text { stud. init. }\end{array}$ & $\begin{array}{c}2 \\
\text { general ques. }\end{array}$ & $\begin{array}{c}3 \\
\text { direct ques. }\end{array}$ & total \\
\hline male (2) & 1 & 33 & 8 & 42 \\
& $(.5)$ & $(16.5)$ & $(4)$ & $(21)$ \\
\hline female (2) & 6 & 31 & 9 & 46 \\
& $(3)$ & $(15.5)$ & $(4.5)$ & $(23)$ \\
\hline total (4) & 7 & $\begin{array}{c}64 \\
(70 \text { asked) }\end{array}$ & 17 & 88 \\
& & \multicolumn{3}{|r}{} \\
\hline
\end{tabular}

TABLE VII

SEATING CHART DATA

INSTRUCTOR A

OBSERVATION 2

\begin{tabular}{|l|c|c|c|c|}
\hline & $\begin{array}{c}1 \\
\text { stud. init. }\end{array}$ & $\begin{array}{c}2 \\
\text { general ques. }\end{array}$ & $\begin{array}{c}3 \\
\text { direct ques. }\end{array}$ & total \\
\hline male (2) & 3 & 12 & 3 & 18 \\
& $(1.5)$ & $(6)$ & $(1.5)$ & $(9)$ \\
\hline female (2) & 9 & 20 & $1(2$ asked $)$ & 30 \\
& $(4.5)$ & $(10)$ & $(.5)$ & $(15)$ \\
\hline total (4) & 12 & 32 & 4 & 48 \\
& & $(45$ asked) & & \\
\hline
\end{tabular}


TABLE VIII

SEATING CHART DATA

INSTRUCTOR A

OBSERVATION 3

\begin{tabular}{|l|c|c|c|c|}
\hline & $\begin{array}{c}1 \\
\text { stud. init. }\end{array}$ & $\begin{array}{c}2 \\
\text { general ques. }\end{array}$ & $\begin{array}{c}3 \\
\text { direct ques. }\end{array}$ & total \\
\hline male (4) & 0 & 3 & 1 & 4 \\
& & $(.75)$ & $(.25)$ & $(2)$ \\
\hline female (6) & 18 & 14 & 7 & 39 \\
& $(3)$ & $(2.33)$ & $(1.16)$ & $(6.5)$ \\
\hline total (10) & 18 & $\begin{array}{c}17 \\
(18 \text { asked) }\end{array}$ & 8 & 43 \\
& & & \\
\hline
\end{tabular}

TABLE IX

SEATING CHART DATA

INSTRUCTOR A

OBSERVATION 4

\begin{tabular}{|l|c|c|c|c|}
\hline & $\begin{array}{c}1 \\
\text { stud. init. }\end{array}$ & $\begin{array}{c}2 \\
\text { general ques. }\end{array}$ & $\begin{array}{c}3 \\
\text { direct ques. }\end{array}$ & total \\
\hline male (4) & 1 & 1 & 15 & 17 \\
& $(.25)$ & $(.25)$ & $(3.75)$ & $(4.25)$ \\
\hline female (5) & 7 & 7 & 16 & 30 \\
& $(1.4)$ & $(1.4)$ & $(3.2)$ & $(6)$ \\
\hline total (9) & 8 & 8 & 31 & 47 \\
& & $(13$ asked) & & \\
\hline
\end{tabular}


TABLE $X$

SEATING CHART DATA

INSTRUCTOR B

OBSERVATION 1

\begin{tabular}{|l|c|c|c|c|}
\hline & $\begin{array}{c}1 \\
\text { stud. init. }\end{array}$ & $\begin{array}{c}2 \\
\text { general ques. }\end{array}$ & $\begin{array}{c}3 \\
\text { direct ques. }\end{array}$ & total \\
\hline male (2) & 3 & 4 & 2 & 9 \\
& $(1.5)$ & $(2)$ & $(1)$ & $(4.5)$ \\
\hline female (4) & 6 & 3 & 4 & 13 \\
& $(1.5)$ & $(.75)$ & $(1)$ & $(3.25)$ \\
\hline total (6) & 9 & $\begin{array}{c}7 \\
(17 \text { asked) }\end{array}$ & 6 & 22 \\
& & & \\
\hline
\end{tabular}

TABLE XI

SEATING CHART DATA

INSTRUCTOR B

OBSERVATION 2

\begin{tabular}{|l|c|c|c|c|}
\hline & $\begin{array}{c}1 \\
\text { stud. init. }\end{array}$ & $\begin{array}{c}2 \\
\text { general ques. }\end{array}$ & $\begin{array}{c}3 \\
\text { direct ques. }\end{array}$ & total \\
\hline male (1) & 1 & 4 & 2 & 7 \\
& $(1)$ & $(4)$ & $(2)$ & $(7)$ \\
\hline female (4) & 11 & 12 & 2 & 25 \\
& $(2.75)$ & $(3)$ & $(.5)$ & $(6.25)$ \\
\hline total (5) & 12 & 16 & 4 & 32 \\
& & (30 asked) & & \\
\hline
\end{tabular}


TABLE XII

\section{SEATING CHART DATA INSTRUCTOR B \\ OBSERVATION 3}

\begin{tabular}{|l|c|c|c|c|}
\hline & $\begin{array}{c}1 \\
\text { stud. init. }\end{array}$ & $\begin{array}{c}2 \\
\text { general ques. }\end{array}$ & $\begin{array}{c}3 \\
\text { direct ques. }\end{array}$ & total \\
\hline male (1) & 1 & 0 & 0 & 1 \\
& $(1)$ & & & $(1)$ \\
\hline female (4) & 12 & 0 & 0 & 12 \\
& $(3)$ & & & $(3)$ \\
\hline total (5) & 13 & 0 & 0 & 13 \\
\hline
\end{tabular}

TABLE XIII

SEATING CHART DATA

INSTRUCTOR B

OBSERVATION 4

\begin{tabular}{|l|c|c|c|c|}
\hline & $\begin{array}{c}1 \\
\text { stud. init. }\end{array}$ & $\begin{array}{c}2 \\
\text { general ques. }\end{array}$ & $\begin{array}{c}3 \\
\text { direct ques. }\end{array}$ & total \\
\hline male (2) & 0 & 0 & 5 & 5 \\
& & & $(2.5)$ & $(2.5)$ \\
\hline female (4) & 9 & 12 & 4 & 25 \\
& $(2.25)$ & $(3)$ & $(1)$ & $(6.25)$ \\
\hline total (6) & 9 & $\begin{array}{c}12 \\
(26 \text { asked) }\end{array}$ & 9 & 22 \\
& & \multicolumn{3}{|l}{} \\
\hline
\end{tabular}


TABLE XIV

SEATING CHART DATA

INSTRUCTOR C

OBSERVATION 1

\begin{tabular}{|l|c|c|c|c|}
\hline & $\begin{array}{c}1 \\
\text { stud. init. }\end{array}$ & $\begin{array}{c}2 \\
\text { general ques. }\end{array}$ & $\begin{array}{c}3 \\
\text { direct ques. }\end{array}$ & total \\
\hline male (6) & 27 & 22 & 14 & 63 \\
& $(4.5)$ & $(3.66)$ & $(2.33)$ & $(10.5)$ \\
\hline female (4) & 7 & 5 & 3 & 15 \\
& $(1.75)$ & $(1.25)$ & $(.75)$ & $(3.75)$ \\
\hline total (10) & 34 & $\begin{array}{c}27 \\
(31 \text { asked) }\end{array}$ & 17 & 78 \\
& & \multicolumn{3}{|c}{} \\
\hline
\end{tabular}

TABLE XV

SEATING CHART DATA

INSTRUCTOR C

OBSERVATION 2

\begin{tabular}{|l|c|c|c|c|}
\hline & $\begin{array}{c}1 \\
\text { stud. init. }\end{array}$ & $\begin{array}{c}2 \\
\text { general ques. }\end{array}$ & $\begin{array}{c}3 \\
\text { direct ques. }\end{array}$ & total \\
\hline male (6) & 28 & 23 & 15 & 66 \\
& $(4.6)$ & $(3.83)$ & $(2.5)$ & $(11)$ \\
\hline female (4) & 8 & 5 & 4 & 17 \\
& $(2)$ & $(1.25)$ & $(1)$ & $(4.25)$ \\
\hline total (10) & 36 & 28 & 19 & 83 \\
& & $(31$ asked) & & \\
\hline
\end{tabular}


TABLE XVI

SEATING CHART DATA

INSTRUCTOR C

OBSERVATION 3

\begin{tabular}{|l|c|c|c|c|}
\hline & $\begin{array}{c}1 \\
\text { stud. init. }\end{array}$ & $\begin{array}{c}2 \\
\text { general ques. }\end{array}$ & $\begin{array}{c}3 \\
\text { direct ques. }\end{array}$ & total \\
\hline male (7) & 8 & 8 & 7 & 23 \\
& $(1.14)$ & $(1.14)$ & $(1)$ & $(3.28)$ \\
\hline female (6) & 2 & 3 & 4 & 9 \\
& $(.33)$ & $(.5)$ & $(.66)$ & $(1.5)$ \\
\hline total (13) & 10 & 11 & 11 & 32 \\
& & $(12$ asked) & & \\
\hline
\end{tabular}

TABLE XVII

SEATING CHART DATA

INSTRUCTOR C

OBSERVATION 4

\begin{tabular}{|l|c|c|c|c|}
\hline & $\begin{array}{c}1 \\
\text { stud. init. }\end{array}$ & $\begin{array}{c}2 \\
\text { general ques. }\end{array}$ & $\begin{array}{c}3 \\
\text { direct ques. }\end{array}$ & total \\
\hline male (7) & 8 & 8 & 7 & 23 \\
& $(1.14)$ & $(1.14)$ & $(1)$ & $(3.28)$ \\
\hline female (6) & 2 & 2 & 3 & 7 \\
& $(.33)$ & $(.33)$ & $(.5)$ & $(1.16)$ \\
\hline total (13) & 10 & $\begin{array}{c}10 \\
(11 \text { asked })\end{array}$ & 10 & 30 \\
\hline
\end{tabular}


TABLE XVIII

SEATING CHART DATA

INSTRUCTOR D

OBSERVATION 1

\begin{tabular}{|l|c|c|c|c|}
\hline & $\begin{array}{c}1 \\
\text { stud. init. }\end{array}$ & $\begin{array}{c}2 \\
\text { general ques. }\end{array}$ & $\begin{array}{c}3 \\
\text { direct ques. }\end{array}$ & total \\
\hline male (7) & 19 & 11 & 6 & 36 \\
& $(2.7)$ & $(1.57)$ & $(.857)$ & $(5.14)$ \\
\hline female (5) & 4 & 3 & 4 & 11 \\
& $(.8)$ & $(.6)$ & $(.8)$ & $(2.2)$ \\
\hline total (12) & 23 & 14 & 10 & 47 \\
& & $(21$ asked) & & \\
\hline
\end{tabular}

TABLE XIX

SEATING CHART DATA

INSTRUCTOR D

OBSERVATION 2

\begin{tabular}{|l|c|c|c|c|}
\hline & $\begin{array}{c}1 \\
\text { stud. init. }\end{array}$ & $\begin{array}{c}2 \\
\text { general ques. }\end{array}$ & $\begin{array}{c}3 \\
\text { direct ques. }\end{array}$ & total \\
\hline male (7) & 20 & 11 & 6 & 37 \\
& $(2.8)$ & $(1.57)$ & $(.857)$ & $(5.28)$ \\
\hline female (5) & 4 & 3 & $5(6$ asked) & 12 \\
& $(.8)$ & $(.6)$ & $(1)$ & $(2.4)$ \\
\hline total (12) & 24 & $\begin{array}{c}14 \\
\text { (22 asked) }\end{array}$ & 11 & 49 \\
& & \multicolumn{4}{|r}{} \\
\hline
\end{tabular}


TABLE XX

SEATING CHART DATA

INSTRUCTOR D

OBSERVATION 3

\begin{tabular}{|l|c|c|c|c|}
\hline & $\begin{array}{c}1 \\
\text { stud. init. }\end{array}$ & $\begin{array}{c}2 \\
\text { general ques. }\end{array}$ & $\begin{array}{c}3 \\
\text { direct ques. }\end{array}$ & total \\
\hline male (7) & 16 & 19 & 1 & 36 \\
& $(2.28)$ & $(2.71)$ & $(.142)$ & $(5.14)$ \\
\hline female (6) & 4 & 8 & 0 & 12 \\
& $(.66)$ & $(1.33)$ & & $(2)$ \\
\hline total (13) & 20 & 27 & 1 & 48 \\
& & $(28$ asked) & & \\
\hline
\end{tabular}

TABLE XXI

SEATING CHART DATA

INSTRUCTOR D

OBSERVATION 4

\begin{tabular}{|l|c|c|c|c|}
\hline & $\begin{array}{c}1 \\
\text { stud. init. }\end{array}$ & $\begin{array}{c}2 \\
\text { general ques. }\end{array}$ & $\begin{array}{c}3 \\
\text { direct ques. }\end{array}$ & total \\
\hline male (7) & 17 & 20 & 2 & 39 \\
& $(2.428)$ & $(2.857)$ & $(.285)$ & $(5.57)$ \\
\hline female (6) & 4 & 9 & 0 & 13 \\
& $(.66)$ & $(1.5)$ & & $(2.16)$ \\
\hline total (13) & 21 & $\begin{array}{c}29 \\
\text { (30 asked) }\end{array}$ & 2 & 52 \\
\hline
\end{tabular}


APPENDIX F

ETHNICITY DATA 
TABLE XXII

ETNICITY DATA

INSTRUCTOR C

OBSERVATION 1

\begin{tabular}{|l|c|c|c|c|}
\hline & 1 & 2 & 3 & total \\
& stud. init. & general ques. & direct ques. & \\
\hline Asian & 4 & 2 & 2 & 8 \\
Females (3) & $(1.33)$ & $(.66)$ & $(.66)$ & $(2.66)$ \\
\hline Russian & 3 & 3 & 1 & 7 \\
Females (1) & $(3)$ & $(3)$ & $(1)$ & $(7)$ \\
\hline Asian Males & 2 & 1 & 2 & 5 \\
$(1)$ & $(2)$ & $(1)$ & $(2)$ & $(5)$ \\
\hline Middle & 26 & 21 & 12 & 59 \\
Eastern & $(5.2)$ & $(4.2)$ & $(2.4)$ & $(11.8)$ \\
Males (5) & & & & \\
\hline total (10) & 35 & 27 & 17 & 79 \\
\hline
\end{tabular}

TABLE XXIII

ETHNICITY DATA

INSTRUCTOR C

OBSERVATION 2

\begin{tabular}{|l|c|c|c|c|}
\hline & $\begin{array}{c}1 \\
\text { stud. init. }\end{array}$ & $\begin{array}{c}2 \\
\text { general ques. }\end{array}$ & $\begin{array}{c}3 \\
\text { direct ques. }\end{array}$ & total \\
\hline Asian & 5 & 2 & 2 & 9 \\
Females (3) & $(1.66)$ & $(.66)$ & $(.66)$ & $(3)$ \\
\hline Russian & 3 & 3 & 2 & 8 \\
Females (1) & $(3)$ & $(3)$ & $(2)$ & $(8)$ \\
\hline Asian Males & 2 & 2 & 2 & 6 \\
$(1)$ & $(2)$ & $(2)$ & $(2)$ & $(6)$ \\
\hline Middle & 25 & 21 & 13 & 59 \\
Eastern & $(5)$ & $(4.2)$ & $(2.6)$ & $(11.8)$ \\
Males (5) & & & & \\
\hline total (10) & 35 & 28 & 19 & 82 \\
\hline
\end{tabular}


TABLE XXIV

\section{ETHNICITY DATA \\ INSTRUCTOR C \\ OBSERVATION 3}

\begin{tabular}{|l|c|c|c|c|}
\hline & 1 & 2 & 3 & total \\
& stud. init. & general ques. & direct ques. & \\
\hline Asian & 1 & 1 & 3 & 5 \\
Females (5) & $(.2)$ & $(.2)$ & $(.6)$ & $(1)$ \\
\hline Russian & 1 & 2 & 0 & 3 \\
Females (1) & $(1)$ & $(2)$ & & $(3)$ \\
\hline Asian Males & 1 & 0 & 1 & 2 \\
$(2)$ & $(.5)$ & & $(.5)$ & $(1)$ \\
\hline Middle & 7 & 8 & 6 & 21 \\
Eastern & $(1.4)$ & $(1.6)$ & $(1.2)$ & $(4.2)$ \\
Males (5) & & & & \\
\hline total (13) & 10 & 11 & 10 & 31 \\
\hline
\end{tabular}

TABLE XXV

ETHNICITY DATA

INSTRUCTOR C

OBSERVATION 4

\begin{tabular}{|l|c|c|c|c|}
\hline & $\begin{array}{c}1 \\
\text { stud. init. }\end{array}$ & $\begin{array}{c}2 \\
\text { general ques. }\end{array}$ & $\begin{array}{c}3 \\
\text { direct ques. }\end{array}$ & total \\
\hline Asian & 1 & 0 & 3 & 4 \\
Females (5) & $(.2)$ & & $(.6)$ & $(.8)$ \\
\hline Russian & 1 & 2 & 1 & 4 \\
Females (1) & $(1)$ & $(2)$ & $(1)$ & $(4)$ \\
\hline Asian Males & 1 & 1 & 1 & 3 \\
$(2)$ & $(.5)$ & $(.5)$ & $(.5)$ & $(1.5)$ \\
\hline Middle & 7 & 7 & 6 & 20 \\
Eastern & $(1.4)$ & $(1.4)$ & $(1.2)$ & $(4)$ \\
Males (5) & & & & \\
\hline total (13) & 10 & 10 & 11 & 31 \\
\hline
\end{tabular}


TABLE XXVI

ETHNICITY DATA

INSTRUCTOR D

OBSERVATION 1

\begin{tabular}{|l|c|c|c|c|}
\hline & $\begin{array}{c}1 \\
\text { stud. init. }\end{array}$ & $\begin{array}{c}2 \\
\text { general ques. }\end{array}$ & $\begin{array}{c}3 \\
\text { direct ques. }\end{array}$ & total \\
\hline Asian & 2 & 3 & 4 & 9 \\
Females (4) & $(.5)$ & $(.75)$ & $(1)$ & $(2.25)$ \\
\hline Russian & 2 & 1 & 0 & 3 \\
Females (1) & $(2)$ & $(1)$ & & $(3)$ \\
\hline Asian Males & 2 & 1 & 2 & 5 \\
$(2)$ & $(1)$ & $(.5)$ & $(1)$ & $(2.5)$ \\
\hline Middle & 13 & 7 & 3 & 23 \\
Eastern & $(3.25)$ & $(1.75)$ & $(.75)$ & $(5.75)$ \\
Males (4) & & & & \\
\hline African & 6 & 2 & 1 & 9 \\
males (1) & $(6)$ & $(2)$ & $(1)$ & $(9)$ \\
\hline total (12) & 25 & 14 & 10 & 49 \\
\hline
\end{tabular}

TABLE XXVII

ETHNICITY DATA

INSTRUCTOR D

OBSERVATION 2

\begin{tabular}{|l|c|c|c|c|}
\hline & $\begin{array}{c}1 \\
\text { stud. init. }\end{array}$ & $\begin{array}{c}2 \\
\text { general ques. }\end{array}$ & $\begin{array}{c}3 \\
\text { direct ques. }\end{array}$ & total \\
\hline Asian & 3 & 2 & 4 & 9 \\
Females (4) & $(.75)$ & $(.5)$ & $(.75)$ & $(2.25)$ \\
\hline Russian & 1 & 0 & 1 & 2 \\
Females (1) & $(1)$ & & $(1)$ & $(2)$ \\
\hline Asian Males & 1 & 2 & 1 & 4 \\
$(2)$ & $(.5)$ & $(1)$ & $(.5)$ & $(2)$ \\
\hline Middle & 12 & 7 & 4 & 23 \\
Eastern & $(3)$ & $(1.75)$ & $(1)$ & $(5.75)$ \\
Males (4) & & & & 9 \\
\hline African & 5 & 3 & 1 & $(9)$ \\
males (1) & $(5)$ & $(3)$ & $(1)$ & 47 \\
\hline total (12) & 22 & 14 & 11 & \\
\hline
\end{tabular}


TABLE XXVIII

ETHNICITY DATA

INSTRUCTOR D

OBSERVATION 3

\begin{tabular}{|l|c|c|c|c|}
\hline & $\begin{array}{c}1 \\
\text { stud. init. }\end{array}$ & $\begin{array}{c}2 \\
\text { general ques. }\end{array}$ & $\begin{array}{c}3 \\
\text { direct ques. }\end{array}$ & total \\
\hline Asian & 4 & 8 & 0 & 12 \\
Females (5) & $(.8)$ & $(1.6)$ & & $(2.4)$ \\
\hline Russian & 0 & 0 & 0 & 0 \\
Females (1) & & & & 4 \\
\hline Asian Males & 2 & 2 & 0 & $(2)$ \\
$(2)$ & $(1)$ & $(1)$ & 12 & $(5.25)$ \\
\hline Middle & 8 & $(3)$ & $(.25)$ & 12 \\
Eastern & $(2)$ & 5 & 0 & $(12)$ \\
Males (4) & & $(5)$ & & 49 \\
\hline African & $(7)$ & 27 & 1 & \\
males (1) & 21 & & & \\
\hline total (13) & & & & \\
\hline
\end{tabular}

TABLE XXIX

ETHNICITY DATA

INSTRUCTOR D

OBSERVATION 4

\begin{tabular}{|l|c|c|c|c|}
\hline & $\begin{array}{c}1 \\
\text { stud. init. }\end{array}$ & $\begin{array}{c}2 \\
\text { general ques. }\end{array}$ & $\begin{array}{c}3 \\
\text { direct ques. }\end{array}$ & total \\
\hline $\begin{array}{l}\text { Asian } \\
\text { Females (5) }\end{array}$ & 4 & 9 & 0 & 13 \\
\hline $\begin{array}{l}\text { Russian } \\
\text { Females (1) }\end{array}$ & 0 & $(1.8)$ & & $(2.6)$ \\
\hline $\begin{array}{l}\text { Asian Males } \\
(2)\end{array}$ & 1 & 2 & 0 & 0 \\
\hline $\begin{array}{l}\text { Middle } \\
\text { Eastern }\end{array}$ & $(1.75)$ & $(3.25)$ & 0 & 3 \\
Males (4) & 7 & $(1)$ & $(.5)$ & $(5.5)$ \\
\hline $\begin{array}{l}\text { African } \\
\text { males (1) }\end{array}$ & 8 & 5 & 0 & 13 \\
\hline total (13) & 20 & 29 & 2 & $(13)$ \\
\hline
\end{tabular}


APPENDIX G

EQUIVALENT TALK CATEGORIES

RAW DATA 
EQUIVALENT TALK CATEGORIES INSTRUCTOR BEHAVIORS PER STUDENT PER OBSERVATION

\begin{tabular}{|ll|}
\hline $1=$ present information & $5=$ respond expanded thinking \\
$2=$ =question restricted thinking & $6=$ react maintain level of participation \\
$3=$ question expanded thinking & $7=$ react extend level of participation \\
$4=$ respond restricted thinking & $8=$ react terminate level of participation \\
\hline
\end{tabular}

TABLE XXX

ETC INSTRUCTOR BEHAVIORS

INSTRUCTOR A

OBSERVATION 1

\begin{tabular}{|l|c|c|c|c|c|c|c|c|}
\hline & 1 & 2 & 3 & 4 & 5 & 6 & 7 & 8 \\
\hline $\begin{array}{l}\text { class } \\
(4)\end{array}$ & 22 & 29 & 17 & & & & & \\
\hline male & 0 & 4 & 2 & 1 & 1 & 9 & 7 & 25 \\
$(2)$ & & $(2)$ & $(1)$ & $(.5)$ & $(.5)$ & $(4.5)$ & $(3.5)$ & $(12.5)$ \\
\hline femal & 2 & 1 & 4 & 3 & 1 & 12 & 12 & 23 \\
e (2) & $(1)$ & $(.5)$ & $(2)$ & $(.5)$ & $(.5)$ & $(6)$ & $(6)$ & $(11.5)$ \\
\hline
\end{tabular}

TABLE XXXI

ETC INSTRUCTOR BEHAVIORS

INSTRUCTOR A

OBSERVATION 2

\begin{tabular}{|c|c|c|c|c|c|c|c|c|}
\hline & 1 & 2 & 3 & 4 & 5 & 6 & 7 & 8 \\
\hline $\begin{array}{l}\text { class } \\
\text { (4) }\end{array}$ & 24 & 11 & 14 & & & & $7 x$ & \\
\hline $\begin{array}{l}\text { male } \\
\text { (2) }\end{array}$ & 0 & 0 & $\begin{array}{c}1 \\
(.5)\end{array}$ & 0 & $\overline{0}$ & $\begin{array}{c}3 \\
(1.5)\end{array}$ & $\begin{array}{c}4 \\
(2)\end{array}$ & $\begin{array}{c}9 \\
(4.5)\end{array}$ \\
\hline $\begin{array}{l}\text { femal } \\
\text { e (2) }\end{array}$ & $\begin{array}{c}1 \\
(.5)\end{array}$ & 0 & 0 & $\begin{array}{c}4 \\
(2)\end{array}$ & 0 & $\begin{array}{c}5 \\
(2.5)\end{array}$ & $\begin{array}{c}2 \\
(1)\end{array}$ & $\begin{array}{l}18 \\
(9)\end{array}$ \\
\hline
\end{tabular}


TABLE XXXII

ETC INSTRUCTOR BEHAVIORS

INSTRUCTOR A

OBSERVATION 3

\begin{tabular}{|l|c|c|c|c|c|c|c|c|}
\hline & 1 & 2 & 3 & 4 & 5 & 6 & 7 & 8 \\
\hline $\begin{array}{l}\text { class } \\
(10)\end{array}$ & 16 & 9 & 2 & & & & & \\
\hline $\begin{array}{l}\text { male } \\
(4)\end{array}$ & 0 & $\begin{array}{c}4 \\
(1)\end{array}$ & 0 & 0 & 0 & $\begin{array}{c}2 \\
(.5)\end{array}$ & 0 & $\begin{array}{c}4 \\
(1)\end{array}$ \\
\hline $\begin{array}{l}\text { femal } \\
\text { e (6) }\end{array}$ & $\begin{array}{c}1 \\
(.166)\end{array}$ & \begin{tabular}{c}
$(1.166)$ \\
\hline
\end{tabular} & 0 & $\begin{array}{c}8 \\
(1.33)\end{array}$ & 0 & $\begin{array}{c}3 \\
(.5)\end{array}$ & 0 & $\begin{array}{c}18 \\
(3)\end{array}$ \\
\hline
\end{tabular}

TABLE XXXIII

ETC INSTRUCTOR BEHAVIORS

INSTRUCTOR A

OBSERVATION 4

\begin{tabular}{|c|c|c|c|c|c|c|c|c|}
\hline & 1 & 2 & 3 & 4 & 5 & 6 & 7 & 8 \\
\hline $\begin{array}{l}\text { class } \\
\text { (9) }\end{array}$ & 16 & 3 & 6 & & & & & $5^{2}$ \\
\hline $\begin{array}{l}\text { male } \\
\text { (4) }\end{array}$ & 0 & $\begin{array}{c}3 \\
(.75)\end{array}$ & $\begin{array}{c}3 \\
(.75)\end{array}$ & 0 & 0 & $\begin{array}{c}14 \\
(3.5)\end{array}$ & $\begin{array}{c}7 \\
(1.75)\end{array}$ & $\begin{array}{c}9 \\
(2.25)\end{array}$ \\
\hline $\begin{array}{l}\text { femal } \\
\text { e (5) }\end{array}$ & $\begin{array}{c}4 \\
(.8)\end{array}$ & $\begin{array}{c}5 \\
(1)\end{array}$ & $\begin{array}{c}2 \\
(.4)\end{array}$ & $\begin{array}{c}9 \\
(1.8)\end{array}$ & $\begin{array}{c}1 \\
(.2)\end{array}$ & $\begin{array}{l}30 \\
(6)\end{array}$ & $\begin{array}{c}9 \\
(1.8)\end{array}$ & $\begin{array}{l}15 \\
(3)\end{array}$ \\
\hline
\end{tabular}

TABLE XXXIV

ETC INSTRUCTOR BEHAVIORS

INSTRUCTOR B

OBSERVATION 1

\begin{tabular}{|c|c|c|c|c|c|c|c|c|}
\hline & 1 & 2 & 3 & 4 & 5 & 6 & 7 & 8 \\
\hline $\begin{array}{l}\text { class } \\
\text { (6) }\end{array}$ & 15 & 2 & 2 & & & & & 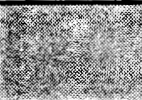 \\
\hline $\begin{array}{l}\text { male } \\
\text { (2) }\end{array}$ & $\begin{array}{c}2 \\
(1)\end{array}$ & $\begin{array}{c}2 \\
(1)\end{array}$ & $\begin{array}{c}1 \\
(.5)\end{array}$ & $\begin{array}{c}4 \\
(.5)\end{array}$ & 0 & $\begin{array}{c}1 \\
(.5)\end{array}$ & 0 & $\begin{array}{c}7 \\
(3.5)\end{array}$ \\
\hline $\begin{array}{l}\text { femal } \\
\text { e (4) }\end{array}$ & $\begin{array}{c}4 \\
(1)\end{array}$ & $\begin{array}{c}4 \\
(1)\end{array}$ & $\begin{array}{c}1 \\
(.25)\end{array}$ & $\begin{array}{c}6 \\
(1.5)\end{array}$ & $\begin{array}{c}1 \\
(.25) \\
\end{array}$ & $\begin{array}{c}5 \\
(1.25)\end{array}$ & $\begin{array}{c}1 \\
(.25)\end{array}$ & $\begin{array}{c}13 \\
(3.25)\end{array}$ \\
\hline
\end{tabular}


TABLE XXXV

ETC INSTRUCTOR BEHAVIORS

INSTRUCTOR B

OBSERVATION 2

\begin{tabular}{|c|c|c|c|c|c|c|c|c|}
\hline & 1 & 2 & 3 & 4 & 5 & 6 & 7 & 8 \\
\hline $\begin{array}{l}\text { class } \\
\text { (5) }\end{array}$ & $\overline{14}$ & 14 & 5 & & & & 43 & \\
\hline $\begin{array}{l}\text { male } \\
\text { (1) }\end{array}$ & $\overline{0}$ & $\begin{array}{c}2 \\
(2)\end{array}$ & $\begin{array}{c}1 \\
(1)\end{array}$ & $\begin{array}{c}1 \\
(1)\end{array}$ & 0 & $\begin{array}{c}4 \\
(4)\end{array}$ & $\begin{array}{c}2 \\
(2)\end{array}$ & $\begin{array}{c}2 \\
(2)\end{array}$ \\
\hline $\begin{array}{l}\text { femal } \\
\text { e (4) }\end{array}$ & $\overline{0}$ & $\begin{array}{c}4 \\
(1)\end{array}$ & $\begin{array}{c}1 \\
(.25)\end{array}$ & $\begin{array}{c}9 \\
(2.25)\end{array}$ & $\begin{array}{c}1 \\
(.25)\end{array}$ & $\begin{array}{c}3 \\
(.75)\end{array}$ & 0 & $\begin{array}{c}18 \\
(4.5)\end{array}$ \\
\hline
\end{tabular}

TABLE XXXVI

ETC INSTRUCTOR BEHAVIORS

INSTRUCTOR B

OBSERVATION 3

\begin{tabular}{|l|c|c|c|c|c|c|c|c|}
\hline & 1 & 2 & 3 & 4 & 5 & 6 & 7 & 8 \\
\hline $\begin{array}{l}\text { class } \\
(5)\end{array}$ & 5 & 0 & 0 & & & & & \\
\hline $\begin{array}{l}\text { male } \\
(1)\end{array}$ & 0 & 0 & 0 & 0 & 0 & 0 & 0 & 0 \\
\hline $\begin{array}{l}\text { femal } \\
\text { e (4) }\end{array}$ & 1 & 0 & 0 & $\begin{array}{c}15 \\
(.25)\end{array}$ & 0 & $\begin{array}{c}2 \\
(.5)\end{array}$ & 0 & $\begin{array}{c}3 \\
(.75)\end{array}$ \\
\hline
\end{tabular}

TABLE XXXVII

ETC INSTRUCTOR BEHAVIORS

INSTSRUCTOR B

OBSERVATION 4

\begin{tabular}{|l|c|c|c|c|c|c|c|c|}
\hline & 1 & 2 & 3 & 4 & 5 & 6 & 7 & 8 \\
\hline $\begin{array}{l}\text { class } \\
(6)\end{array}$ & 21 & 10 & 3 & & & & & \\
\hline $\begin{array}{l}\text { male } \\
(2)\end{array}$ & 0 & 0 & $\begin{array}{c}1 \\
(.5)\end{array}$ & 0 & 0 & 0 & 0 & $\begin{array}{c}2 \\
(1)\end{array}$ \\
\hline $\begin{array}{l}\text { femal } \\
\text { e (4) }\end{array}$ & 1 & $\begin{array}{c}(.25) \\
(.75)\end{array}$ & 0 & $\begin{array}{c}4 \\
(1)\end{array}$ & $\begin{array}{c}2 \\
(.5)\end{array}$ & $\begin{array}{c}(.5) \\
(.75)\end{array}$ & $\begin{array}{c}17 \\
(4.25)\end{array}$ \\
\hline
\end{tabular}


TABLE XXXVIII

ETC INSTRUCTOR BEHAVIORS

INSTRUCTOR C

OBSERVATION 1

\begin{tabular}{|c|c|c|c|c|c|c|c|c|}
\hline & 1 & 2 & 3 & 4 & 5 & 6 & 7 & 8 \\
\hline $\begin{array}{l}\text { class } \\
\text { (10) }\end{array}$ & 13 & 9 & 12 & & & & & \\
\hline $\begin{array}{l}\text { male } \\
\text { (6) }\end{array}$ & $\begin{array}{c}4 \\
(.66)\end{array}$ & $\begin{array}{c}3 \\
(.5)\end{array}$ & $\overline{0}$ & $\begin{array}{c}1 \\
(.166)\end{array}$ & $\begin{array}{c}2 \\
(.33)\end{array}$ & $\begin{array}{c}9 \\
(1.5)\end{array}$ & $\begin{array}{c}2 \\
(.33)\end{array}$ & $\begin{array}{l}24 \\
(4)\end{array}$ \\
\hline $\begin{array}{l}\text { female } \\
\text { (4) }\end{array}$ & 0 & $\begin{array}{c}1 \\
(.25)\end{array}$ & $\begin{array}{c}1 \\
(.25)\end{array}$ & $\begin{array}{c}1 \\
(.25)\end{array}$ & $\begin{array}{c}2 \\
(.5)\end{array}$ & $\begin{array}{c}2 \\
(.5)\end{array}$ & $\begin{array}{c}1 \\
(.25)\end{array}$ & $\begin{array}{c}5 \\
(1.25)\end{array}$ \\
\hline
\end{tabular}

TABLE XXXIX

ETC INSTRUCTOR BEHAVIORS

INSTRUCTOR C

OBSERVATION 2

\begin{tabular}{|c|c|c|c|c|c|c|c|c|}
\hline & 1 & 2 & 3 & 4 & 5 & 6 & 7 & 8 \\
\hline $\begin{array}{l}\text { class } \\
\text { (10) }\end{array}$ & 12 & 10 & 11 & & & & 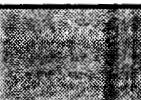 & \\
\hline $\begin{array}{l}\text { male } \\
(6)\end{array}$ & $\begin{array}{c}4 \\
(.66) \\
\end{array}$ & $\begin{array}{r}3 \\
(.5) \\
\end{array}$ & 0 & $\begin{array}{c}2 \\
(.33) \\
\end{array}$ & $\begin{array}{c}1 \\
(.166) \\
\end{array}$ & $\begin{array}{c}10 \\
(1.66) \\
\end{array}$ & $\begin{array}{c}3 \\
(.5)\end{array}$ & $\begin{array}{l}24 \\
(4) \\
\end{array}$ \\
\hline $\begin{array}{l}\text { female } \\
\text { (4) }\end{array}$ & 0 & $\begin{array}{c}2 \\
(.5)\end{array}$ & 0 & $\begin{array}{c}1 \\
(.25)\end{array}$ & $\begin{array}{c}1 \\
(.25)\end{array}$ & $\begin{array}{c}2 \\
(.5)\end{array}$ & $\begin{array}{c}1 \\
.25)\end{array}$ & $\begin{array}{c}6 \\
(1.5)\end{array}$ \\
\hline
\end{tabular}

TABLE XL

ETC INSTRUCTOR BEHAVIORS

INSTRUCTOR C

OBSERVATION 3

\begin{tabular}{|l|c|c|c|c|c|c|c|c|}
\hline & 1 & 2 & 3 & 4 & 5 & 6 & 7 & 8 \\
\hline $\begin{array}{l}\text { class } \\
(13)\end{array}$ & 11 & 1 & 9 & & & & & \\
\hline $\begin{array}{l}\text { male } \\
(7)\end{array}$ & 0 & $\begin{array}{c}3 \\
(.428)\end{array}$ & $4(.571)$ & $\begin{array}{c}2 \\
(.285)\end{array}$ & $3(.428)$ & $6(.857)$ & $\begin{array}{c}2 \\
(.285)\end{array}$ & $\begin{array}{c}10 \\
(1.428)\end{array}$ \\
\hline $\begin{array}{l}\text { female } \\
(6)\end{array}$ & 0 & 0 & $\begin{array}{c}3 \\
(.5)\end{array}$ & 0 & $\begin{array}{c}1 \\
(.166)\end{array}$ & $\begin{array}{c}3 \\
(.5)\end{array}$ & 0 & $\begin{array}{c}6 \\
(1)\end{array}$ \\
\hline
\end{tabular}


TABLE XLI

ETC INSTRUCTOR BEHAVIORS

INSTRUCTOR C

OBSERVATION 4

\begin{tabular}{|c|c|c|c|c|c|c|c|c|}
\hline & 1 & 2 & 3 & 4 & 5 & 6 & 7 & 8 \\
\hline $\begin{array}{l}\text { class } \\
\text { (13) }\end{array}$ & 10 & 1 & 9 & & & & & \\
\hline $\begin{array}{l}\text { male } \\
\text { (7) }\end{array}$ & $\begin{array}{c}1 \\
(.142)\end{array}$ & $\begin{array}{c}2 \\
(.285)\end{array}$ & $\begin{array}{c}5 \\
(.714)\end{array}$ & $\begin{array}{c}3 \\
(.428)\end{array}$ & $\begin{array}{c}4 \\
(.571)\end{array}$ & $\begin{array}{c}6 \\
(.857)\end{array}$ & $\begin{array}{c}3 \\
(.428)\end{array}$ & $\begin{array}{c}11 \\
(1.571)\end{array}$ \\
\hline $\begin{array}{l}\text { female } \\
\text { (6) }\end{array}$ & 0 & 0 & $\begin{array}{c}4 \\
(.666)\end{array}$ & 0 & $\begin{array}{c}1 \\
(.166)\end{array}$ & $\begin{array}{c}2 \\
(.33)\end{array}$ & $\begin{array}{c}1 \\
(.166)\end{array}$ & $\begin{array}{c}7 \\
(1.166)\end{array}$ \\
\hline
\end{tabular}

TABLE XLII

ETC INSTRUCTOR BEHAVIORS

INSTRUCTOR D

OBSERVATION 1

\begin{tabular}{|l|c|c|c|c|c|c|c|c|}
\hline & 1 & 2 & 3 & 4 & 5 & 6 & 7 & 8 \\
\hline $\begin{array}{l}\text { class } \\
(12)\end{array}$ & 12 & 9 & 9 & & & & & \\
\hline $\begin{array}{l}\text { male } \\
(7)\end{array}$ & 0 & 2 & 0 & 3 & 1 & 9 & 4 & 12 \\
\hline $\begin{array}{l}\text { female } \\
(5)\end{array}$ & 1 & 1 & 0 & 0 & 0 & 2 & 2 & 3 \\
$(.2)$ & $(.2)$ & & & & $(.4)$ & $(.4)$ & $(.6)$ \\
\hline
\end{tabular}

TABLE XLIII

ETC INSTRUCTOR BEHAVIORS

INSTRUCTOR D

OBSERVATION 2

\begin{tabular}{|l|c|c|c|c|c|c|c|c|}
\hline & 1 & 2 & 3 & 4 & 5 & 6 & 7 & 8 \\
\hline $\begin{array}{l}\text { class } \\
(12)\end{array}$ & 11 & 10 & 9 & & & & & \\
\hline $\begin{array}{l}\text { male } \\
(7)\end{array}$ & 0 & $\begin{array}{c}2 \\
(.285)\end{array}$ & 0 & $\begin{array}{c}3 \\
(.428)\end{array}$ & 0 & 9 & $\begin{array}{c}3 \\
(1.285)\end{array}$ & $\begin{array}{c}13 \\
(.428)\end{array}$ \\
\hline $\begin{array}{l}\text { female } \\
(5)\end{array}$ & & & & & & & & \\
\hline
\end{tabular}


TABLE XLIV

ETC INSTRUCTOR BEHAVIORS

INSTRUCTOR D

OBSERVATION 3

\begin{tabular}{|c|c|c|c|c|c|c|c|c|}
\hline & 1 & 2 & 3 & 4 & 5 & 6 & 7 & 8 \\
\hline $\begin{array}{l}\text { class } \\
\text { (13) }\end{array}$ & 19 & 6 & 16 & & & & & (5) \\
\hline $\begin{array}{l}\text { male } \\
\text { (7) }\end{array}$ & $\begin{array}{c}2 \\
(.285)\end{array}$ & 0 & $\overline{0}$ & $\begin{array}{c}4 \\
(.571)\end{array}$ & $6(.857)$ & $\begin{array}{c}7 \\
(1)\end{array}$ & $\begin{array}{c}3 \\
(.428)\end{array}$ & $\begin{array}{c}23 \\
(3.26)\end{array}$ \\
\hline $\begin{array}{l}\text { female } \\
\text { (6) }\end{array}$ & $\begin{array}{c}1 \\
(.166)\end{array}$ & 0 & 0 & 0 & $\begin{array}{c}3 \\
(.5)\end{array}$ & $\begin{array}{c}4 \\
(.66)\end{array}$ & $\begin{array}{c}3 \\
(.5)\end{array}$ & $\begin{array}{c}6 \\
(1)\end{array}$ \\
\hline
\end{tabular}

TABLE XLV

ETC INSTRUCTOR BEHAVIORS

INSTRUCTOR D

OBSERVATION 4

\begin{tabular}{|c|c|c|c|c|c|c|c|c|}
\hline & 1 & 2 & 3 & 4 & 5 & 6 & 7 & 8 \\
\hline $\begin{array}{l}\text { class } \\
\text { (13) }\end{array}$ & 19 & 6 & 17 & & & & & \\
\hline $\begin{array}{l}\text { male } \\
\text { (7) }\end{array}$ & $\begin{array}{c}1 \\
(.142)\end{array}$ & 0 & 0 & $\begin{array}{c}5 \\
(.714)\end{array}$ & $6(.857)$ & $\begin{array}{c}7 \\
(1)\end{array}$ & $\begin{array}{c}4 \\
(.571)\end{array}$ & $\begin{array}{c}24 \\
(3.42)\end{array}$ \\
\hline $\begin{array}{l}\text { female } \\
\text { (6) }\end{array}$ & 0 & 0 & 0 & 0 & $\begin{array}{c}2 \\
(.333)\end{array}$ & $\begin{array}{c}4 \\
(.66)\end{array}$ & $\begin{array}{c}3 \\
(.5)\end{array}$ & $\begin{array}{c}7 \\
(1.166)\end{array}$ \\
\hline
\end{tabular}


EQUIVALENT TALK CATEGORIES INVENTORY OF STUDENT BEHAVIORS

key:

$9=$ present information $12=$ respond restricted $\quad 15=$ react extend $10=$ question restricted $\quad 13=$ respond expanded $16=$ react terminate $11=$ question expanded $14=$ react maintain

TABLE XLVI

ETC STUDENT BEHAVIORS

INSTRUCTOR A

OBSERVATION 1

\begin{tabular}{|c|c|c|c|c|c|c|c|c|}
\hline & 9 & 10 & 11 & 12 & 13 & 14 & 15 & 16 \\
\hline $\begin{array}{l}\text { male } \\
\text { (2) }\end{array}$ & $\begin{array}{c}2 \\
(1)\end{array}$ & $\begin{array}{c}1 \\
(.5)\end{array}$ & $\begin{array}{c}1 \\
(.5)\end{array}$ & $\begin{array}{c}29 \\
(14.5)\end{array}$ & $\begin{array}{c}17 \\
(8.5)\end{array}$ & $\begin{array}{c}1 \\
(.5)\end{array}$ & 0 & $\begin{array}{c}1 \\
(.5)\end{array}$ \\
\hline $\begin{array}{l}\text { female } \\
\text { (2) }\end{array}$ & $\begin{array}{c}5 \\
(2.5)\end{array}$ & $\begin{array}{c}3 \\
(1.5)\end{array}$ & $\begin{array}{c}1 \\
\text { (.5) }\end{array}$ & $\begin{array}{c}31 \\
(15.5)\end{array}$ & $\begin{array}{c}26 \\
(13)\end{array}$ & $\begin{array}{c}2 \\
(1)\end{array}$ & 0 & 0 \\
\hline
\end{tabular}

TABLE XLVII

ETC STUDENT BEHAVIORS

INSTRUCTOR A

OBSERVATION 2

\begin{tabular}{|l|c|c|c|c|c|c|c|c|}
\hline & 9 & 10 & 11 & 12 & 13 & 14 & 15 & 16 \\
\hline $\begin{array}{l}\text { male } \\
(2)\end{array}$ & 1 & 0 & 0 & $\begin{array}{c}4 \\
(2)\end{array}$ & $\begin{array}{c}15 \\
(7.5)\end{array}$ & $\begin{array}{c}1 \\
(.5)\end{array}$ & 0 & $\begin{array}{c}1 \\
(.5)\end{array}$ \\
\hline $\begin{array}{l}\text { female } \\
(2)\end{array}$ & 3 & 5 & 0 & 11 & 12 & 1 & 0 & 0 \\
$(1.5)$ & $(2.5)$ & & $(5.5)$ & $(6)$ & $(.5)$ & & \\
\hline
\end{tabular}


TABLE XLVIII

ETC STUDENT BEHAVIORS

INSTRUCTOR A

OBSERVATION 3

\begin{tabular}{|l|c|c|c|c|c|c|c|c|}
\hline & 9 & 10 & 11 & 12 & 13 & 14 & 15 & 16 \\
\hline $\begin{array}{l}\text { male } \\
(4)\end{array}$ & 0 & 0 & 0 & $\begin{array}{c}6 \\
(1.5)\end{array}$ & 0 & 0 & 0 & 0 \\
\hline $\begin{array}{l}\text { female } \\
(6)\end{array}$ & 3 & 11 & 0 & $\begin{array}{c}19 \\
(.5)\end{array}$ & $\begin{array}{c}2 \\
(1.83)\end{array}$ & $\begin{array}{c}6 \\
(3.16)\end{array}$ & 0 & $\begin{array}{c}2 \\
(.33)\end{array}$ \\
\hline
\end{tabular}

TABLE XLIX

ETC STUDENT BEHAVIORS

INSTRUCTOR A

OBSERVATION 4

\begin{tabular}{|l|c|c|c|c|c|c|c|c|}
\hline & 9 & 10 & 11 & 12 & 13 & 14 & 15 & 16 \\
\hline $\begin{array}{l}\text { male } \\
(4)\end{array}$ & 1 & 0 & 0 & 9 & 19 & 1 & 0 & 1 \\
$(.25)$ & & & $(2.25)$ & $(4.75)$ & $(.25)$ & & $(.25)$ \\
\hline $\begin{array}{l}\text { female } \\
(5)\end{array}$ & 12 & 3 & 2 & 16 & 25 & 8 & 0 & 5 \\
$(2.4)$ & $(.6)$ & $(.4)$ & $(3.2)$ & $5)$ & $(1.6)$ & & $(1)$ \\
\hline
\end{tabular}

TABLE L

ETC STUDENT BEHAVIORS

INSTRUCTOR B

OBSERVATION 1

\begin{tabular}{|l|c|c|c|c|c|c|c|c|}
\hline & 9 & 10 & 11 & 12 & 13 & 14 & 15 & 16 \\
\hline $\begin{array}{l}\text { male } \\
(2)\end{array}$ & 1 & 2 & 0 & 3 & 6 & 1 & 0 & 1 \\
$(.5)$ & $(1)$ & & $(1.5)$ & $(3)$ & $(.5)$ & & $(.5)$ \\
\hline $\begin{array}{l}\text { female } \\
(4)\end{array}$ & 4 & 6 & 1 & 8 & 8 & 0 & 0 & 2 \\
$(1)$ & $(1.25)$ & $(.25)$ & $(2)$ & $(2)$ & & & $(.5)$ \\
\hline
\end{tabular}


TABLE LI

ETC STUDENT BEHAVIORS

INSTRUCTOR B

OBSERVATION 2

\begin{tabular}{|l|c|c|c|c|c|c|c|c|}
\hline & 9 & 10 & 11 & 12 & 13 & 14 & 15 & 16 \\
\hline $\begin{array}{l}\text { male } \\
(1)\end{array}$ & 0 & 0 & 0 & $\begin{array}{c}6 \\
(6)\end{array}$ & $\begin{array}{c}4 \\
(4)\end{array}$ & 0 & $\begin{array}{c}1 \\
(1)\end{array}$ & 0 \\
\hline $\begin{array}{l}\text { female } \\
(4)\end{array}$ & 3 & 9 & 1 & 16 & 4 & 0 & 0 & 3 \\
$(.75)$ & $(2.25)$ & $(.25)$ & $(4)$ & $(1)$ & & & $(.75)$ \\
\hline
\end{tabular}

TABLE LII

ETC STUDENT BEHAVIORS

INSTRUCTOR B

OBSERVATION 3

\begin{tabular}{|l|c|c|c|c|c|c|c|c|}
\hline & 9 & 10 & 11 & 12 & 13 & 14 & 15 & 16 \\
\hline $\begin{array}{l}\text { male } \\
(1)\end{array}$ & 0 & 0 & 0 & 0 & 0 & 0 & 0 & 0 \\
\hline $\begin{array}{l}\text { female } \\
(4)\end{array}$ & $\begin{array}{c}2 \\
(.5)\end{array}$ & $\begin{array}{c}9 \\
(2.25)\end{array}$ & 0 & $\begin{array}{c}1 \\
(.25)\end{array}$ & 0 & $\begin{array}{c}9 \\
(2.25)\end{array}$ & 0 & $\begin{array}{c}2 \\
(.5)\end{array}$ \\
\hline
\end{tabular}

TABLE LIII

ETC STUDENT BEHAVIORS

INSTRUCTOR B

OBSERVATION 4

\begin{tabular}{|l|c|c|c|c|c|c|c|c|}
\hline & 9 & 10 & 11 & 12 & 13 & 14 & 15 & 16 \\
\hline $\begin{array}{l}\text { male } \\
(2)\end{array}$ & 0 & 0 & 0 & 0 & $\begin{array}{c}2 \\
(1)\end{array}$ & 0 & 0 & 0 \\
\hline $\begin{array}{l}\text { female } \\
(4)\end{array}$ & 6 & 5 & 3 & 14 & 4 & 4 & 2 & 1 \\
$(1.5)$ & $(1.25)$ & $(.75)$ & $(3.5)$ & $(1)$ & $(1)$ & $(.5)$ & $(.25)$ \\
\hline
\end{tabular}


TABLE LIV

ETC STUDENT BEHAVIORS

INSTRUCTOR C

OBSERVATION 1

\begin{tabular}{|l|c|c|c|c|c|c|c|c|}
\hline & 9 & 10 & 11 & 12 & 13 & 14 & 15 & 16 \\
\hline $\begin{array}{l}\text { male } \\
(6)\end{array}$ & 4 & 3 & 2 & 21 & 13 & 0 & 0 & $\begin{array}{c}1 \\
(.66)\end{array}$ \\
\hline female & 1 & 1 & $(.33)$ & $(3.5)$ & $(2.16)$ & & & $(.166)$ \\
$(4)$ & $(.25)$ & $(.25)$ & $(.75)$ & $(.75)$ & $(1.75)$ & & & 0 \\
\hline
\end{tabular}

TABLE LV

ETC STUDENT BEHAVIORS

INSTRUCTOR C

OBSERVATION 2

\begin{tabular}{|c|c|c|c|c|c|c|c|c|}
\hline & 9 & 10 & 11 & 12 & 13 & 14 & 15 & 16 \\
\hline $\begin{array}{l}\text { male } \\
(6)\end{array}$ & $\begin{array}{c}4 \\
(.66)\end{array}$ & $\begin{array}{c}2 \\
(33)\end{array}$ & $\begin{array}{c}2 \\
(.33)\end{array}$ & $\begin{array}{c}22 \\
(3.66)\end{array}$ & $\begin{array}{c}13 \\
(2.16)\end{array}$ & 0 & 0 & 0 \\
\hline $\begin{array}{l}\text { female } \\
\text { (4) }\end{array}$ & 0 & $\begin{array}{c}1 \\
(.25)\end{array}$ & $\begin{array}{c}2 \\
(.5)\end{array}$ & $\begin{array}{c}3 \\
(.75)\end{array}$ & $\begin{array}{c}6 \\
(1.5)\end{array}$ & 0 & 0 & 0 \\
\hline
\end{tabular}

TABLE LVI

ETC STUDENT BEHAVIORS

INSTRUCTOR C

OBSERVATION 3

\begin{tabular}{|l|c|c|c|c|c|c|c|c|}
\hline & 9 & 10 & 11 & 12 & 13 & 14 & 15 & 16 \\
\hline $\begin{array}{l}\text { male } \\
(7)\end{array}$ & 0 & $\begin{array}{c}2 \\
(.285)\end{array}$ & $\begin{array}{c}3 \\
(.428)\end{array}$ & $\begin{array}{c}7 \\
(1)\end{array}$ & $\begin{array}{c}14 \\
(2)\end{array}$ & 0 & 0 & 0 \\
\hline $\begin{array}{l}\text { female } \\
(6)\end{array}$ & 0 & 0 & $\begin{array}{c}1 \\
(.166)\end{array}$ & 0 & $\begin{array}{c}10 \\
(1.66)\end{array}$ & 0 & $\begin{array}{c}1 \\
(.166)\end{array}$ & 0 \\
\hline
\end{tabular}


TABLE LVII

ETC STUDENT BEHAVIORS

INSTRUCTOR C

OBSERVATION 4

\begin{tabular}{|l|c|c|c|c|c|c|c|c|}
\hline & 9 & 10 & 11 & 12 & 13 & 14 & 15 & 16 \\
\hline $\begin{array}{l}\text { male } \\
(7)\end{array}$ & 0 & $\begin{array}{c}2 \\
(.285)\end{array}$ & $\begin{array}{c}4 \\
(.571)\end{array}$ & $\begin{array}{c}6 \\
(.857)\end{array}$ & $\begin{array}{c}15 \\
(2.14)\end{array}$ & 0 & 0 & 0 \\
\hline $\begin{array}{l}\text { female } \\
(6)\end{array}$ & 1 & 0 & $\begin{array}{c}1 \\
(.166)\end{array}$ & $\begin{array}{c}1 \\
(.166)\end{array}$ & $\begin{array}{c}10 \\
(1.66)\end{array}$ & 0 & $\begin{array}{c}1 \\
(.166)\end{array}$ & 0 \\
\hline
\end{tabular}

TABLE LVIII

ETC STUDENT BEHAVIORS

INSTRUCTOR D

OBSERVATION 1

\begin{tabular}{|l|c|c|c|c|c|c|c|c|}
\hline & 9 & 10 & 11 & 12 & 13 & 14 & 15 & 16 \\
\hline $\begin{array}{l}\text { male } \\
(7)\end{array}$ & 4 & 3 & 1 & 7 & 16 & 1 & 0 & 0 \\
\hline $\begin{array}{l}\text { female } \\
(5)\end{array}$ & 0 & $\begin{array}{c}(.571) \\
(.428)\end{array}$ & $(.142)$ & $(1)$ & $(2.285)$ & $(.142)$ & & \\
\hline
\end{tabular}

TABLE LVIX

ETC STUDENT BEHAVIORS

INSTRUCTOR D

OBSERVATION 2

\begin{tabular}{|l|c|c|c|c|c|c|c|c|}
\hline & 9 & 10 & 11 & 12 & 13 & 14 & 15 & 16 \\
\hline $\begin{array}{l}\text { male } \\
(7)\end{array}$ & 5 & 4 & 0 & $\begin{array}{c}7 \\
(1)\end{array}$ & $\begin{array}{c}17 \\
(2.428)\end{array}$ & 0 & 0 & 0 \\
\hline $\begin{array}{l}\text { female } \\
(5)\end{array}$ & 0 & 0 & 0 & $\begin{array}{c}3 \\
(.571)\end{array}$ & $\begin{array}{c}6 \\
(1.2)\end{array}$ & 0 & 0 & 0 \\
\hline
\end{tabular}


TABLE LX

ETC STUDENT BEHAVIORS

INSTRUCTOR D

OBSERVATION 3

\begin{tabular}{|l|c|c|c|c|c|c|c|c|}
\hline & 9 & 10 & 11 & 12 & 13 & 14 & 15 & 16 \\
\hline $\begin{array}{l}\text { male } \\
(7)\end{array}$ & 6 & 3 & 5 & 4 & 22 & 1 & 2 & 2 \\
$(.857)$ & $(.428)$ & $(.714)$ & $(.571)$ & $(3.14)$ & $(.142)$ & $(.285)$ & $(.285)$ \\
\hline $\begin{array}{l}\text { female } \\
(6)\end{array}$ & 1 & 0 & 3 & 7 & 5 & 0 & 0 & 0 \\
\hline
\end{tabular}

TABLE LXI

ETC STUDENT BEHAVIORS

INSTRUCTOR D

OBSERVATION 4

\begin{tabular}{|c|c|c|c|c|c|c|c|c|}
\hline & 9 & 10 & 11 & 12 & 13 & 14 & 15 & 16 \\
\hline $\begin{array}{l}\text { male } \\
\text { (7) }\end{array}$ & $\begin{array}{c}5 \\
(.714)\end{array}$ & $\begin{array}{c}4 \\
(.571)\end{array}$ & $\begin{array}{c}5 \\
(.714)\end{array}$ & $\begin{array}{c}4 \\
(.571)\end{array}$ & $\begin{array}{c}22 \\
(3.14)\end{array}$ & $\begin{array}{c}1 \\
(.142)\end{array}$ & $\begin{array}{c}1 \\
(.142)\end{array}$ & $\begin{array}{c}2 \\
(.285)\end{array}$ \\
\hline $\begin{array}{l}\text { female } \\
\text { (6) }\end{array}$ & 0 & 0 & $\begin{array}{c}3 \\
(.5)\end{array}$ & $\begin{array}{c}7 \\
(1.16)\end{array}$ & $\begin{array}{c}5 \\
(.833)\end{array}$ & 0 & 0 & 0 \\
\hline
\end{tabular}

